INSTITUTO DE PESQUISAS ENERGÉTICAS E NUCLEARES

AUTARQUIA ASSOCIADA À UNIVERSIDADE DE SÃO PAULO

\title{
RADIOGRAFIA COM ELÉTRONS INDUZIDA POR NÊUTRONS
}

\author{
MARCOS LEANDRO GARCIA ANDRADE
}

Tese apresentada como parte dos requisitos para obtenção do Grau de "Doutor na Área de Tecnologia Nuclear - Aplicações"

Orientador:

Dr. Reynaldo Pugliesi 


\section{DEDICATÓRIA}

A minha esposa Paula

Ao meu filho Augusto

Aos meus pais José Carlos (in memorian) e Janete

A Deus 


\section{AGRADECIMENTOS}

Agradeço a todos que, de algum modo, tenham participado na realização deste trabalho, dos quais particularmente destaco:

Prof. Dr. Reynaldo Pugliesi por sua dedicação na orientação deste trabalho, apoio e incentivo desde o início da minha formação científica.

IPEN pela oportunidade e permissão de realizar este trabalho em suas instalações, e apoio técnico-administrativo.

Aos amigos do CRPq e Reator pelo apoio e discussões técnicas importantes para a realização deste trabalho.

Aos amigos Mário, Marco e Fábio pela convivência e cooperação no grupo de trabalho.

A minha mãe e meus irmãos, Paulus, Veridiana, e Juninho pelo incentivo durante mais esta etapa vencida.

Ao meu sogro e sogra, Shiguehiki e Claudete, pelo incentivo e paciência durante todo esse tempo.

Especialmente à minha esposa, Paula, pelo apoio, incentivo, dedicação, compreensão e acima de tudo o seu amor durante todos esses anos de convivência e trabalho.

E acima de tudo e todos a Deus, por mais esta etapa vencida. 


\section{SUMÁRIO}

LISTA DE TABELAS

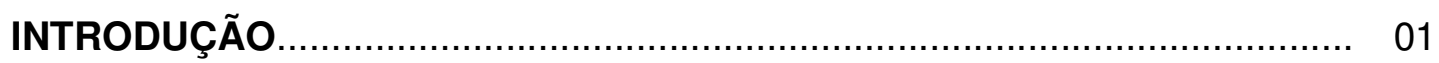

CAPÍTULO 1 - FUNDAMENTOS TEÓRICOS ............................................ 08

1.1 Nêutrons e a matéria......................................................................... 08

1.1.1 Interação nêutron - núcleo..................................................... 09

1.1.2 Transmissão de nêutrons pela matéria........................................... 10

1.2 A Técnica da radiografia com nêutrons............................................ 11

1.2.1 Histórico................................................................................. 11

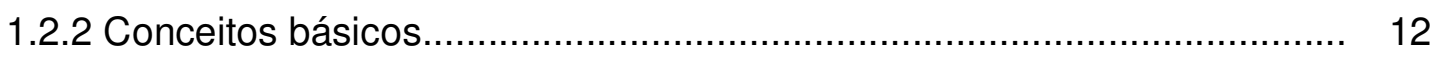

1.2.3 Fonte de nêutrons................................................................. 13

1.2.4 Colimador de nêutrons............................................................. 14

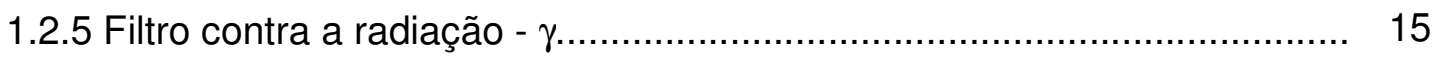

1.2.6 Métodos para obtenção da imagem em radiografia com nêutrons........... 16

1.3 Elétrons e a matéria.................................................................... 18

1.3.1 Absorção de elétrons monoenergéticos........................................... 19

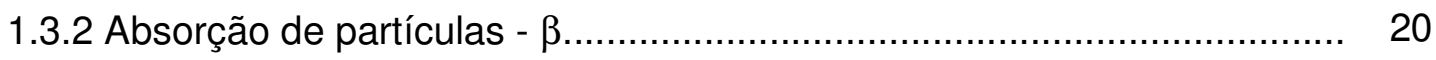

1.3.3 A técnica da radiografia com elétrons........................................... 21

1.3.3.1 Transmissão..................................................................... 21

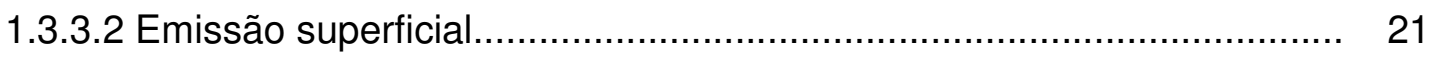

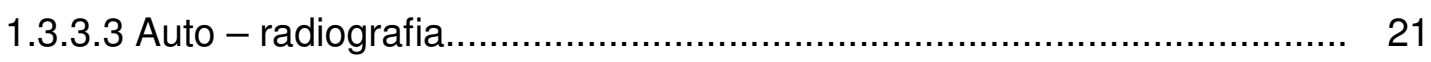

1.4 Filmes e formação da imagem...................................................... 22

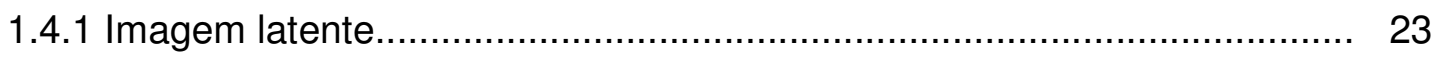

1.4 .2 Imagem visível....................................................................... 24

1.4.2.1 Revelador......................................................................... 24

1.4.2.2 Banho de parada.................................................................. 25

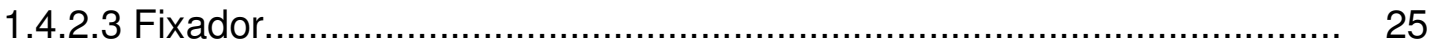




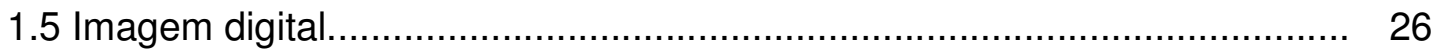

1.6 Caracterização de técnicas radiográficas............................................... 26

1.6.1 Determinação do intervalo de exposição para se obter melhor contraste 27

1.6.2 Sensibilidade............................................................................ 27

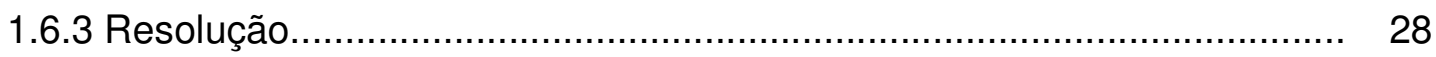

1.7 Considerações gerais a respeito da técnica da radiografia induzida........... 29

CAPÍTULO 2 - PARTE EXPERIMENTAL ….......................................... 31

2.1 Tela conversora e cassete para irradiação............................................... 31

2.2 Filme radiográfico .......................................................................... 32

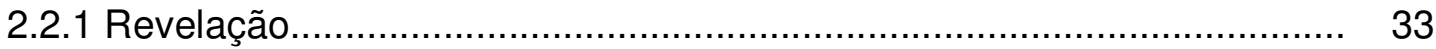

2.3 Equipamento para radiografia com nêutrons............................................ 34

2.4 Obtenção de radiografia com elétrons induzida por nêutrons...................... 39

2.5 Sistema digital para análise e processamento das imagens...................... 41

CAPÍTULO 3 - OBTENÇÃO E ANÁLISE DOS DADOS ............................. 43

3.1 Caracterização da técnica da radiografia com elétrons induzida por nêutrons..................................................................................... 43

3.1.1 Intervalo de exposição.................................................................... 43

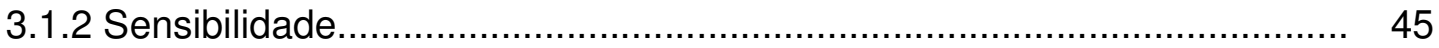

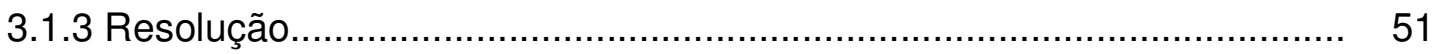

3.1.4 Influência das outras radiações na formação da imagem........................ 55

3.1.5 Reprodutibilidade do sistema digital na determinação da intensidade da

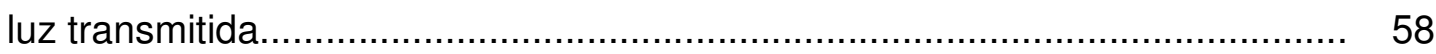

3.2 Comparação com o sistema de leitura analógico...................................... 59

3.2.1 Intervalo de exposição........................................................................ 62

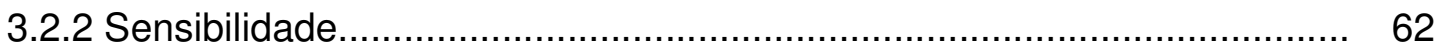

3.3 Comparação com as outras técnicas radiográficas.................................... 66

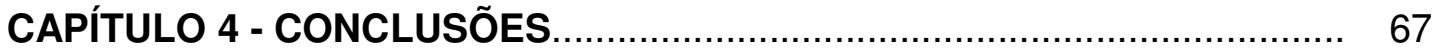

REFERÊNCIAS BIBLIOGRÁFICAS .................................................... 75 


\section{LISTA DE TABELAS}

1.1 - Classificação dos nêutrons de acordo com sua energia cinética.

2.1 - Valores do alcance dos elétrons na emulsão fotográfica e na base plástica

2.2 - Características do feixe de nêutrons extraído do arranjo experimental.....

3.1 - Valores do alcance dos elétrons de $72 \mathrm{keV}$ e $150 \mathrm{keV}$ nos materiais estudados.

3.2 - Resultados obtidos para a espessura mínima detectável para os materiais estudados.

3.3 - Valores médios de Ut em função da espessura da amostra de alumínio.. 53

3.4 - Resultados obtidos para a espessura mínima detectável para os materiais estudados

4.1 - Resumo das condições e das características radiográficas da técnica (NIER). 


\section{LISTA DE FIGURAS}

1.1 - Coeficientes de atenuação para nêutrons térmicos e raios - $X$ em função do número atômico dos elementos............................................................... 13

1.2 - Esquema de um colimador do tipo cônico divergente.................................. 14

1.3 - Resolução geométrica para um colimador tipo cônico divergente, mostrando o efeito da divergência angular................................................... 15

1.4 - Curva típica de transmissão para elétrons monoenergéticos, onde $R_{e}$ é o alcance extrapolado.

1.5 - Filme radiográfico convencional: lado esquerdo - a emulsão foi retirada para mostrar a base plástica; lado direito - mostra a emulsão depositada

2.1 - Cassete de alumínio com tela conversora de gadolínio.

2.2 - Cubas com as soluções utilizadas no processo de revelação. Da direita para a esquerda: revelador (REV), banho de parada (BP), fixador (FIX), água corrente e agente químico $(\mathrm{AQ})$

2.3 - Esquema do arranjo experimental.

2.4 - Interior da blindagem do arranjo experimental de radiografia com nêutrons.

2.5 - Visão externa do arranjo experimental de radiografia com nêutrons

2.6 - Diagrama esquemático demonstrando a obtenção de uma radiografia com elétrons induzida por nêutrons.

2.7 - Fotografia do cassete mostrando a disposição da tela conversora, o filme e das amostras.

2.8 - Sistema digital utilizado no trabalho.

3.1 - Imagem digitalizada dos filmes Kodak AA, utilizados para a confecção da curva NC x E

3.2 - Comportamento do nível de cinza em função da exposição, destacando a região de melhor contraste.

3.3 - Comportamento do nível de cinza em função da espessura para a amostra de alumínio.

3.4 - Comportamento do nível de cinza em função da espessura para a amostra de makrofol $-K G$. 
3.5 - Comportamento do nível de cinza em função da espessura para a amostra de papel branco

3.6 - Comportamento do nível de cinza em função da espessura para a amostra de adesivo

3.7 - Comportamento da sensibilidade " $\Delta x$ " em função da espessura para a amostra de alumínio.

3.8 - Comportamento da sensibilidade " $\Delta x$ " em função da espessura para a amostra de makrofol - KG.

3.9 - Comportamento da sensibilidade " $\Delta x$ " em função da espessura para a amostra de papel branco

3.10 - Comportamento da sensibilidade " $\Delta x$ " em função da espessura para a amostra de adesivo.

3.11 - Resultado típico da varredura obtido para espessura de $12 \mu \mathrm{m}$ de alumínio.

3.12 - Valores médios da resolução total em função da espessura do material alumínio.

3.13 - Contribuições das outras radiações na formação da imagem radiográfica para a amostra de alumínio

3.14 - Contribuições das outras radiações na formação da imagem radiográfica para a amostra de makrofol - KG.

3.15 - Contribuições das outras radiações na formação da imagem radiográfica para a amostra de papel branco.

3.16 - Contribuições das outras radiações na formação da imagem radiográfica para a amostra de adesivo.

3.17 - Negatoscópio utilizado neste trabalho para leitura da densidade ótica dos filmes irradiados

3.18 - Densitômetro ótico utilizado neste trabalho: a) visão superior; b) detalhe do leitor com $0,07 \mathrm{~cm}^{2}$ de área.

3.19 - Comportamento da densidade ótica em função da exposição para o sistema analógico, destacando a região de melhor contraste.

3.20 - Sensibilidade em função da espessura da amostra de alumínio obtida para ambos os sistemas analógico e digital. 
3.21 - Sensibilidade em função da espessura da amostra de makrofol - KG obtida para ambos os sistemas analógico e digital........................................... 64

3.22 - Sensibilidade em função da espessura da amostra de papel branco obtida para ambos os sistemas analógico e digital

3.23 - Sensibilidade em função da espessura da amostra de adesivo obtida para ambos os sistemas analógico e digital

4.1 - Radiografias com elétrons induzidas por nêutrons de plantas.

4.2 - Radiografias com elétrons induzidas por nêutrons. Cédula de $\mathrm{R} \$ 2,00$ : a) inteira; b) detalhe com a marca d'agua..

4.3 - Radiografias com elétrons induzidas por nêutrons. Cédula de $\mathrm{R} \$ 50,00$ : a) inteira; b) detalhe com a marca d'agua.

4.4 - Exemplos de radiografias com elétrons induzidas por nêutrons utilizando imaging plates - IP 


\title{
RADIOGRAFIA COM ELÉTRONS INDUZIDA POR NÊUTRONS
}

\author{
Marcos Leandro Garcia Andrade
}

\section{RESUMO}

No presente trabalho foi desenvolvida uma nova técnica radiográfica que utiliza feixes de elétrons de baixa energia como radiação penetrante para inspecionar amostras finas com espessuras da ordem de micra. Esta técnica é denominada, radiografia com elétrons induzida por nêutrons e os feixes são obtidos mediante a irradiação de uma tela de gadolínio com nêutrons térmicos. Foram determinadas as condições ótimas para a obtenção de radiografias no filme convencional para raios - $\mathrm{X}$, Kodak Industrex AA, utilizando um sistema digital para análise do grau de enegrecimento dos filmes. Todas as irradiações foram realizadas em um equipamento radiográfico instalado no canal de irradiação 08 do reator nuclear de pesquisas IEA-R1 do IPEN-CNEN/SP. O tempo de irradiação necessário para se obter a radiografia com o melhor contraste foi de 100 segundos e nesta condição foi possível discernir $1 \mu \mathrm{m}$ em $24 \mu \mathrm{m}$ de alumínio com uma resolução máxima de $32 \mu \mathrm{m}$. As imagens radiográficas obtidas no IPENCNEN/SP por esta técnica apresentam visualmente uma qualidade superior quando comparadas as obtidas pelas outras técnicas radiográficas usuais que utilizam elétrons como radiação penetrante e filmes para o registro da imagem. Além disto, o sistema digital propiciou uma maior praticidade referente à aquisição e a análise dos dados e uma melhor visualização das imagens radiográficas. 


\title{
NEUTRON INDUCED ELETRON RADIGRAPHY
}

\author{
Marcos Leandro Garcia Andrade
}

\begin{abstract}
In the present paper a new radiography technique, the "Neutron Induced Electron Radiography - NIER, to inspect low thickness samples on the order of micra, has been developed. This technique makes use of low energy electrons as penetrating radiation generated from metallic gadolinium screens when irradiated by thermal neutrons. The conditions to obtain the best image for the conventional X-ray film Kodak-AA were determined by using a digital system to quantify the darkening level of the film. The irradiations have been performed at a radiography equipment installed at the beam-hole \#8 of the 5 MW IEA-R1 nuclear research reactor of IPEN-CNEN/SP. The irradiation time to obtain the best radiography was 100 seconds and for such condition the technique was able to discern $1 \mu \mathrm{m}$ in $24 \mu \mathrm{m}$ of aluminum at a resolution of $32 \mu \mathrm{m}$. By visual comparison the images obtained by the NIER shown a higher quality when compared with the ones from other usual techniques the make use of electrons a penetrating radiation and films for image registration. Furthermore the use of the digital system has provided a smaller time for data acquisition and data analysis as well as an improvement in the image visualization.
\end{abstract}




\section{INTRODUÇÃO}

Existe um grande interesse das áreas de biologia, medicina, tecnologia forense, metalurgia, etc, na investigação da estrutura interna de amostras com pouca espessura. Dentre as técnicas disponíveis para esta finalidade estão as de radiografia, das quais para o objetivo do presente trabalho será dada ênfase especial a que utiliza feixe de elétrons como radiação penetrante [1-4]. Existem três métodos para se obter uma radiografia com elétrons [5]:

- Transmissão: o feixe é gerado por algum radioisótopo emissor beta, como $0^{3} \mathrm{H}$, ${ }^{14} \mathrm{C},{ }^{35} \mathrm{~S}$, ou em folhas de chumbo irradiadas por raios - $\mathrm{X}$ e atravessa toda a espessura da amostra;

- Emissão superficial: o feixe é gerado na superfície da própria amostra quando irradiada por raios - $\mathrm{X}$;

- Auto - radiografia: o feixe é gerado pela própria amostra no interior da qual é inserido um radioisótopo emissor beta.

Dentre as principais características desta técnica destacam-se:

- Tempo elevado para obtenção de uma imagem (dias, semanas ou meses);

- Problemas de manipulação de substâncias altamente tóxicas e radioativas;

- Meia - vida do radioisótopo;

- Necessidade de filmes específicos.

Desde 1988 o IPEN-CNEN/SP emprega a técnica da radiografia com nêutrons na obtenção de imagens para diversas aplicações tanto acadêmicas quanto tecnológicas [6-20]. A radiografia é feita posicionando a amostra, a ser estudada, em um feixe homogêneo de nêutrons térmicos e o padrão de intensidade transmitido é transformado em imagem por meio de uma tela conversora e um filme. Estas telas são confeccionadas com materiais de elevada seção de choque para a absorção de nêutrons térmicos, como o gadolínio, boro, disprósio, índio e, têm a função de converter o nêutron em uma radiação capaz de sensibilizar um filme, estes podendo ser os convencionais para raios - $X$, formando uma imagem $[8,19]$. A interpretação da informação contida na imagem 
radiográfica é feita mediante a quantificação do grau de enegrecimento do filme. Até 2002 os estudos referentes a esta quantificação eram realizados no IPEN em sistemas padrões que utilizavam um negatoscópio (fonte de luz) e um densitômetro ótico (sensor), ou em algumas aplicações especiais um microfotômetro ótico. No presente trabalho ambos serão denominados de "sistema analógico". Neste caso o grau de enegrecimento do filme é medido em uma escala de densidade ótica definida como:

$\mathrm{D}=\log \left(1 / \mathrm{I}_{0}\right)$

onde $I_{0}$ e I são as intensidades da luz incidente e transmitida pelo filme respectivamente.

Um valor de densidade ótica 1 corresponde a uma transmissão de luz de $10 \%$ pela região enegrecida, 2 de $1 \%$ e assim por diante. Usualmente os densitômetros óticos são capazes de medir densidades óticas numa escala que varia de 0 a 4 .

Durante 15 anos este sistema forneceu dados e resultados confiáveis através dos quais foram também determinadas e estudadas as características da técnica da radiografia com nêutrons no IPEN $[8,19]$. No fim de 2000 o grupo de trabalho iniciou atividades referentes à utilização de sistemas digitais para esta finalidade o qual prontamente demonstrou ser uma ferramenta poderosa tanto referente à qualidade e rapidez na aquisição de dados quanto na melhoraria da visualização das imagens radiográficas.

No início de 2002 havia interesse do grupo de trabalho do IPEN referente à inspeção radiográfica de amostras finas, com espessuras da ordem de micra. Entretanto mediante o uso da técnica da radiografia com nêutrons, as únicas amostras finas que poderiam ser inspecionadas eram aquelas confeccionadas a base de gadolínio, cádmio, ou de algum outro material com elevada seção de choque para absorção de nêutrons. Embora tivéssemos realizado alguns testes com diversas amostras, a imagem registrada no filme era de péssima qualidade, apresentando pouco contraste e pouca resolução. Esta era a principal deficiência técnica do grupo, sendo portanto a principal motivação deste trabalho. 
Foi nesta época que surgiram as primeiras idéias referentes ao desenvolvimento e a implantação de uma nova técnica radiográfica para inspecionar amostras finas. Dentre estas idéias, talvez a mais importante, a partir da qual a técnica proposta neste trabalho pôde ser desenvolvida, foi a de intercalar a amostra a ser radiografada entre uma tela conversora de gadolínio e um filme convencional para raios - X. Quando o conjunto "filme - amostra conversor" é irradiado em um feixe de nêutrons térmicos, a reação nuclear nêutron - gadolínio gera o feixe de radiação penetrante. Dentre as radiações emitidas, as mais intensas são elétrons de $72 \mathrm{keV}$ e de $150 \mathrm{keV}$ os quais são adequados para a inspeção de amostras finas uma vez que seus alcances na matéria são da ordem de centenas de micra. Daí o nome da presente técnica, ou seja, radiografia com elétrons induzida por nêutrons (NIER).

Desta forma o desenvolvimento desta técnica não partiria do patamar "zero" uma vez que todo o conhecimento adquirido, infra-estrutura disponível tais como tela de gadolínio, filmes, câmara para revelação de filmes que estavam sendo empregados para a técnica da radiografia com nêutrons poderiam ser utilizados. Além disto, o custo geral para o seu desenvolvimento não seria elevado uma vez que a parte mais dispendiosa, que é a geração do feixe de nêutrons, já estaria disponível, pois seria utilizado o equipamento de radiografia que já se encontrava instalado no canal de irradiação 08 do reator IEA-R1.

A primeira etapa referente ao desenvolvimento desta técnica foi a sua caracterização, ou seja, a determinação da exposição (ou do tempo de irradiação) para se obter o melhor contraste no filme, bem como da sua sensibilidade para discernir variações de espessuras e da resolução espacial da imagem radiográfica. Nesta etapa, todas as medidas para estas determinações foram realizadas utilizando o sistema analógico mencionado acima uma vez que o seu desempenho e confiabilidade já haviam sido comprovados anteriormente $[8,19]$. 0 sistema digital mencionado anteriormente não foi utilizado nesta fase, pois este não se adequava tanto ao tamanho quanto ao grau de enegrecimento dos filmes irradiados.

A segunda etapa foi à obtenção de algumas imagens para verificar a sua potencialidade.

Estas idéias e resultados foram reunidos em um projeto que foi submetido à Agência Internacional de Energia Atômica - I.A.E.A. o qual foi 
aprovado com início a partir de março de 2003. Fazia também parte destas idéias o desenvolvimento de um sistema digital adequado para a aquisição de dados e para o processamento de imagens.

Este trabalho foi então desenvolvido a partir deste projeto e teve por objetivo tornar operacional uma nova técnica radiográfica que faz uso de feixes de nêutrons e de telas conversoras à base de gadolínio, para gerar feixes de elétrons de baixa energia, para serem utilizados como radiação penetrante [21,22].

Dentre as principais características desta nova técnica destacam-se:

- O ensaio não é destrutivo, pois não é necessário inserir material radioativo no interior da amostra;

- O feixe de radiação penetrante é gerado por meio de uma reação nuclear com nêutrons térmicos;

- A radiação gerada penetra por toda a espessura da amostra;

- O emprego de um sistema digital para a captura e processamento das imagens radiográficas.

Quando comparada com as outras técnicas de radiografia com elétrons [1-5], a técnica proposta apresenta:

- Menor tempo para a obtenção de uma radiografia;

- Não é necessário manipular substâncias tóxicas e radioativas.

Suas principais limitações são:

- A impossibilidade de radiografar in loco, ou seja, a obtenção da radiografia é restrita ao local de instalação do reator;

- A resolução máxima obtida na imagem é de $8 \mu \mathrm{m}$, que é a dimensão mínima do elemento de imagem (pixel) fornecida pelo sistema digital atual;

- As energias dos elétrons emitidos pelo conversor de gadolínio (72 keV e 150 $\mathrm{keV})$ o que restringe as inspeções a amostras, dos materiais utilizados no trabalho, com espessuras de até $~ 300 \mu \mathrm{m}$.

\section{Originalidade}

A originalidade do trabalho baseia-se fundamentalmente nos seguintes pontos:

- Na metodologia proposta a obtenção da radiografia difere das existentes pela maneira na qual o feixe de radiação penetrante é gerado o que veio a evitar a 
manipulação de substâncias radioativas líquidas e permitiu um tempo inferior para a obtenção da radiografia. Além disto, a radiação penetra por toda a espessura da amostra;

- Desenvolvimento de um sistema digital para aquisição, análise e processamento de imagens e dos dados registradas nos filmes radiográficos.

\section{Metodologia}

O presente trabalho foi desenvolvido de acordo com a seguinte metodologia:

1. Seleção do filme radiográfico;

2. Verificação da viabilidade do sistema digital;

3. Caracterização da técnica radiográfica proposta, utilizando o sistema digital;

4. Aplicações da técnica.

\section{Visão Geral do Trabalho}

A Tese foi dividida em 4 capítulos e os assuntos abordados em cada um, são os seguintes:

No capítulo 1 são apresentados os fundamentos teóricos da interação dos nêutrons e dos elétrons com a matéria necessários para o entendimento das técnicas da radiografia com nêutrons e com elétrons induzida por nêutrons. São abordados os principais tipos de interação nêutron - núcleo, os conceitos de seções de choque microscópica e macroscópica, bem como as interações responsáveis pela perda de energia dos elétrons ao atravessarem a matéria.

Como será enfatizado em todo o transcorrer do trabalho, foi utilizado um sistema digital para a aquisição de dados e para o processamento de imagens. Desta forma foi necessária também uma introdução básica a respeito da conversão imagem analógica $\rightarrow$ imagem digital, do conceito de pixel, bem como da possibilidade de realizar operações matemáticas entre pixels ou entre imagens de modo a modificar diversas características da imagem original.

São também abordadas algumas das características dos métodos convencionais para obtenção de uma radiografia com elétrons.

Desde que no presente trabalho todas as imagens radiográficas foram registradas em filmes convencionais para raios - X são também descritos alguns 
conceitos referentes à formação da imagem latente e, da imagem visível nestes filmes.

Finalmente é mencionada a metodologia que foi empregada para caracterizar a presente técnica radiográfica, ou seja, a determinação da exposição para se obter o melhor contraste no filme, a quantificação da sensibilidade ou capacidade para discernir variações de espessuras dos materiais e também da resolução espacial ou capacidade para distinguir objetos ou pontos de uma mesma imagem.

O capítulo 2 é dedicado a parte experimental do trabalho onde são descritas as características do cassete para irradiação dos filmes e da tela conversora de gadolínio, destacando os isótopos que possuem os maiores valores das seções de choque para a absorção de nêutrons térmicos e que mais contribuem para a formação da imagem. São fornecidas algumas das características do filme radiográfico empregado e do processo de sua revelação.

São também descritos com bastante detalhe, o arranjo experimental, ou melhor, o equipamento de radiografia com nêutrons onde foram realizadas todas as irradiações e, o procedimento empregado para se obter uma radiografia com elétrons induzida por nêutrons. Finalmente é descrito o sistema digital para análise e processamento das imagens e são fornecidas as suas principais características.

No capítulo 3 são abordados os detalhes sobre a obtenção e a análise dos dados referentes à caracterização da técnica da radiografia com elétrons induzida por nêutrons. Foi também analisada a reprodutibilidade do "método radiográfico" com relação às leituras da intensidade da luz transmitidas pelas regiões enegrecidas do filme irradiado, uma vez que este é o parâmetro que participa de todas as etapas de caracterização da técnica. Aqui, o termo "método radiográfico" significa todas as etapas experimentais que participam no enegrecimento do filme. Foi também verificado que a influência isolada do sistema digital na reprodutibilidade das leituras da intensidade de luz é desprezível.

Para finalizar, os resultados obtidos para o intervalo de exposição para obter o melhor contraste e para a sensibilidade foram comparados com os determinados utilizando o sistema analógico. Pode-se concluir que ambos possuem características muito similares quanto a estes parâmetros, mas que o 
digital exibiu uma sensibilidade um pouco melhor para alguns dos materiais estudados. Além disto, o sistema digital mostrou ser superior quando praticidade, rapidez e precisão são levadas em consideração nas leituras de intensidade da luz transmitida. São também discutidos alguns aspectos técnicos e econômicos da presente técnica e a sua relação com as usuais que utilizam elétrons como radiação penetrante.

No capítulo 4 são apresentadas as conclusões relevantes deste trabalho, bem como a condição ótima de exposição para a obtenção de uma radiografia com elétrons induzida por nêutrons. Ainda neste capítulo são apresentadas algumas radiografias obtidas pela técnica proposta nas quais, a técnica do processamento digital foi empregada para a visualização das imagens e onde sua potencialidade e viabilidade podem ser constatadas. 


\section{CAPÍTULO 1 - FUNDAMENTOS TEÓRICOS}

Como mencionado na Introdução, a técnica proposta neste trabalho foi desenvolvida a partir da técnica da radiografia com nêutrons em filmes convencionais para raios - $\mathrm{X}$. Desta forma, além da abordagem dos processos de interação dos elétrons com a matéria, das técnicas de radiografia existentes para inspecionar amostras finas e, dos princípios de formação da imagem nestes filmes convencionais torna-se necessário também uma abordagem dos processos básicos da interação do nêutron com a matéria bem como da técnica da radiografia com nêutrons. Além disto, e por causa da metodologia empregada para captura e processamento de imagens, é também apresentada uma introdução básica sobre o processamento de imagens digitais.

\subsection{Nêutrons e a matéria}

Apesar de desconhecerem, os primeiros pesquisadores a trabalharem com nêutrons foram Bothe e Becker na Alemanha em 1930 e, o casal Curie na França em 1931. Eles estavam estudando a natureza de uma radiação penetrante, do resultado do bombardeamento de partículas - $\alpha$ do elemento polônio em alvos de elementos leves. Descobriram em se tratar de radiação - $\gamma$ com energias de alguns MeV. Entretanto havia uma dificuldade ao se atribuir o caráter de radiação - $\gamma$ para a radiação oriunda do alvo de berílio. A sua energia deveria ser muito elevada e de acordo com os estudos realizados por Webster, Curie e Joliot (1932) este valor deveria ser da ordem de $50 \mathrm{MeV}$. Neste mesmo ano, Chadwick comprovou experimentalmente que esta radiação era um nêutron, uma partícula sem carga e, com massa comparável à do próton, a qual havia sido proposta por Rutherford em 1912 [23].

O nêutron possui spin $=1 / 2$, momento de dipolo magnético $\mu=-1,913$ $\mu_{\mathrm{N}}\left(\mu_{\mathrm{N}} \equiv\right.$ magneton nuclear), a sua massa é de 1,008664904(14) u.m.a. e, se possuir carga líquida, esta deve ser menor que $1,5 \times 10^{-20} \mathrm{e}$ ( $\mathrm{e} \equiv$ carga do elétron). A meia - vida do nêutron livre é de 12,8 minutos e decai pela emissão de um próton, um elétron e um anti - neutrino. 
$n \rightarrow p+e^{-}+v$

De acordo com as teorias atuais, o nêutron é composto por três quarks ( 1 up e 2 down $\rightarrow$ udd) e decai em um próton (uud) mediante a transformação de um quark "d", em um "u", ou seja [24]:

$d \rightarrow u+e^{-}+v$

\subsubsection{Interação nêutron - núcleo}

Pelo fato de o nêutron possuir carga líquida nula e momento magnético, a sua interação com a matéria ocorre mediante forças nucleares, ou magnéticas. Devido à sua importância para o presente trabalho, será dada ênfase à primeira. Neste processo eles podem ser espalhados ou absorvidos pelos núcleos alvo. No processo de espalhamento elástico a interação pode ocorrer, ou como resultado de uma colisão do tipo "bola de bilhar" ou então o nêutron penetra no núcleo excitando-o e, este retorna ao seu estado fundamental emitindo um nêutron. Em ambos os casos a energia cinética do sistema nêutron - núcleo alvo se conserva. No processo de espalhamento inelástico o nêutron penetra no núcleo e este também emite um nêutron, mas neste caso a energia cinética do sistema não se conserva e parte dela é utilizada como energia de excitação nuclear.

No processo de absorção o nêutron penetra no núcleo deixando-o excitado o qual retorna ao seu estado fundamental mediante a emissão de partículas e/ou de radiações - $\gamma$.

A probabilidade de ocorrência destes processos é caracterizada por meio de uma grandeza denominada secção de choque microscópica $(\sigma)$, expressa na unidade barn (1 barn $\equiv 10^{-24} \mathrm{~cm}^{2}$ ). Classicamente é interpretada como uma área efetiva que o núcleo alvo apresenta ao nêutron para a ocorrência da interação. A secção de choque total $\left(\sigma_{T}\right)$ para a ocorrência de qualquer um destes processos é dada simbolicamente por:

$\sigma_{\mathrm{T}}=\sigma_{\mathrm{abs}}+\sigma_{\mathrm{esp}}$ 
onde $\sigma_{\text {abs }}$ e $\sigma_{\text {esp }}$ são as secções de choque microscópicas para absorção e espalhamento, respectivamente [23,25].

Devido à especificidade destas interações, os nêutrons são classificados de acordo com a sua energia cinética. Uma classificação usual é apresentada na TAB. 1.1 [26].

TABELA 1.1 - Classificação dos nêutrons de acordo com sua energia cinética.

\begin{tabular}{cc}
\hline CLASSES & FAIXA DE ENERGIA (eV) \\
Lentos & $0<\mathrm{E}<1 \times 10^{-3}$ \\
Frios & $\mathrm{E}<0,01$ \\
Térmicos & $0,01<\mathrm{E}<0,5$ \\
Epitérmicos & $0,5<\mathrm{E}<1 \times 10^{4}$ \\
Ressonância & $1<\mathrm{E}<100$ \\
Rápidos & $1 \times 10^{3}<\mathrm{E}<20 \times 10^{6}$ \\
Ultra-rápidos & $\mathrm{E}>20 \times 10^{6}$ \\
\hline
\end{tabular}

\subsubsection{Transmissão de nêutrons pela matéria}

Teoricamente a transmissão de nêutrons pela matéria é governada por uma lei exponencial do tipo [26]:

$\phi(x)=\phi_{0} \cdot e^{-N \cdot \sigma_{T}(v) \cdot x}$

sendo:

$\phi_{0}=$ fluxo de nêutrons incidente no material $\left(\mathrm{n} / \mathrm{s} . \mathrm{cm}^{2}\right)$;

$\phi(x)=$ fluxo de nêutrons que não sofreu interação após atravessar o material de espessura " $x$ ";

$\mathrm{N}=$ densidade atômica do material $\left(\mathrm{cm}^{-3}\right)$.

O produto $\mathrm{N} . \sigma_{T}(\mathrm{v})$ é denominado secção de choque total macroscópica e representa a probabilidade do nêutron, com velocidade "v", sofrer qualquer tipo de interação por unidade de caminho percorrido neste material, ou seja:

$\Sigma_{\mathrm{T}}(\mathrm{v})=\mathrm{N} \cdot \sigma_{\mathrm{T}}(\mathrm{v})$ 
Caso o feixe de nêutrons incidente possua uma distribuição de velocidades $n(v)$, a secção de choque total a ser considerada é a efetiva para este espectro, ou seja [27]:

$$
\Sigma_{\mathrm{T}}=\mathrm{N} \frac{\int \mathrm{n}(\mathrm{v}) \cdot \mathrm{v} \cdot \sigma_{\mathrm{T}}(\mathrm{v}) \cdot \mathrm{dv}}{\ln (\mathrm{v}) \cdot \mathrm{v} \cdot \mathrm{dv}}
$$

Experimentalmente a expressão (1.4) é verificada se a medida de transmissão for realizada na condição de boa geometria, mediante colimação dos feixes de nêutrons, incidente e transmitido pelo material, de modo a se minimizar a detecção dos nêutrons que sofreram espalhamento ao atravessá-lo. Caso a medida de transmissão seja realizada na condição de má geometria, esta expressão deverá conter um termo adicional " $\phi_{s}$ " que leve em conta a fração dos nêutrons espalhados pelo material e, que foram detectados [16].

No caso de materiais tipicamente espalhadores, é importante salientar que a expressão (1.4) continua sendo válida se a razão " $\mathrm{T}=\phi(\mathrm{x}) / \phi_{0}$ " estiver compreendida entre $1 / e^{2}<T<1 / e$, satisfazendo a condição de que, em média, somente ocorra uma interação entre o nêutron e o alvo, minimizando o efeito do espalhamento múltiplo [26].

\subsection{A Técnica da radiografia com nêutrons}

\subsection{1 - Histórico [28]}

As primeiras pesquisas sobre a técnica da radiografia com nêutrons foram realizadas por Kallmann e Kuhn na Alemanha em 1935 utilizando um acelerador para produção de um feixe com intensidade em torno de $4 \times 10^{7}$ nêutrons por segundo $(\mathrm{n} / \mathrm{s})$.

No ano de 1956, Thewlis e Derbyshire em Harwell na Inglaterra publicam o primeiro trabalho referente a esta técnica, utilizando um reator nuclear. Neste caso o emprego de um feixe bem colimado de uma fonte mais intensa permitiu obter radiografias de melhor qualidade, quando comparadas às anteriores com aceleradores. A partir deste trabalho, Thewlis apontou o caminho para as possíveis aplicações práticas desta técnica de ensaio não destrutivo [29]. 
No início dos anos 70 existia cerca de 40 instalações capazes de realizar serviços em radiografia com nêutrons e, no final dos anos 90 este número ultrapassava 100 [30]. As pesquisas mais recentes nesta área concentram-se em aprimorar sistemas para tomografia tri - dimensional e desenvolver novos processos para a geração de imagens [31-36].

\subsection{2 - Conceitos básicos}

Pelo fato da interação do nêutron com a matéria ocorrer mediante forças nucleares, a dependência dos coeficientes de atenuação $\left(^{*}\right)$ com o número atômico $Z$ do elemento alvo, não pode ser representada por uma função monotônica como no caso dos raios - X. A FIG. 1.1 [25] mostra dados comparativos destes valores, referentes a nêutrons térmicos e a raios - $X$ de 125 $\mathrm{keV}$, na qual pode-se verificar que para alguns elementos de baixo número atômico os coeficientes para nêutrons exibem valores elevados em relação aos raios - $\mathrm{X}$, enquanto que para a maioria dos elementos pesados ocorre o inverso. Estas diferenças significativas de atenuação, também são observadas para alguns elementos com números atômicos próximos bem como para alguns isótopos, atribuindo a esta técnica características únicas, tornando possível, por exemplo, a inspeção de materiais hidrogenados como óleo, graxas, plásticos, explosivos, água, sangue, adesivos, mesmo quando envoltos por espessas camadas de alguns metais.

O procedimento básico para a obtenção de uma radiografia com nêutrons é semelhante ao das técnicas convencionais com raios $-X$ e raios $-\gamma$. $O$ material a ser inspecionado é colocado em um feixe colimado e homogêneo e a intensidade modulada transmitida, é então registrada. Pelo fato de o nêutron não ser uma radiação ionizante, torna-se necessário o emprego de uma tela ou placa conversora cuja finalidade é transformar o nêutron em uma radiação, capaz de sensibilizar um filme [37].

Basicamente um equipamento para radiografia com nêutrons típico apresenta quatro partes:

$\left(^{*}\right)$ coeficiente de atenuação para nêutrons $=\Sigma / \rho$ sendo $\rho$ a densidade do material. 


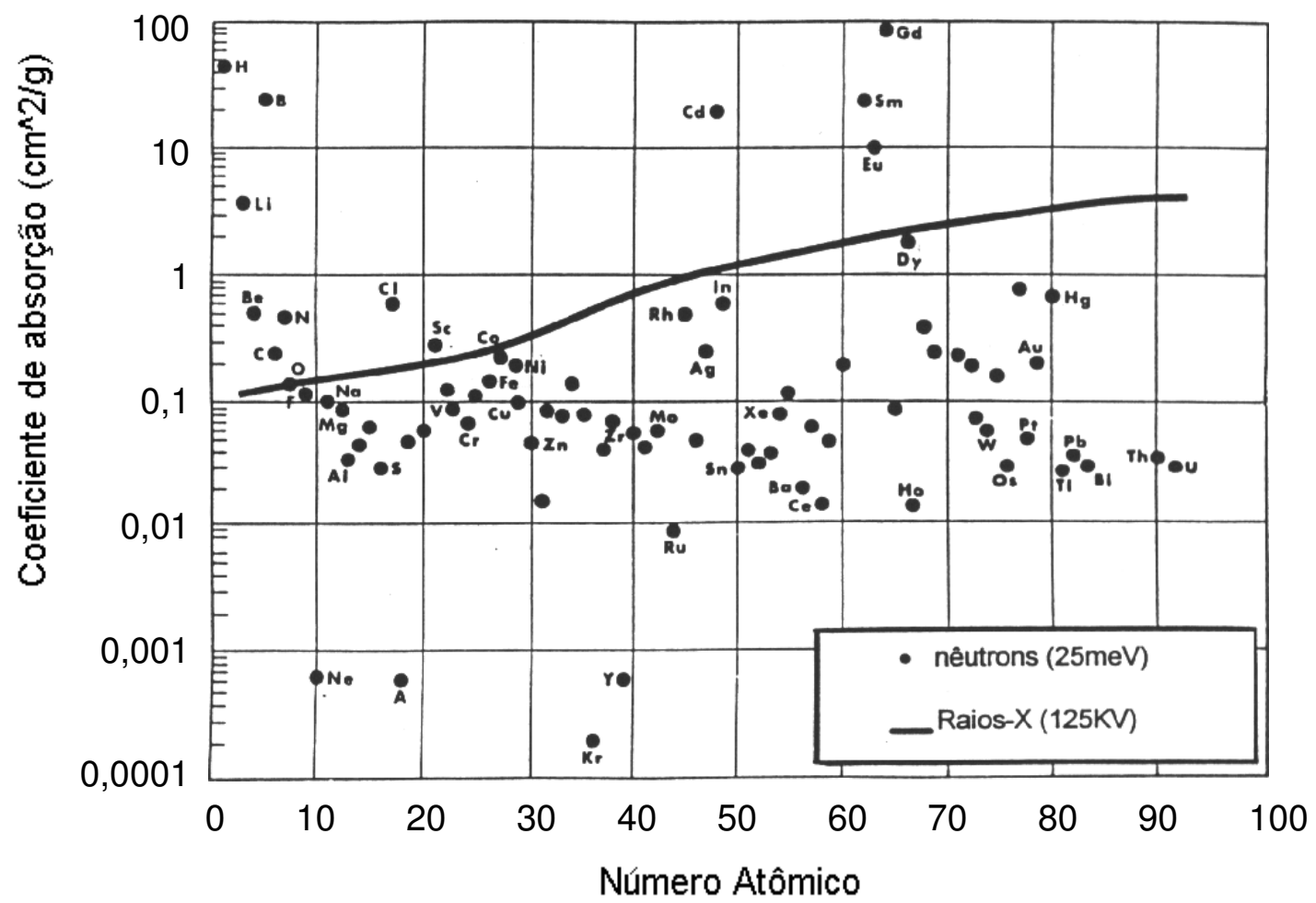

FIGURA 1.1 - Coeficientes de atenuação para nêutrons térmicos e raios - $X$ em função do número atômico dos elementos.

\subsubsection{Fonte de nêutrons [30]}

Os feixes de nêutrons para fins radiográficos podem ser oriundos de um acelerador, de um radioisótopo, ou de um reator nuclear e são removidos do núcleo atômico por um processo de transmutação e emergem com energias correspondentes às dos nêutrons rápidos.

De uma forma geral, a faixa de energia de maior interesse para fins radiográficos é aquela dos nêutrons térmicos, uma vez que os coeficientes de atenuação dos elementos exibem grandes diferenças entre os seus valores e, porque as telas conversoras apresentam os maiores valores para a secção de choque de absorção, ou seja, são mais eficientes para a conversão. Desta maneira as fontes devem ser munidas de um meio moderador que, mediante reações de espalhamento elástico, reduz a sua energia cinética inicial. Por causa do elevado fluxo que podem fornecer, as fontes mais comumente empregadas são os aceleradores do tipo "spallation sources" e, os reatores nucleares. No presente trabalho será dada ênfase aos reatores nucleares uma vez que esta é a 
que foi utilizada. Um reator nuclear pode prover um fluxo de nêutrons entre $100 \mathrm{e}$ 10.000 vezes mais intenso do que os extraídos de aceleradores do tipo cíclotrons e de fontes radioisotópicas e assim as radiografias obtidas podem apresentar uma melhor resolução e, o tempo de irradiação para a formação da imagem ser menor. A principal desvantagem na utilização de reatores é a sua falta de mobilidade o que restringe a obtenção de radiografias ao seu local de instalação [36].

\subsubsection{Colimador de nêutrons}

Os colimadores tem a finalidade de dar forma ao feixe de nêutrons e geralmente são instalados no interior dos canais de irradiação dos reatores $[25,29,36]$. Dentre os mais empregados destaca-se o do tipo cônico divergente, mostrado na FIG. 1.2.

Para definir a forma do feixe, as suas paredes internas devem ser revestidas com materiais que possuam alta secção de choque para absorção de nêutrons. Além disso, a radiação secundária produzida pela sua absorção deve ficar retida nestas paredes e, ter baixa probabilidade de ser registrada pelo filme [29].

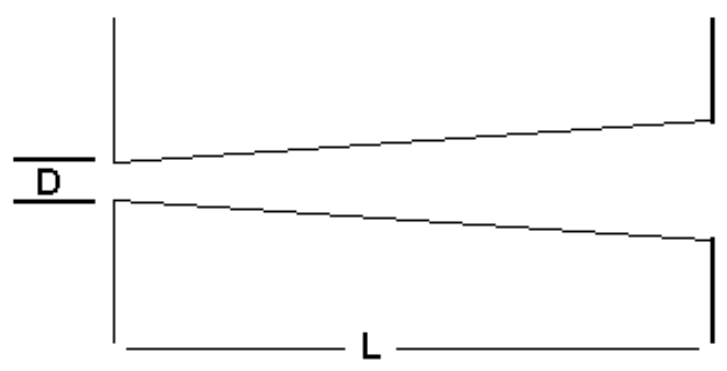

FIGURA 1.2 - Esquema de um colimador do tipo cônico divergente

A razão entre o comprimento - $L$ e o diâmetro - $D$ de entrada do feixe do colimador, é usada para caracterizar a divergência angular do feixe extraído e, tipicamente varia entre $100<\mathrm{L} / \mathrm{D}<500$. Quanto maior a razão L/D menores serão as distorções (penumbra) na imagem radiográfica, conforme mostrado na FIG. 1.3. Esta distorção é relacionada à "resolução geométrica" - $U_{g}$ da imagem e vem dada por [36]: 
$\mathrm{U}_{\mathrm{g}}=\mathrm{x} /(\mathrm{L} / \mathrm{D})$

onde "x" é a distância da amostra ao filme.

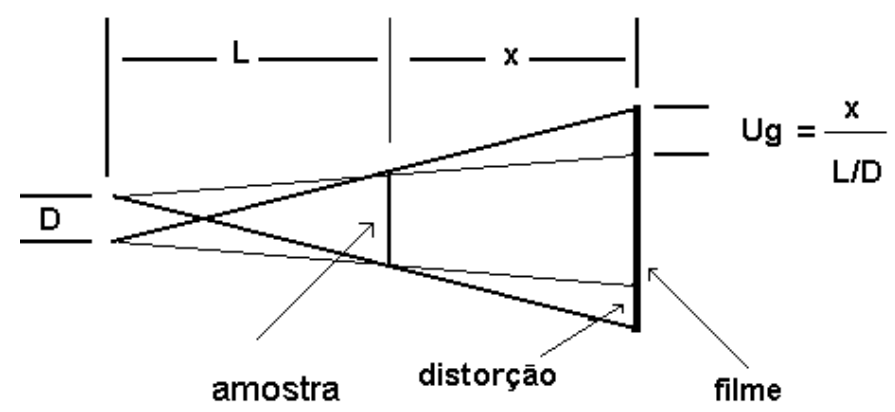

FIGURA 1.3 - Resolução geométrica para um colimador tipo cônico divergente, mostrando o efeito da divergência angular.

O fluxo " $\phi$ " de nêutrons na saída do colimador é dado por:

$\phi=(1 / 16) \cdot(\mathrm{D} / \mathrm{L})^{2} \cdot \phi_{\mathrm{o}}$

onde $\phi_{0} \equiv$ fluxo de nêutrons na entrada do colimador

\subsubsection{Filtro contra a radiação $-\gamma$}

Estes componentes têm a finalidade de reduzir a intensidade da radiação - $\gamma$ presente no feixe de nêutrons, oriundo do núcleo do reator, sem no entanto atenuar demasiadamente o último. Isto porque alguns dos métodos utilizados em radiografia com nêutrons fazem uso de telas conversoras e de filmes, que apresentam elevada sensibilidade à radiação - $\gamma$. Assim, acima de certos valores de intensidade, ter-se-á uma gamagrafia de fundo sobreposta a uma radiografia com nêutrons. A experiência mostra que a razão ideal entre 0 fluxo de nêutrons $\left(\mathrm{n} / \mathrm{s} . \mathrm{cm}^{2}\right)$ e a dose de radiação - $\gamma(\mathrm{mRem} / \mathrm{s})$ na amostra deve ser $n / \gamma>5 \times 10^{5} \mathrm{n} / \mathrm{cm}^{2}$.mRem [29].

Usualmente estes filtros são confeccionados de materiais que possuem elevado número atômico e, uma pequena secção de choque total para a atenuação de nêutrons térmicos, tais como o chumbo e o bismuto [38]. 


\subsubsection{Métodos para obtenção da imagem em radiografia com nêutrons}

Como já mencionado anteriormente, pelo fato de o nêutron ser uma radiação não ionizante ele não é capaz de sensibilizar um filme radiográfico. Desta forma, para que um feixe de nêutrons possa ser empregado para esta finalidade, há a necessidade de utilização de uma tela conversora cuja finalidade é transformá-lo em um tipo de radiação capaz de sensibilizar este filme. Os materiais que compõe estas telas devem possuir elevada secção de choque para a absorção de nêutrons térmicos e, dentre eles destacam-se o gadolínio, disprósio, boro e o lítio. Como estes processos de transformação ocorrem mediante reações nucleares, as suas características de decaimento, darão origem a dois diferentes métodos radiográficos conhecidos como, direto e indireto [29].

No primeiro são utilizadas as telas conversoras cujas reações nucleares são prontas e a amostra a ser inspecionada, a tela e o filme são irradiados ao mesmo tempo. As telas mais empregadas são aquelas confeccionadas à base de gadolínio natural, no formato de placas metálicas retangulares com espessuras de até $100 \mu \mathrm{m}$, combinadas com filmes convencionais para raios - $\mathrm{X}$. Outro tipo de tela conversora muito empregada são as cintiladoras, de fluoreto de lítio-6 ou de oxisulfeto de gadolínio. Nestes casos os tempos de irradiação podem ser até 100 vezes menores, quando comparados com a anterior. Este tipo de conversor combinado com intensificadores de luz, câmeras de vídeo de alta sensibilidade e, softwares para o processamento de imagens digitais propiciaram, desde a década de 70, o desenvolvimento de equipamentos operacionais para radiografia com nêutrons em tempo - real [10].

Outra possibilidade é a utilização de telas à base de boro ou de lítio combinadas com os detetores de traços nucleares de estado sólido (SSNTD). Muito embora os SSNTD exibam uma imagem com pouco contraste ótico, a elevada resolução obtida na imagem e a sua insensibilidade às radiações dos tipos $\beta$ e $\gamma$, bem como à luz visível, tornam este sistema desejável, por exemplo, para a inspeção de materiais altamente radioativos $[9,19]$.

No segundo método a amostra a ser inspecionada é irradiada juntamente com a tela formando-se nesta, uma imagem radioativa. Em seguida a tela é colocada em contato com um filme (convencional para raios - X) em um ambiente protegido da luz (câmara escura) e, a radioatividade induzida sensibiliza o filme formando (transferindo) a imagem. As telas mais comumente empregadas 
são aquelas confeccionadas à base de disprósio, no formato de placas metálicas retangulares com espessuras de aproximadamente $100 \mu \mathrm{m}$. A principal vantagem deste método é a sua insensibilidade para as outras radiações, o que possibilita o seu uso em feixes de nêutrons com elevada contaminação de radiações $\beta, \gamma$, ou $X$ ou então radiografar materiais altamente radioativos. Para este método, o mais recomendável é o uso de telas com meia - vida curta, permitindo tempos de exposição e de transferência em torno de poucas horas. Uma das mais utilizadas é a de disprósio que possui meia - vida de 2,3 horas.

Um último tipo de tela conversora que vale a pena ser mencionado é a "imaging plate" - IP. Estas telas possuem algumas vantagens inerentes quando comparadas aos outros métodos de formação da imagem [1,2,39,40]:

- Maior linearidade de resposta;

- Alta resolução;

- Grande área para registro da imagem;

- Não é necessário o uso de filme radiográfico, pois a imagem é formada na própria IP.

As IP são confeccionadas por uma fina camada de um material que consiste de uma mistura de um fósforo armazenador, um conversor de nêutrons e, um aglutinante orgânico, cobertos por um filme polimérico. O princípio operacional para formar a imagem radiográfica é baseado na seqüência dos seguintes processos:

- Exposição ao feixe de nêutrons;

- Absorção de nêutrons;

- Conversão de nêutrons em radiação secundária;

- Geração de pares elétron-lacuna no fósforo armazenador;

- Detecção de luz gerada em um processo de foto - luminescência estimulada a laser;

- Leitura da informação armazenada.

Durante a exposição, os nêutrons são absorvidos pelo conversor e são transformados em uma radiação ionizante secundária. Esta por sua vez é absorvida pelo fósforo armazenador e gera pares elétron - lacuna. Um feixe laser focalizado realiza uma varredura ponto a ponto na IP estimulando a foto luminescência de modo que os elétrons armazenados durante a exposição são liberados e recombinam - se com as lacunas emitindo luz. Durante a varredura a 
intensidade da luz de cada ponto da IP é armazenada em um computador de modo a se recuperar a informação da imagem original armazenada.

A luz gerada é capturada por uma válvula fotomultiplicadora a qual dá origem a uma corrente elétrica suficientemente elevada para ser facilmente detectada e processada pelo sistema de aquisição de dados.

Dentre os materiais conversores, os mais utilizados são aqueles a base de Li, B e Gd. Estes devem ser transparentes e disponíveis na forma de pó com tamanho de grãos da ordem de alguns micra. Dentre os fósforos armazenadores destaca-se o BaFBr:Eu.

Para finalizar é importante mencionar que tipicamente um equipamento para radiografia com nêutrons possui as seguintes características [25]:

a) Fluxo de nêutrons na amostra em torno de $10^{6} \mathrm{n} / \mathrm{s} . \mathrm{cm}^{2}$;

b) Energia cinética do feixe de nêutrons na região térmica;

c) Razão de colimação entre $100<$ L/D < 500;

d) Razão $\mathrm{n} / \gamma>5 \times 10^{5} \mathrm{n} / \mathrm{cm}^{2}$.mrem;

e) Variação máxima do sinal no sistema de registro da imagem $5 \%$ em toda a região do feixe de nêutrons.

\subsection{Elétrons e a matéria [5, 41]}

Elétrons interagem com a matéria mediante a ação de campos Coulombianos. Nestes processos podem perder energia mediante colisões causando excitação e ionização dos átomos do meio ou, se passarem próximo ao núcleo do átomo poderão ser desacelerados abruptamente e parte de sua energia cinética ser convertida em radiação, neste caso, raios - $\mathrm{X}$ num processo conhecido como bremmstrahlung. O tipo de interação predominante dependerá de sua energia, bem como da composição do meio que estão atravessando. Pelo fato de possuírem uma massa igual a dos elétrons orbitais com os quais interagem, a trajetória dos elétrons é tipicamente muito tortuosa.

A perda de energia dos elétrons por unidade de comprimento, no meio absorvedor, é chamada de poder de freamento ou stopping power (S), e é expressa por:

$\mathrm{S}=(\mathrm{dE} / \mathrm{dx})=(\mathrm{dE} / \mathrm{dx})_{\mathrm{col}}+(\mathrm{dE} / \mathrm{dx})_{\mathrm{rad}}$ 
onde:

$(\mathrm{dE} / \mathrm{dx})_{\mathrm{col}}=\left(2 \pi \mathrm{e}^{4} \mathrm{NZ} / \mathrm{m}_{0} \mathrm{v}^{2}\right) \mathrm{B}$

$B=\ln \left[m_{0} v^{2} E / 2 l^{2}\left(1-\beta^{2}\right)\right]-(\ln 2)\left(2 \sqrt{ } 1-\beta^{2}-1+\beta^{2}\right)+\left(1-\beta^{2}\right)+1 / 8\left(1-\sqrt{ } 1-\beta^{2}\right)^{2}, \beta=v / c$

e

$(d E / d x)_{r a d}=\left[N E Z(Z+1) e^{4} / 137 m_{0}^{2} c^{4}\right]\left[4 \ln \left(2 E / m_{0} c^{2}\right)-4 / 3\right)$

sendo:

- v = velocidade da partícula;

- Ze = carga da partícula;

- $\mathrm{N}$ = densidade atômica;

- $\mathrm{Z}$ = número atômico do meio;

- $\mathrm{m}_{0}=$ massa de repouso do elétron;

- e = carga eletrônica;

- I = potencial médio de excitação e ionização do absorvedor;

- $\mathrm{E}=$ energia cinética do elétron em MeV.

A razão entre as perdas de energia por colisão e por radiação é dada por:

$(\mathrm{dE} / \mathrm{dx})_{\mathrm{rad}} /(\mathrm{dE} / \mathrm{dx})_{\mathrm{col}}=\mathrm{EZ} / 700$

\subsubsection{Absorção de elétrons monoenergéticos}

O conceito de alcance para partículas leves é complexo, pois como a trajetória é tortuosa o caminho total percorrido é consideravelmente maior do que a distância percorrida em linha reta no meio absorvedor. Experimentalmente o alcance $\left(R_{e}\right)$ dos elétrons pode ser determinado a partir de curvas de transmissão - I em função da espessura $-x$ do meio absorvedor, extrapolando a parte linear desta curva até que intercepte o eixo da espessura, como mostrado na FIG. 1.4. 


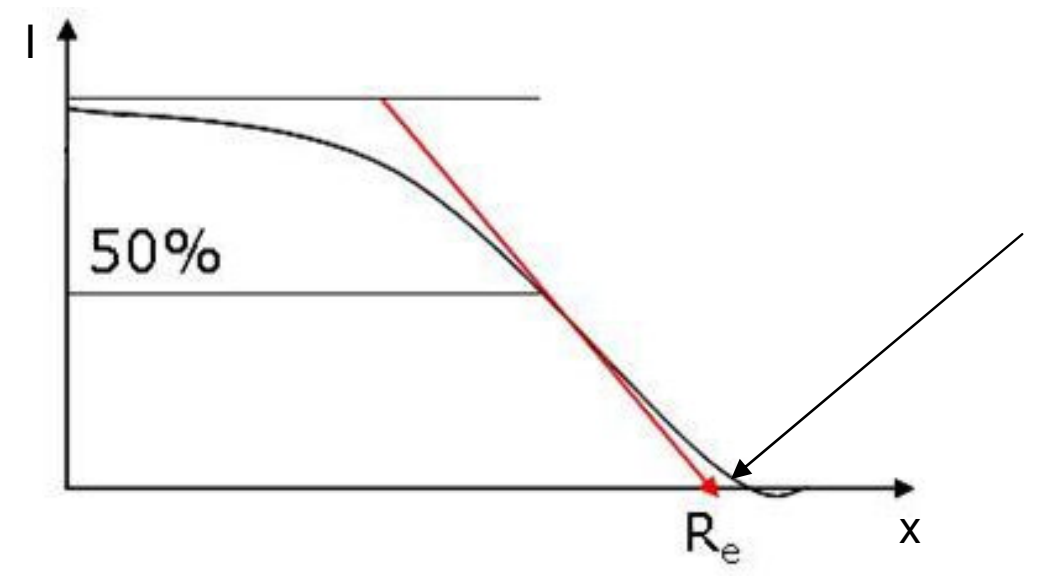

Alcance

FIGURA 1.4 - Curva típica de transmissão para elétrons monoenergéticos, onde $R_{e}$ é o alcance extrapolado.

O alcance também pode ser determinado teoricamente através da expressão (1.9) e por razões práticas este método é o mais utilizado e os dados para o cálculo estão disponíveis, por exemplo, no site do National Institute of Standards and Technology (NIST) [42].

\subsubsection{Absorção de partículas beta - $\beta$}

No caso de partículas - $\beta$ emitidas pelos radioisótopos, as curvas de transmissão diferem significativamente das curvas para elétrons monoenergéticos, uma vez que seu espectro de emissão exibe uma distribuição contínua de energia entre 0 e $E_{\text {máx }}$, característico de cada radioisótopo. Nestes casos o formato da curva se aproxima ao de uma função exponencial dada por:

$I=I_{0}^{*} e^{-\mu \cdot x}$

sendo:

$\mathrm{I}_{0}=$ intensidade incidente no meio absorvedor;

I = intensidade transmitida;

$\mathrm{X}=$ espessura do absorvedor;

$\mu=$ coeficiente de absorção do meio absorvedor. 


\subsubsection{A técnica da radiografia com elétrons [1-5]}

A técnica da radiografia com elétrons é especialmente dedicada a inspeções de amostras finas com espessura da ordem de micra. Dentre as principais aplicações destacam-se inspeções de marcas d' água e texturas em documentos, impressões digitais, amostras biológicas, botânica, etc. Existem basicamente 3 métodos para obtenção de uma radiografia com elétrons:

\subsubsection{Transmissão}

Neste método a amostra a ser inspecionada é colocada entre uma fina folha de chumbo e um filme convencional de emulsão para raios - X. Este conjunto é mantido em firme contato no interior de um cassete o qual é irradiado com raios - X gerados em tubos de 200 a $250 \mathrm{kV}$. Os raios - $\mathrm{X}$ incidindo na folha de chumbo liberam elétrons os quais atuarão como a radiação penetrante e o padrão de intensidade transmitido pela amostra em estudo é registrado no filme formando a imagem. É possível também utilizar como fonte de radiação penetrante uma fina camada de algum radioisótopo emissor - $\beta$ como, por exemplo, o carbono - 14 , fósforo - 32 , enxofre -35 , depositada em uma lâmina de alumínio.

\subsubsection{Emissão superficial}

Neste método um feixe de raios - $X$ atravessa o filme radiográfico convencional para raios - $\mathrm{X}$ o qual está em firme contato com a superfície metálica de uma amostra a ser inspecionada. $O$ raio - $X$ incidindo no metal faz com que sejam emitidos elétrons bem como raios - $X$ característicos deste metal. Como a resposta do filme aos elétrons é muito superior à dos raios - $\mathrm{X}$ incidentes, estes últimos terão um pequeno efeito na formação da imagem.

Se o metal inspecionado for composto por elementos com números atômicos diferentes é possível diferenciá-los, pois a emissão de elétrons difere de elemento para elemento, tanto em quantidade quanto em alcance.

\subsubsection{Auto - radiografia}

Este método se diferencia dos outros mencionados acima, pois a fonte de radiação penetrante é a própria amostra a ser inspecionada. Neste caso uma substância radioativa é inserida na amostra em estudo e esta é mantida em firme 
contato com o filme (convencional para raios - X) formando a imagem. A sua utilização teve grande impulso devido à crescente quantidade de radioisótopos artificiais (vide item 1.3.3.1) disponíveis. Em particular, a auto - radiografia é uma ferramenta muito importante para a biologia no estudo de células.

Algumas desvantagens deste método são que a amostra em estudo será contaminada, exigindo cuidados especiais de radioproteção e, dependendo da meia-vida do radioisótopo a amostra não poderá ser reutilizada, tornando - se uma técnica de ensaio destrutiva. Além disso, o tempo de exposição para se obter imagens com qualidade é muito longo, chegando a horas, semanas ou meses, tornando - a inadequada para algumas aplicações.

\subsection{Filmes e formação da imagem [5,19]}

O termo filme convencional utilizado neste trabalho refere-se aqueles utilizados em radiografia com raios - $X$ que consistem de uma emulsão, sensível a radiação, depositada em um ou em ambos os lados de uma base plástica transparente e flexível (FIG. 1.5).

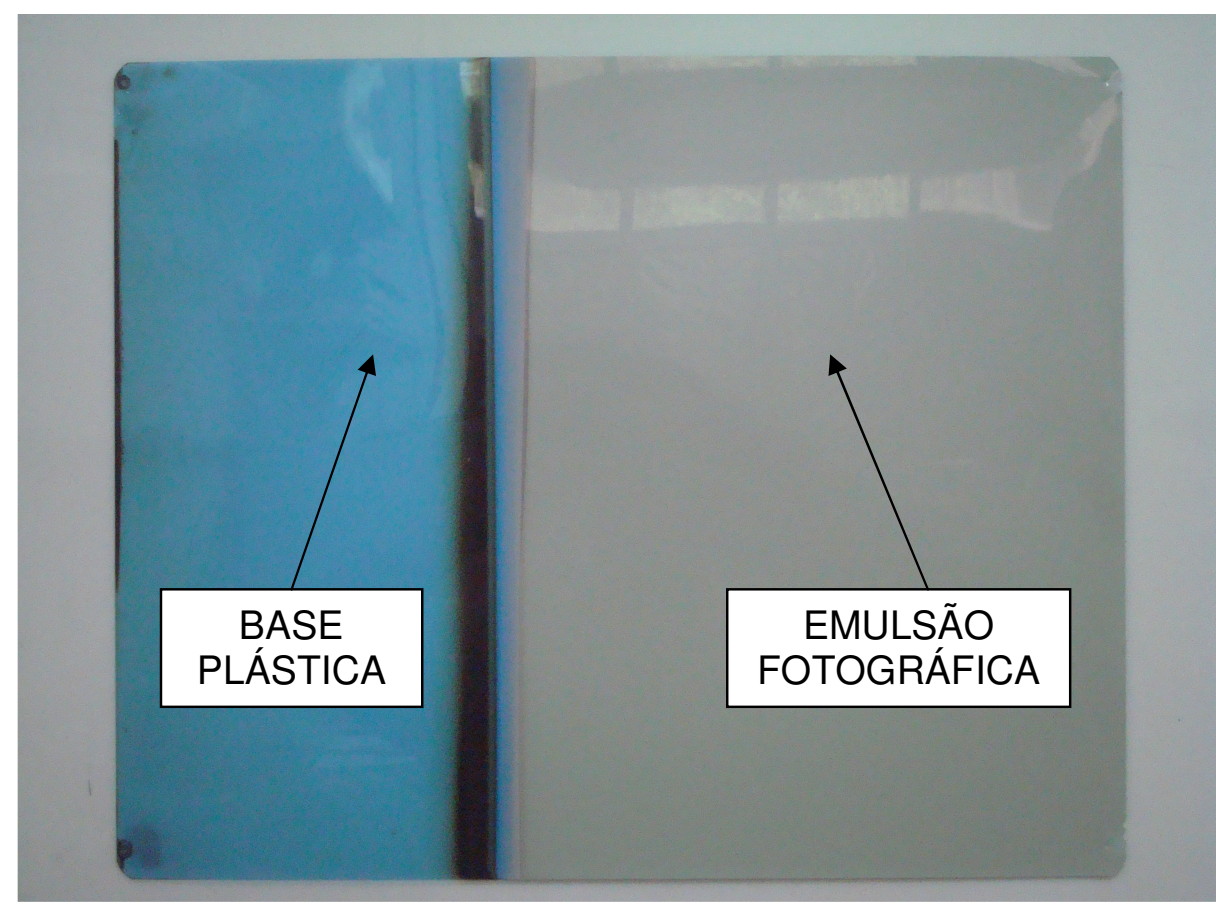

FIGURA 1.5 - Filme radiográfico convencional: lado esquerdo - a emulsão foi removida para mostrar a base plástica; lado direito - mostra a emulsão depositada. 
Tipicamente a emulsão possui espessura entre 10 e $20 \mu \mathrm{m}$ e a base plástica entre 150 e $200 \mu \mathrm{m}$. A emulsão é composta por uma gelatina e cristais de brometo de prata. A gelatina tem a função de manter os cristais dispersos e, proteger os não sensibilizados do ataque do revelador. Os cristais têm a função de fornecer partículas de prata metálica para constituírem a imagem visível. A base plástica é confeccionada em acetato de celulose ou em poliéster.

A sensibilização, que acontece quando o filme é exposto à radiação, causa uma mudança na estrutura física dos cristais (imagem latente) a qual não pode ser detectada por métodos físicos ordinários. Contudo quando este filme é atacado por um conjunto de soluções químicas adequadas, ocorrerão reações que tornarão possível a formação de uma imagem visível, a qual é uma combinação de pontos enegrecidos (cristais atingidos pela radiação) e pontos transparentes (cristais não atingidos). Tradicionalmente o grau de enegrecimento é quantificado pela grandeza denominada densidade ótica, já definida na Introdução:

Dop $=\log \left(I_{0} / l\right)$

onde $I_{0}$ e I são as intensidades de luz incidente e transmitida pelo filme respectivamente.

\subsubsection{Imagem latente}

A imagem latente é definida como uma mudança na estrutura física nos cristais de brometo de prata, capaz de iniciar a sua revelação. Estes tem dimensões de $\sim 1 \mu \mathrm{m}$ e contém moléculas de brometo de prata, com íons de bromo ( $\mathrm{Br}-)$ e de prata $(\mathrm{Ag}+)$ dispostos alternadamente formando uma estrutura cristalina. Os cristais não são perfeitos, pois em seu interior existem alguns íons de prata em posições intersticiais os quais, por estarem fora de suas posições naturais, podem migrar pelo cristal. Além disto, em alguns espaços entre estes íons encontram-se partículas isoladas de sulfeto de prata, inseridas na fabricação do filme, que causam defeitos superficiais nos cristais. Ambas as imperfeições auxiliam o processo de formação da imagem latente. 
Quando a radiação ionizante atinge uma molécula de brometo de prata, pode ocorrer a liberação de um ou mais elétrons, que se movem através do cristal. Estes elétrons podem ser atraídos para uma destas imperfeições, dando ao seu captor uma carga negativa. O captor com esta carga pode atrair os íons de prata intersticiais, convertendo-os em prata metálica. Se este processo é repetido um número de vezes, ter-se-á imagens latentes, que possibilitarão a revelação do filme. Devido à existência de várias imperfeições em um cristal de brometo de prata, poderá haver nele mais de uma imagem latente estável a qual é composta, no mínimo, por 5 átomos de prata metálica.

A maior dessemelhança entre a formação das imagens latentes de uma radiografia e de uma fotografia surge das diferenças de energias envolvidas. No caso de uma fotografia a absorção de um único foton de luz visível transfere uma quantidade muito pequena de energia (da ordem de $\sim \mathrm{eV}$ ) ao cristal, suficiente para liberar um único elétron. Vários fótons sucessivos são necessários para tornar um cristal revelável, isto é para produzir uma imagem latente estável. $\mathrm{Na}$ radiografia a passagem de um único elétron pode transferir centenas de vezes mais energia. Mesmo que esta energia seja utilizada ineficientemente, a quantidade é suficiente para torná-lo revelável. De fato, um elétron pode ter um longo caminho na emulsão de modo a deixar, neste caminho, muitos cristais reveláveis.

\subsubsection{Imagem visível}

A imagem latente torna - se visível através de um processo químico, que envolve basicamente a ação seqüencial de três soluções:

\subsubsection{Revelador}

Em geral, as soluções reveladoras são comercializadas para serem diluídas em água e tem uma fórmula que garante uma solução final uniforme. Em geral, os reveladores são à base de fenidona e hidroquinona.

Quando um filme exposto à radiação é imerso no revelador, a solução penetra na emulsão e transforma os cristais de brometo de prata com imagens latentes, inteiramente em prata metálica. Um cristal revelado contém aproximadamente $10^{9}$ vezes mais prata metálica do que outro com apenas imagem latente. 
A rapidez do processo de revelação é afetada pela temperatura da solução. Assim, quando a temperatura é baixa, a reação é lenta e o tempo de revelação deve ser revisto para que não ocorra uma sub - revelação. O mesmo deve ser observado quando a temperatura é alta. Os fabricantes fornecem cartas que permitem a determinação do tempo de revelação em função da temperatura da solução numa faixa entre 16 e $25^{\circ} \mathrm{C}$.

Outro cuidado essencial durante a revelação é a agitação da solução durante todo o processo, para minimizar variações da uniformidade no enegrecimento do filme.

\subsubsection{Banho de parada}

Após o término da etapa anterior, o revelador remanescente no filme precisa ter a sua ação interrompida, o que normalmente é conseguido imergindoo em uma solução ácida ou, quando isto não é possível enxaguando-o em água corrente e limpa durante alguns minutos. Se este banho de parada é omitido, a revelação continua durante os instantes seguintes provocando não uniformidade no enegrecimento, o que prejudica a análise da imagem radiográfica. Por isso, a remoção do revelador tanto quanto possível, antes da fixação, além de prolongar a vida da solução fixadora, assegura a produção de radiografias de melhor qualidade.

O banho de parada consiste normalmente de uma solução de ácido acético glacial diluído na proporção de $35 \mathrm{ml}$ por litro de água, conforme prática dos laboratórios de revelação.

Em geral, após retirados do revelador, os filmes escorrem por alguns segundos antes de serem imersos no banho de parada, onde permanecem entre 30 e 60 segundos, com moderada agitação, para temperaturas entre 18 e $21^{\circ} \mathrm{C}$ para então serem transferidos ao fixador.

\subsubsection{Fixador}

O processo de fixação compreende duas etapas:

1. Dissolução dos cristais de brometo de prata não revelados e sua difusão para fora da emulsão; 
2. Endurecimento da gelatina.

Os fixadores são em geral à base de tiosulfato de amônia e cloreto de alumínio, que atuam nas etapas 1 e 2 respectivamente. Em uma solução fixadora, o tempo de fixação não excede, em geral 15 minutos, pois um tempo maior poderá ocasionar a remoção de cristais revelados da emulsão diminuindo o efeito de enegrecimento.

Ao longo de seu uso a solução acumula sais de prata dissolvidos, o que gradualmente inibe a sua capacidade de dissolver os cristais não expostos da emulsão. Além disto, a solução torna-se diluída pela água de enxáguo ou pelo banho de parada remanescentes no filme. O resultado é a diminuição da taxa de fixação ou incapacitação da solução em endurecer a gelatina.

\subsection{Imagem digital [25,43]}

Imagens registradas em filmes radiográficos são imagens analógicas. Estas por sua vez podem ser digitalizadas, ou seja, transformadas em uma matriz na qual cada um de seus elementos representa um ponto da imagem analógica original. Estes elementos são denominados "pixels" (picture element) e cada um deles tem sua própria coordenada espacial e seu próprio nível de cinza de modo a reproduzir a posição e o tom de enegrecimento de todos os pontos da imagem analógica original. Em uma imagem digital de 8 bits existem 256 níveis de cinza que podem ser atribuídos aos pixels de forma que o nível 0 é atribuído ao mais escuro e o 255 ao mais claro. Desde que cada pixel é caracterizado por números (dígitos) torna-se possível a manipulação matemática ou o processamento destas imagens. Ou seja, é possível realizar operações matemáticas entre pixels ou entre imagens de modo a modificar diversas caraterísticas da imagem original, tais como alterar seu brilho e contraste, minimizar ruído, realçar bordas, etc.

\subsection{Caracterização de técnicas radiográficas $[21,22]$}

A caracterização de uma técnica radiográfica consiste basicamente em determinar a exposição ou o tempo de irradiação, para se obter o melhor contraste no filme, a sua sensibilidade ou capacidade para discernir variações de espessuras e, a sua resolução espacial. Fundamentalmente esta avaliação é realizada através da análise da intensidade da luz transmitida pelas regiões enegrecidas do filme a qual no presente trabalho foi realizada mediante 0 
emprego de um sistema digital. Neste caso a intensidade da luz é avaliada em uma escala de níveis de cinza.

\subsubsection{Determinação do intervalo de exposição para se obter o melhor contraste}

Esta determinação é feita através de uma curva que relaciona nível de cinza - NC em função da exposição - E. A exposição é definida como:

$E=\phi * t$

sendo " $\phi$ " o fluxo do feixe de radiação e "t" o tempo de irradiação.

Por meio desta curva determina-se o intervalo de exposição ótimo para a obtenção de uma radiografia, ou seja, para o qual o contraste ótico definido por $\mathrm{G}=\Delta(\mathrm{NC}) / \Delta(\mathrm{E})$, é máximo.

\subsubsection{Sensibilidade $[21,36]$}

A sensibilidade de uma técnica radiográfica é geralmente definida como a sua capacidade para discernir variações de espessuras dos materiais em inspeção. Normalmente ela é avaliada partindo da relação:

$\mathrm{NC}=\mathrm{G} \times \mathrm{E}$

Considerando que a transmissão do feixe de radiação penetrante pela matéria seja governada pela função (1.16), o comportamento da exposição em função da espessura da amostra será dado por (1.17):

$\phi(x)=\phi_{0^{*}} f(x, \mu)$
$E(x)=E_{0^{*}} f(x, \mu)$

onde $\phi_{0}$ e $\phi(x)$ são os fluxos incidente e transmitido do feixe pela amostra de espessura " $x$ " e coeficiente de atenuação $\mu$.

Combinando (1.15) e (1.16) com (1.17): 
$N C(x)=G * E_{0 *} f(x, \mu)$

A sensibilidade ou a espessura mínima discernível é obtida mediante a diferenciação da equação (1.18) e vem dada por:

$\Delta x=-\Delta N C /\left[G * E_{0^{*}} f^{\prime}(x, \mu) *(x, \mu)^{\prime}\right]$

No caso em que a transmissão da radiação pela matéria obedeça a uma lei exponencial (1.20), o comportamento da exposição em função da espessura da amostra é dado por (1.21):

$\phi(x)=\phi_{0^{*}} \exp (-\mu . x)$

$E(x)=E_{0^{*}} \exp (-\mu . x)$

Assim a expressão (1.18) pode ser dada por:

$N C(x)=G * E_{0} * \exp (-\mu . x)$

A sensibilidade vem dada por:

$\Delta \mathrm{x}=-\Delta \mathrm{NC} /(\mathrm{NC} * \Sigma)$

sendo $\Delta \mathrm{NC}$ a mínima variação de nível de cinza discernível.

\subsubsection{Resolução}

A resolução na imagem radiográfica é definida como a menor distância distinguível entre dois objetos [44]. Geralmente é determinada mediante a varredura do nível de cinza existente na interface entre duas imagens: a primeira de uma amostra de um material, parcial ou totalmente opaco ao feixe de radiação penetrante e, a segunda do feixe direto. Idealmente, esta distribuição possui a forma de uma função "delta". Entretanto o efeito do alcance limitado das radiações no próprio conversor e no filme, bem como a espessura e o tipo da amostra, distorcem esta forma ideal, para uma com o aspecto de um "S" 
estendido. A esta distribuição é ajustada uma ESF (Edge Spread Function), uma função do tipo [44,45]:

$\mathrm{NC}=\mathrm{P}_{1}-\mathrm{P}_{2^{*}} \arctan \left[\mathrm{P}_{3^{*}}\left(\mathrm{X}-\mathrm{P}_{4}\right)\right]$

onde $P_{1}, P_{2}, P_{3}$ e $P_{4}$ são parâmetros livres e "X" é a coordenada de varredura.

A resolução é usualmente determinada em termos do parâmetro denominado "resolução total" - Ut que é a largura à meia altura da diferencial da ESF, denominada LSF (Line Spread Function) que é uma distribuição de Lorentz, e é calculada pela expressão:

$U_{t}=2 / P_{3}$

A "resolução total" resulta do efeito combinado da "resolução intrínseca" - $U_{i}$ e da "resolução geométrica" - $U_{g}$ e estão relacionadas pela equação $[36,44]$ :

$\left(U_{t}\right)^{n}=\left(U_{i}\right)^{n}+\left(U_{g}\right)^{n} \operatorname{com} 1<n<3$

A magnitude das distorções na imagem causada pela "resolução intrínseca" depende do tipo da radiação gerada, do seu alcance na tela conversora e no filme empregado, bem como de suas espessuras, enquanto que a "resolução geométrica" está relacionada à penumbra na imagem e que depende da distância "amostra - filme", bem como das características do colimador utilizado. Quanto maior a distância e o diâmetro de entrada do feixe no colimador, maiores serão as distorções (penumbra) na imagem radiográfica [8].

\subsection{Considerações gerais a respeito da técnica da radiografia induzida}

Neste ponto do trabalho é importante reunir as idéias que deram origem à técnica da radiografia com elétrons induzida por nêutrons (NIER) e descrever as etapas e os processos envolvidos na obtenção de uma imagem. Passo a passo eles podem ser descritos da seguinte maneira. Um feixe de nêutrons térmicos oriundo de um equipamento para radiografia com nêutrons induz reações nucleares do tipo $(n, \gamma)$ em uma tela conversora a base de gadolínio 
gerando o feixe de radiação penetrante. A intensidade deste feixe que é transmitida pela amostra em estudo incide em um filme o qual após ser revelado forma uma imagem bidimensional da estrutura interna da amostra. Esta imagem é analisada em um sistema digital que dentre outras características, propicia uma melhora significativa na sua qualidade final. Os detalhes experimentais para a obtenção e análise desta imagem serão abordados no capítulo 2. 


\section{CAPÍTULO - 2 PARTE EXPERIMENTAL}

\subsection{Tela conversora e cassete para irradiação}

A tela conversora utilizada foi confeccionada à base de gadolínio natural e, foi adquirida da empresa Aerotest (USA). É composta por uma base de alumínio, com dimensão aproximada de $43 \mathrm{~cm} \times 35 \mathrm{~cm}$ e $2 \mathrm{~mm}$ de espessura, na superfície da qual é depositada uma camada homogênea de gadolínio evaporado com $25 \mu \mathrm{m}$ de espessura. Em seguida esta camada é coberta por uma fina membrana de safira de modo a evitar a sua oxidação. Esta tela é montada no interior de um cassete de alumínio, vedado contra a luz, com paredes de $1 \mathrm{~mm}$ de espessura, como mostrado na FIG. 2.1. Este cassete possui uma válvula por meio da qual pode ser feito vácuo em seu interior.

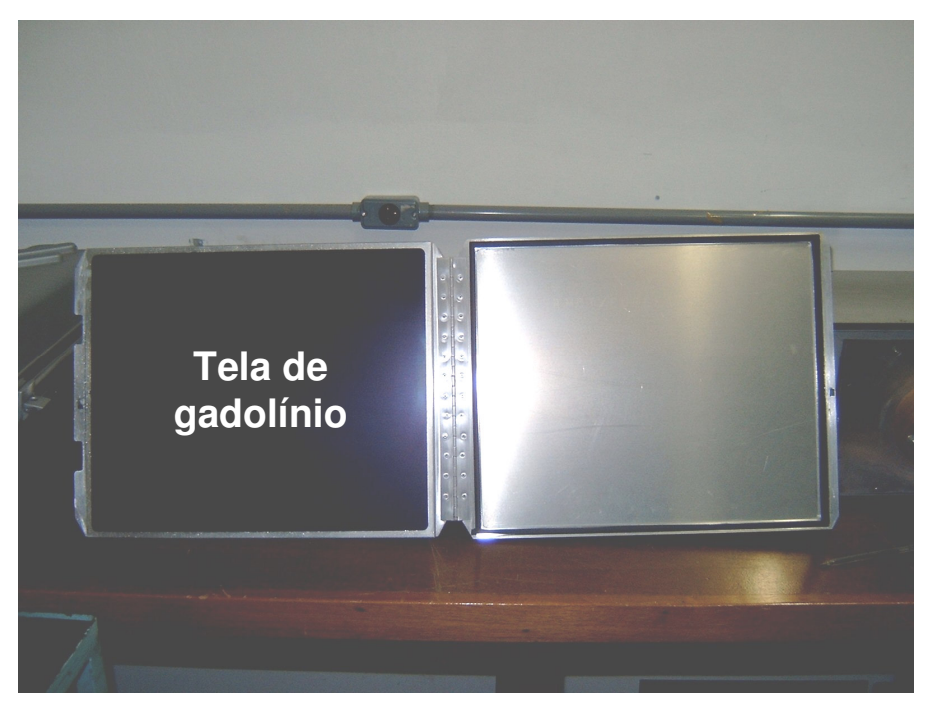

FIGURA 2.1- Cassete de alumínio com tela conversora de gadolínio.

O gadolínio é um elemento químico de número atômico $Z=64$ massa atômica $A=157,26$ e possui sete isótopos naturais $152(0,20 \%), 154(2,2 \%), 155$ (14,9\%), $156(20,6 \%), 157$ (15,7\%), 158 (24,7\%) e 160 (21,7\%). É o elemento químico que possui um dos maiores valores para a seção de choque de absorção de nêutrons térmicos, valendo 46.000 barn. Dentre estes isótopos, os 
de massa 155 e 157 são os que mais contribuem para este valor elevado possuindo 61.000 e 254.000 barn respectivamente $[36,46]$.

Desde que o feixe de nêutrons extraído do arranjo experimental empregado neste trabalho possui energia média de $7 \mathrm{meV}$, a seção de choque efetiva de absorção para o gadolínio natural tem o valor de 80.000 barn o que conduz à uma transmissão de nêutrons de 0,3\% pela tela [38].

Como resultado da interação nêutron - gadolínio ocorrerão reações nucleares do tipo $(n, \gamma)$ cujos principais produtos, são [36, 46]:

- Feixes de elétrons de conversão com 11 energias diferentes, sendo o de 72 $\mathrm{keV}$ o mais intenso, seguido pelo de $150 \mathrm{keV}$ com aproximadamente $10 \%$ da intensidade do primeiro, emitidos pelos isótopos 157 e 155 respectivamente;

- Raios - X de 6 keV;

- Radiação - $\gamma$ de 79 keV.

Destas radiações, os elétrons de $72 \mathrm{keV}$ e de $150 \mathrm{keV}$ são os responsáveis por $\sim 80 \%$ do enegrecimento do filme $[8,17,46,47,48]$. Isto justifica 0 título do presente trabalho de "Radiografia com Elétrons Induzida por Nêutrons".

É muito importante salientar que por causa da distância que as reações nucleares ocorrem da superfície da tela de gadolínio, ao invés de elétrons monoenergéticos ter-se-á um espectro contínuo incidente na amostra, com energias entre 0 e $150 \mathrm{keV}$.

\subsection{Filme radiográfico}

O filme disponível utilizado no presente trabalho para o registro da imagem foi o convencional para radiografia com raios - $X$ denominado Kodak Industrex AA 400 com folhas individuais de dimensões $43 \mathrm{~cm}$ x $35 \mathrm{~cm}$. Este filme, mostrado na FIG. 1.5, possui emulsão dupla, ou seja, depositada em ambos os lados da base plástica, neste caso confeccionada em poliéster. As espessuras da emulsão e da base plástica são de $12,5 \mu \mathrm{m}$ e de $180 \mu \mathrm{m}$ respectivamente de modo que a espessura total do filme é de $205 \mu \mathrm{m}$ [19].

Os valores dos alcances dos elétrons gerados na tela de gadolínio, tanto na emulsão quanto na base plástica estão mostrados na TAB. 2.1. 
TABELA 2.1 - Valores do alcance dos elétrons na emulsão fotográfica e na base plástica [8,42].

\begin{tabular}{ccc}
\hline Elétrons $(\mathrm{keV})$ & emulsão $(\mu \mathrm{m})$ & base plástica $(\mu \mathrm{m})$ \\
\hline 72 & 32 & 57 \\
150 & 113 & 210 \\
\hline
\end{tabular}

Baseado nestes valores pode-se afirmar que a sensibilização do filme e, portanto a imagem radiográfica é quase que totalmente formada em um único lado do filme, ou seja, naquele em que o elétron incide [17].

\subsubsection{Revelação}

Após a irradiação, os filmes foram então revelados de acordo com os procedimentos sugeridos pelo seu fabricante $[8,19]$. As soluções químicas empregadas nesta etapa são depositadas em cubas de aço inoxidável, mostradas na FIG. 2.2. O filme é primeiramente atacado quimicamente no revelador por um intervalo de tempo de aproximadamente 5 minutos, pois a temperatura ambiente é mantida próxima a $25^{\circ} \mathrm{C}$. Em seguida o filme foi imerso no banho de parada durante 30 segundos para então ser atacado pelo fixador por um intervalo de tempo que normalmente é o dobro daquele da revelação, ou seja, 10 minutos. Ao término deste processo o filme é inserido em uma cuba para ser lavado em água corrente por um intervalo de tempo típico de 20 minutos para finalmente ser lavado em um agente químico que diminui a tensão superficial da água e evita a formação de bolhas em sua superfície durante a secagem. Este último processo é realizado em uma estufa por aproximadamente 30 minutos. Neste ponto o filme está pronto para ser analisado. 


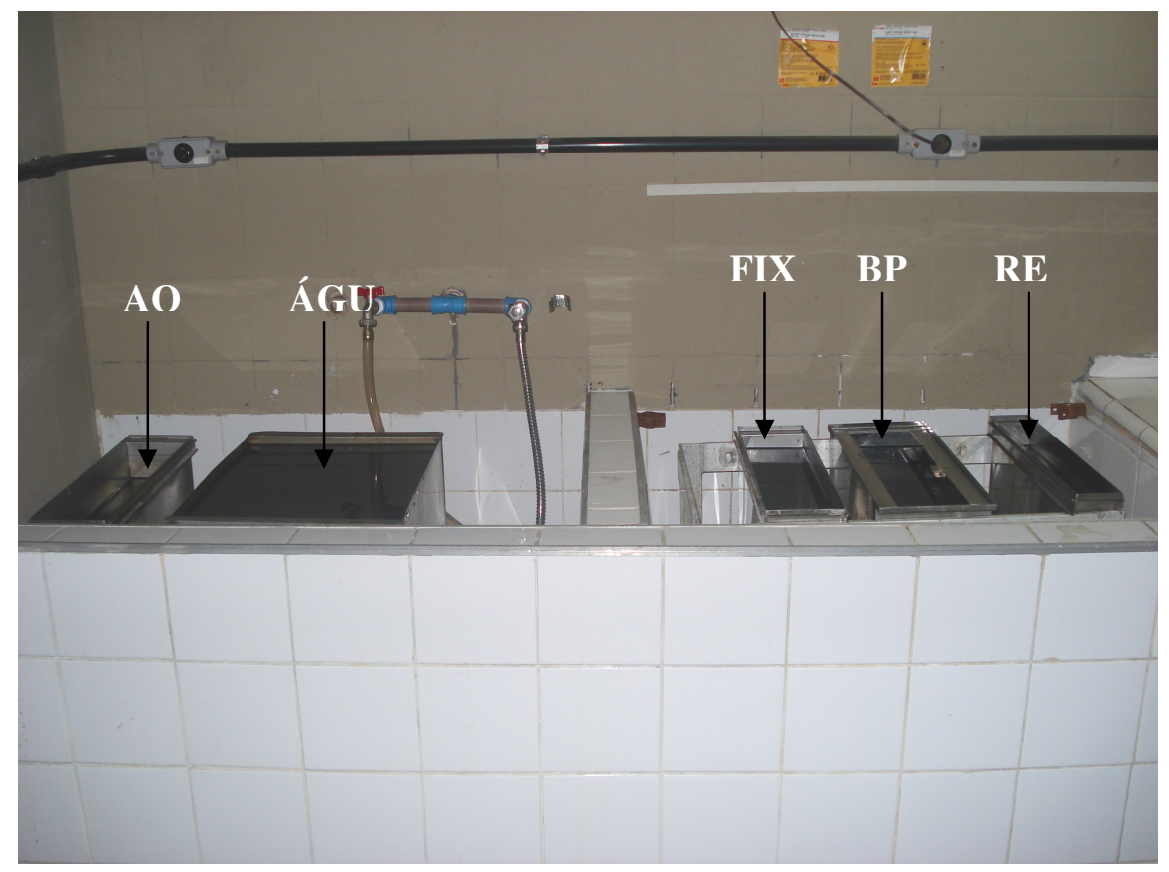

FIGURA 2.2 - Cubas com as soluções utilizadas no processo de revelação. Da direita para a esquerda: revelador (REV), banho de parada (BP), fixador (FIX), água corrente e agente químico $(\mathrm{AQ})$.

\subsection{Equipamento para radiografia com nêutrons}

As irradiações referentes a este trabalho foram realizadas no canal de irradiação 08 do Reator Nuclear de Pesquisas IEA-R1 do IPEN-CNEN/SP, onde existe instalado um equipamento operacional para radiografia com nêutrons esquematizado na FIG. 2.3. Este canal é radial em relação ao seu núcleo, com diâmetro interno de $20 \mathrm{~cm}$. Em seu interior estão inseridos dois tubos de alumínio, soldados entre si, com comprimento total 2,9 m e diâmetro externo $\sim 20 \mathrm{~cm}$ e, que tem por finalidade conter os colimadores, filtros e outros componentes essenciais à extração do feixe de nêutrons.

O feixe, proveniente do núcleo do reator, penetra pela face frontal deste tubo e, em seu caminho atinge:

- Um filtro contra radiação - $\gamma$ confeccionado em bismuto. As suas dimensões foram calculadas de modo a manter a razão nêutron $/ \gamma>10^{5} \mathrm{n} / \mathrm{cm}^{2} \cdot \mathrm{mRem}$ e, neste caso sua espessura deve ser de $25 \mathrm{~cm}$ com diâmetro de $14 \mathrm{~cm}$. Com estas dimensões os filtros conduzem à uma redução de um fator $\sim 6 \times 10^{-6}$ para a intensidade da radiação $-\gamma$ e de $\sim 2 \times 10^{-3}$ para a intensidade dos nêutrons com energia superior a 1,8 meV e de $\sim 0,69$ para energias menores. É 
importante salientar que a eficácia do bismuto para atenuação da radiação - $\gamma$ é similar à do chumbo, pois seus números atômicos são muito próximos. Entretanto a sua seleção deu-se principalmente porque este elemento apresenta uma maior transparência aos nêutrons pois, possui uma seção de choque para absorção de 34 mbarn a qual é 5 vezes menor que a do chumbo, enquanto que as de espalhamento permanecem ambas próximas à 9 barn.

- Colimador cônico divergente composto por uma estrutura de alumínio de alta pureza e preenchido com uma mistura de ácido bórico e parafina derretida. Este colimador possui as seguintes características:

- comprimento: $150 \mathrm{~cm}$;

- diâmetro da abertura frontal: $7,5 \mathrm{~cm}$;

- diâmetro da abertura de saída: 15,5 cm;

- razão de colimação - L/D 70, dada pela razão entre a distância de entrada do feixe ao local de irradiação da amostra. 


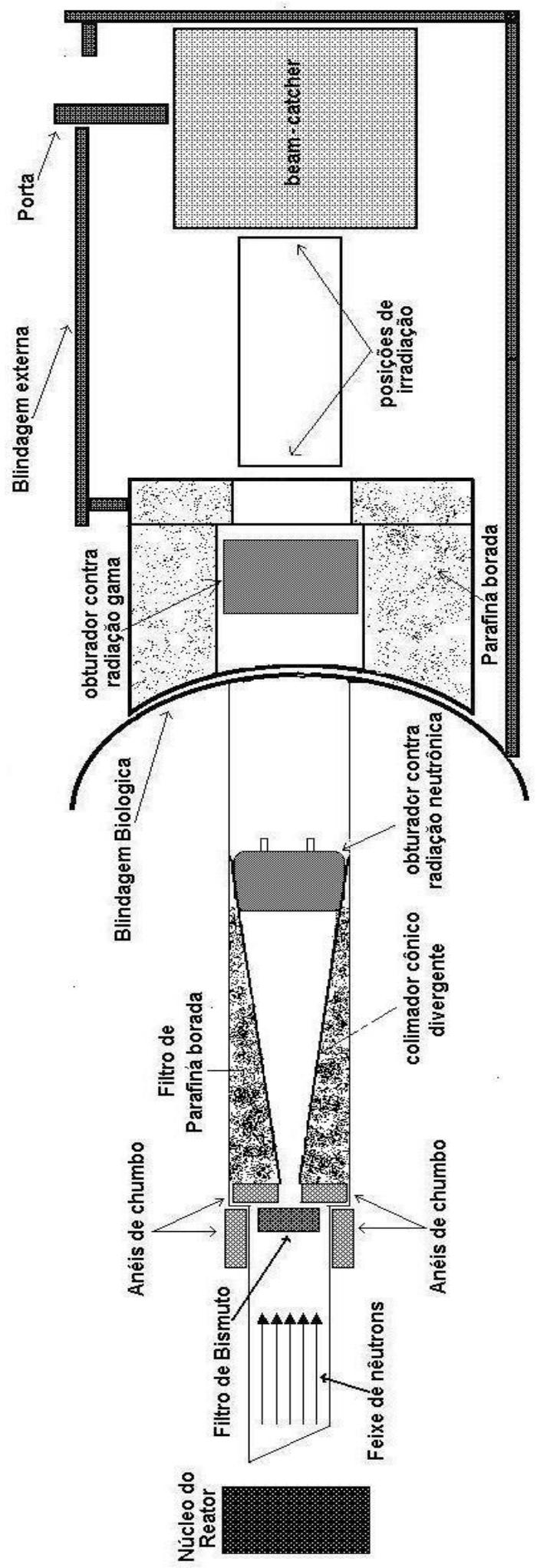

FIGURA 2.3 - Esquema do arranjo experimental. 
Com estas características, este colimador conduz a uma redução de $1,2 \times 10^{-5}$ ao feixe de nêutrons que incide em sua abertura frontal.

Nestas condições a redução total ao fluxo de nêutrons causado pelos filtros e pela colimação será de $2,5 \times 10^{-8}$, resultando um fluxo de $\sim 1,58 \times 10^{6}$ $\mathrm{n} / \mathrm{s} . \mathrm{cm}^{2}$ no local de irradiação com uma dose - $\gamma$ e de nêutrons de $\sim 2$ Rem/h e $\sim 7$ Rem/h respectivamente.

- Anel de chumbo revestido com cádmio com diâmetro externo de $20 \mathrm{~cm}$ e interno de $\sim 14 \mathrm{~cm}$ e comprimento $25 \mathrm{~cm}$ no interior do qual o filtro de bismuto é inserido para minimizar o "efeito coroa" das radiações - $\gamma$ e nêutrons.

- Obturadores de feixe. Com o intuito de aumentar a segurança do equipamento em termos de proteção radiológica, foram instalados dois obturadores, um contra radiação neutrônica, e outro contra radiação - $\gamma$. O primeiro se encontra no interior da blindagem biológica do reator, e posicionado junto ao colimador de nêutrons. Confeccionado em alumínio, é acionado por um sistema de ar comprimido, o qual é totalmente preenchido com água deionizada quando o feixe não esta sendo utilizado e esvaziado quando se quer dar início a irradiação. O segundo é uma estrutura composta de chumbo, gadolínio, cádmio com dimensões de $40 \mathrm{~cm}$ x $40 \mathrm{~cm}$ e $20 \mathrm{~cm}$ de espessura na direção do feixe, posicionado junto a blindagem biológica do reator. Este obturador se movimenta na direção vertical por meio de uma talha elétrica e intercepta perpendicularmente o feixe de nêutrons quando este não esta sendo utilizado.

Estes dois dispositivos permitem que as doses de radiação permaneçam a níveis seguros tanto na parte interna quanto externa da blindagem. As FIG. 2.4 e 2.5 mostram o interior da blindagem com as posições de irradiação e o seu exterior respectivamente.

Faz parte deste equipamento uma blindagem externa, composta basicamente por parafina, ácido bórico, cádmio, chumbo e concreto de barita, que é posicionada junto à blindagem biológica do reator. Possui duas paredes de chumbo de dimensões $2,0 \mathrm{~m} \times 1,0 \mathrm{~m}$ e espessura $0,1 \mathrm{~m}$, e duas outras independentes, uma de concreto de barita e outra de parafina borada que dão continuidade às de chumbo com dimensões $2,0 \mathrm{~m} \times 3,5 \mathrm{~m}$ e espessura de $0,3 \mathrm{~m}$ cada uma. 


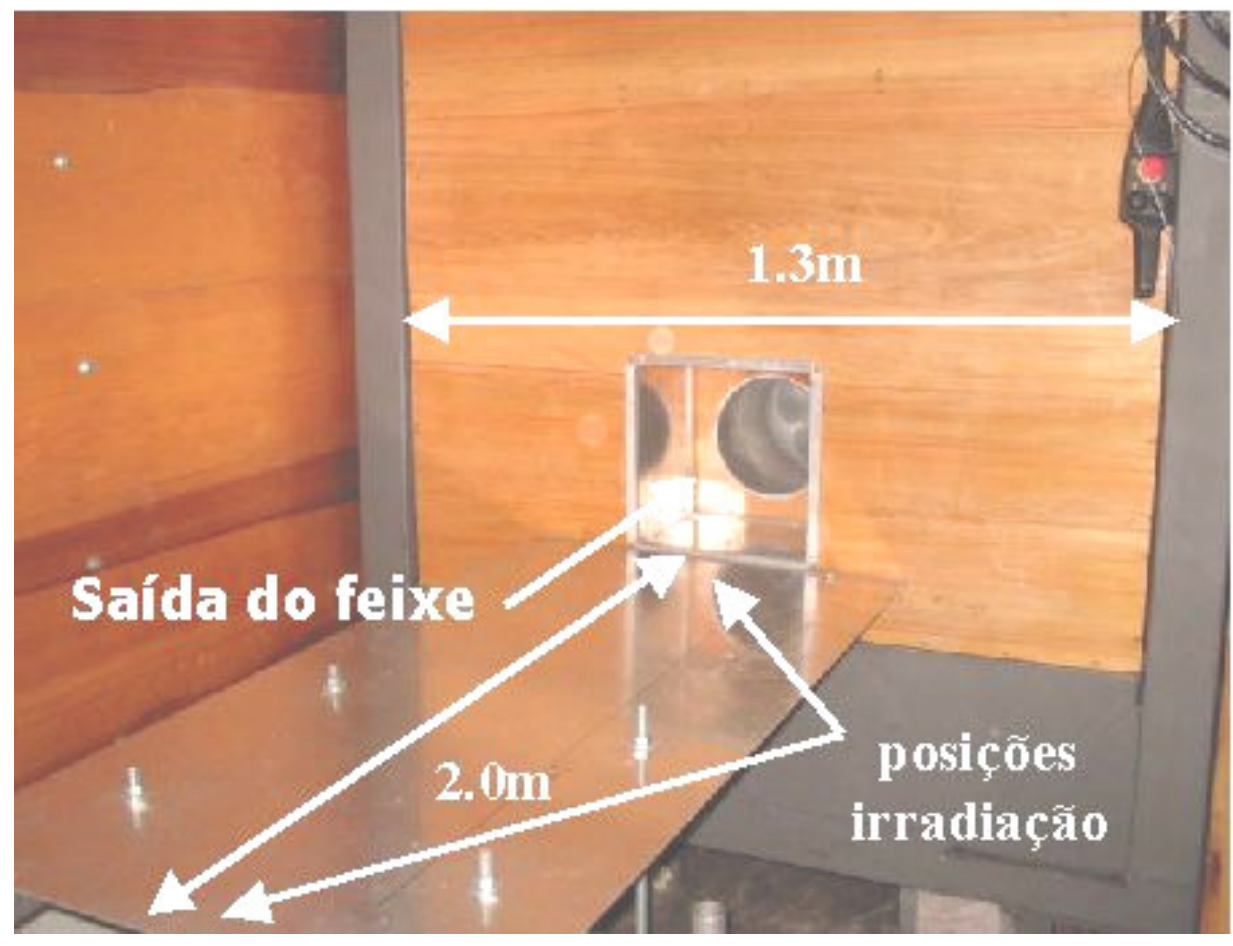

FIGURA 2.4 - Interior da blindagem do arranjo experimental de radiografia com nêutrons.

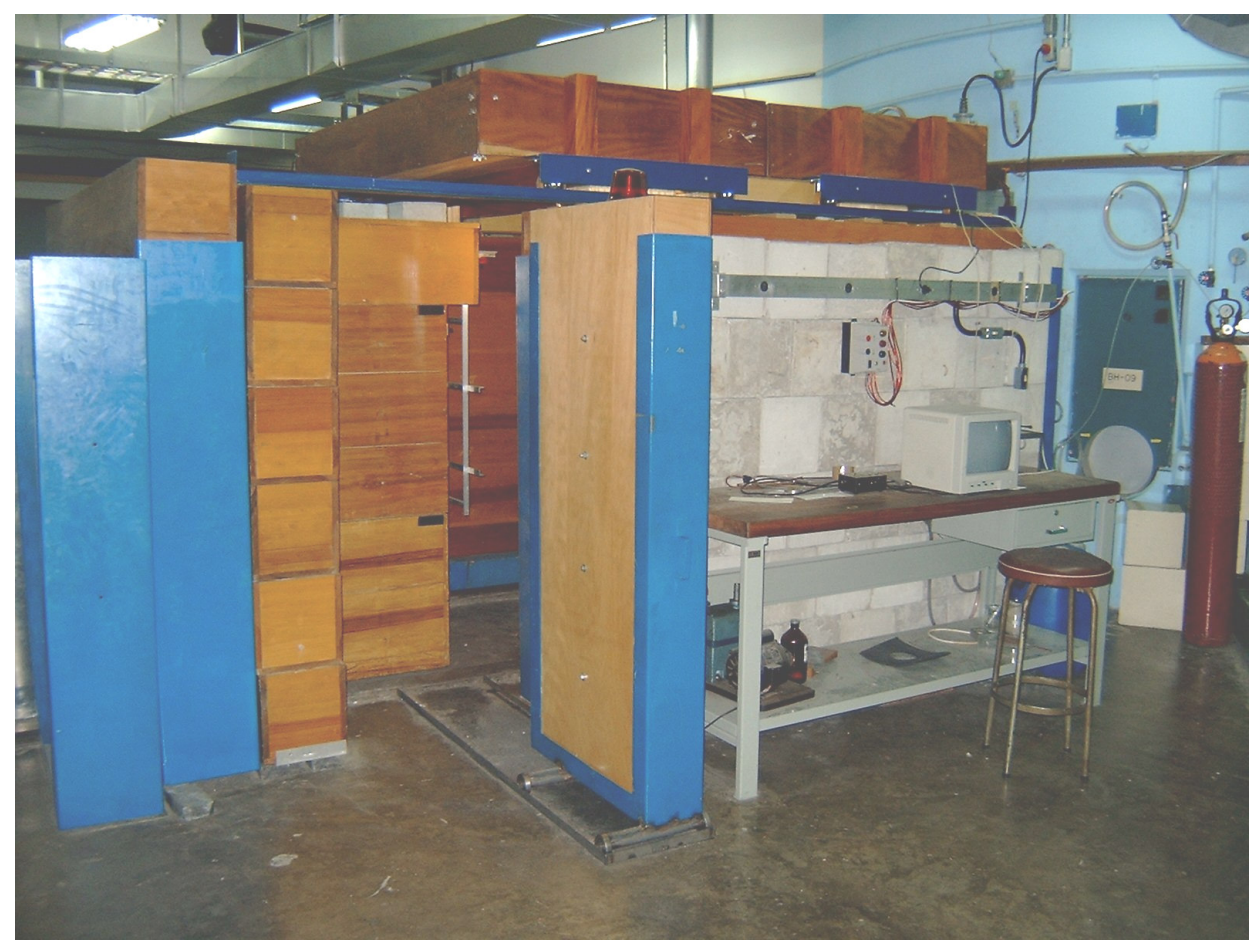

FIGURA 2.5 - Visão externa do arranjo experimental de radiografia com nêutrons. 
Por fim possui também um beam-catcher com aproximadamente 4.000 $\mathrm{kg}$ que pode se mover horizontalmente, sobre rodízios e trilhos, até $2 \mathrm{~m}$ ao longo do feixe de nêutrons permitindo várias posições de irradiação, um fácil manuseio de amostras e, uma contribuição desprezível dos nêutrons e da radiação - $\gamma$ espalhadas pela própria blindagem, na formação da imagem radiográfica [16]. As características do feixe de nêutrons na posição onde o fluxo de nêutrons é máximo estão apresentadas na TAB. 2.2 [8].

TABELA 2.2 - Características do feixe de nêutrons extraído do arranjo experimental.

\begin{tabular}{cc}
\hline Fluxo no local de irradiação & $1,58 \times 10^{6} \mathrm{n} / \mathrm{cm}^{2} . \mathrm{s}$ \\
Razão fluxo térmico/epitérmico & 5,7 \\
Razão de cádmio & 150 \\
Razão n/ & $8 \times 10^{5} \mathrm{n} / \mathrm{cm}^{2} . \mathrm{mrem}$ \\
Razão de colimação & 70 \\
Homogeneidade* & $\sim 5 \%$ \\
Dimensões do feixe & Diâmetro útil de $20 \mathrm{~cm}$ \\
Energia média & $7 \mathrm{meV}$ \\
${ }^{*}$ variações da densidade ótica ao longo do diâmetro útil do feixe. &
\end{tabular}

\subsection{Obtenção de radiografia com elétrons induzida por nêutrons}

A FIG. 2.6 mostra o diagrama esquemático de como obter uma radiografia com elétrons induzida por nêutrons. É empregando um cassete, no interior do qual o filme, a amostra a ser inspecionada e a tela conversora e, nesta ordem com relação ao feixe de nêutrons, são mantidas em firme contato durante a irradiação. O feixe de nêutrons passa através do filme, passa através da amostra e atinge a tela onde geram, por meio de reações nucleares do tipo $(n, \gamma)$, elétrons de conversão interna. Os elétrons são atenuados pela amostra e a intensidade modulada transmitida sensibiliza o filme formando a imagem. Dentre os elétrons emitidos, os de $72 \mathrm{keV}$ e os de $150 \mathrm{keV}$ são os principais responsáveis pela formação da imagem radiográfica. No presente trabalho as imagens formadas nos filmes são digitalizadas e processadas mediante um software específico. A FIG. 2.7 é a fotografia do cassete com a tela de gadolínio, mostrando a disposição do filme e das amostras a serem radiografadas. 


\section{Como a radiografia é feita}

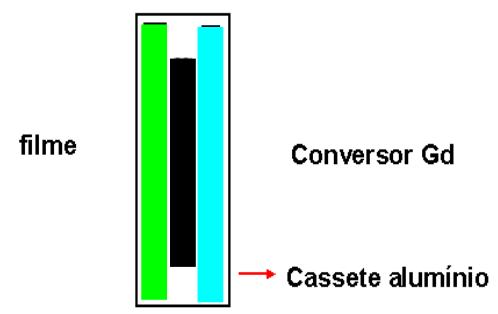

amostra

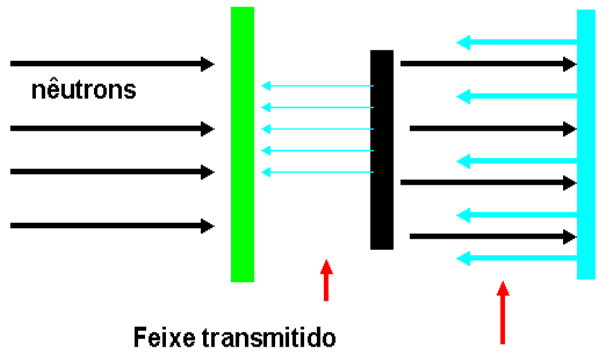

Feixe de elétrons

FIGURA 2.6 - Diagrama esquemático mostrando a obtenção de uma radiografia com elétrons induzida por nêutrons.

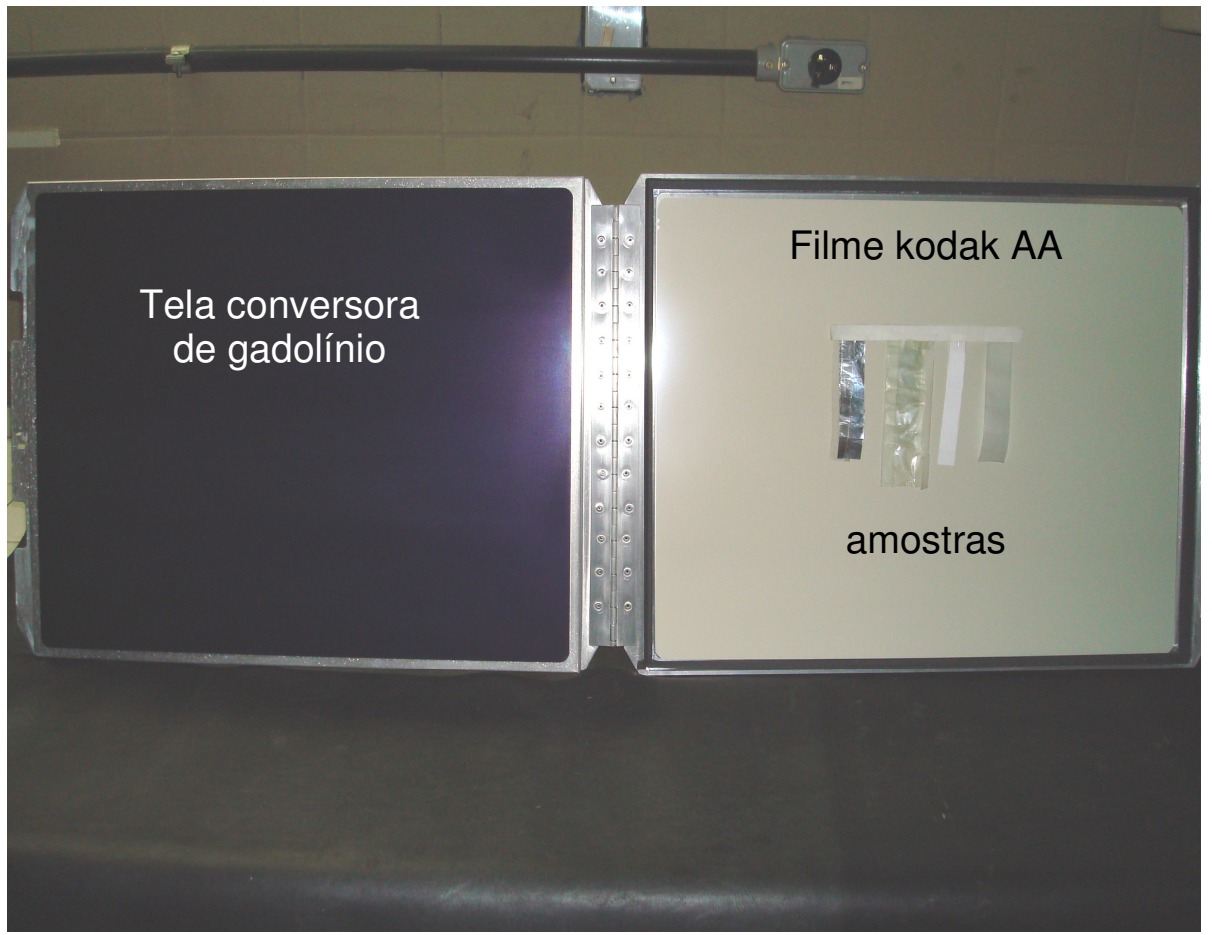

FIGURA 2.7 - Fotografia do cassete mostrando a disposição da tela conversora, do filme e das amostras. 


\subsection{Sistema digital para análise e processamento das imagens}

O sistema digital, mostrado na FIG. 2.8, foi utilizado para avaliar intensidade de luz transmitida pelos filmes e, consta basicamente de um scanner acoplado a um PC e, um software para o processamento do sinal. Para estas leituras os filmes são colocados lado a lado em uma bandeja de vidro de alta transparência do scanner e, um feixe de luz varre toda a área da bandeja. A intensidade da luz transmitida é capturada por um sensor e avaliada em uma escala de níveis de cinza de 8 bits ou de 16 bits. No primeiro caso a escala possui 256 níveis de cinza variando de 0 (para o pixel mais escuro) a 255 (para o mais claro) e, no segundo 65536 níveis de cinza.

As principais características destes equipamentos são:

\section{Scanner}

Marca: Microtek

Modelo: ScanMaker i900

Resolução: 150 a 3200 dpi (dots per inch)

Faixa de densidade ótica: 0 a 4,2

Faixa dinâmica máxima: 8 ou 16 bits para imagens em níveis de cinza

Modos de operação: reflexão e transmissão de luz

Área máxima de varredura : 8,5" x 14"

\section{Computador}

Processador Intel Pentium IV

$1 \mathrm{~Gb}$ de memória RAM

Sistema operacional: Windows 98 ( $2^{\mathrm{a}}$ edição)

\section{Software}

Image - pro plus versão 4.1 


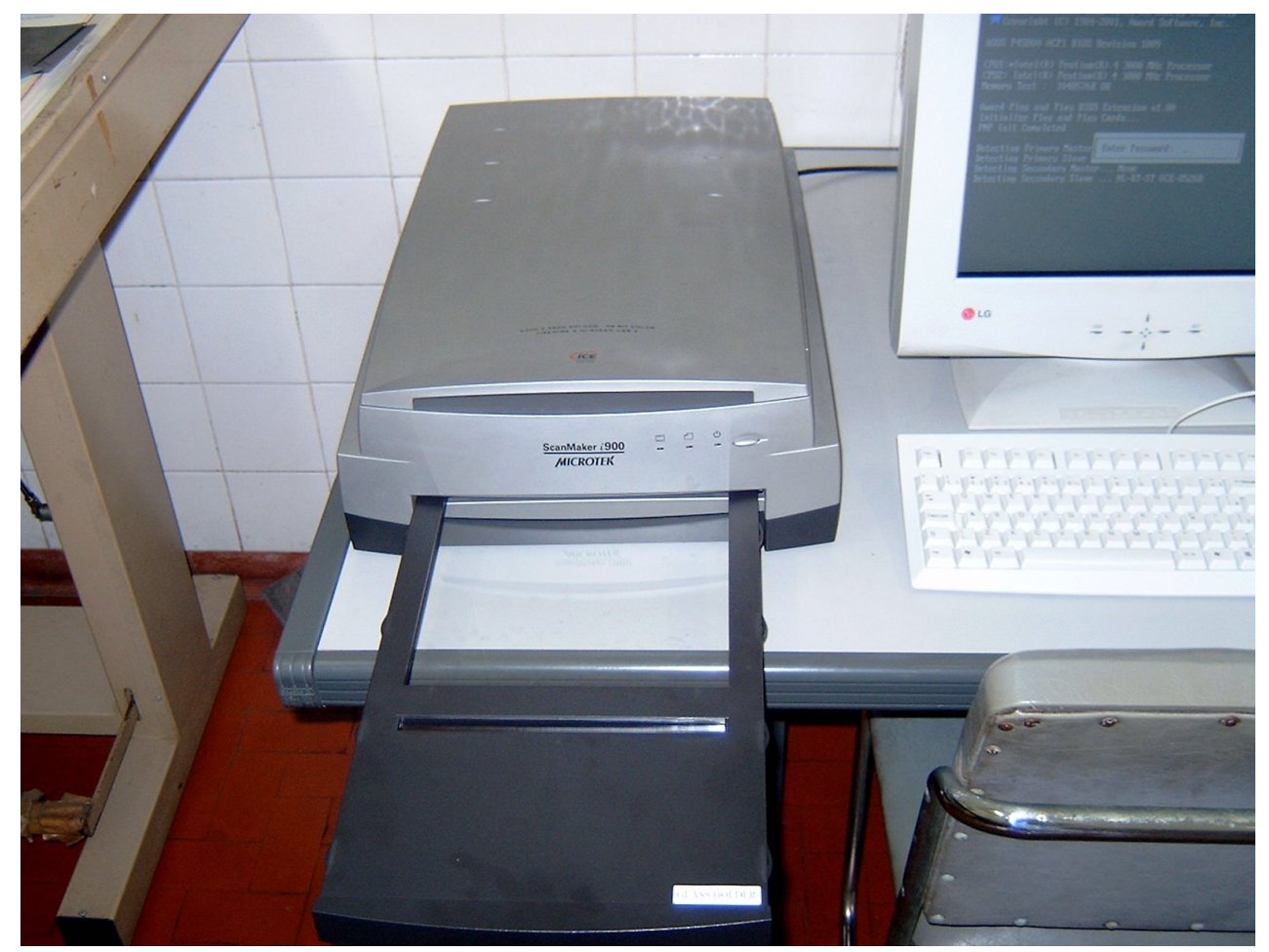

FIGURA 2.8 - Sistema digital utilizado no trabalho. 


\section{CAPÍTULO 3 - OBTENÇÃO E ANÁLISE DOS DADOS}

\subsection{Caracterização da técnica da radiografia com elétrons induzida por nêutrons}

Esta caracterização consistiu basicamente na execução das etapas que foram descritas no item 1.6, ou seja, na determinação do intervalo de exposição para obtenção do melhor contraste ótico no filme, da sensibilidade da técnica para discernir variações de espessuras e, da resolução espacial. Fez também parte desta caracterização o estudo da influência do sistema digital na reprodutibilidade da quantificação da intensidade da luz transmitida pelos filmes e de uma comparação entre os resultados obtidos com os sistemas digital e analógico.

\subsubsection{Intervalo de exposição}

A determinação do intervalo de exposição no qual o contraste ótico é máximo foi feita através da curva que relaciona intensidade do nível de cinza (NC) em função da exposição $[21,25,36]$. Desde que o feixe de elétrons foi gerado por um feixe de nêutrons e, pela facilidade de se quantificar o último, a exposição (E) expressa por (1.14), foi determinada em função do feixe de nêutrons, ou seja:

$E\left(n / \mathrm{cm}^{2}\right)=\phi\left(n / s \cdot \mathrm{cm}^{2}\right)+t(\mathrm{~s})$

onde " $\phi$ " é o fluxo de nêutrons incidente na amostra e " $\mathrm{t}$ " o tempo de irradiação.

$O$ contraste ótico definido por $G=\Delta(N C) / \Delta(E)$ (item 1.6.1) é máximo para o intervalo de exposição correspondente a região mais íngreme desta curva [36].

Para esta determinação foram irradiadas diversas tiras do filme Kodak AA, cada uma com dimensão aproximada de $3,5 \mathrm{~cm} \times 6 \mathrm{~cm}$, as quais foram fixadas no interior do cassete de alumínio no qual foi feito vácuo. Os tempos de irradiação variaram entre 0 e 240 segundos o que corresponde ao intervalo de 
exposição $0<E<3,8 \times 10^{8} \mathrm{n} / \mathrm{cm}^{2}$. Após a irradiação os filmes foram revelados e posicionados no scanner do sistema digital. O nível de cinza correspondente a cada filme foi determinado utilizando o software Image - pro, o qual pode avaliar de uma só vez a média da intensidade de aproximadamente 15.000 pixels individuais o que corresponde a uma área de $1 \mathrm{~cm}^{2}$ do filme. A imagem digitalizada destas tiras está mostrada na FIG. 3.1.

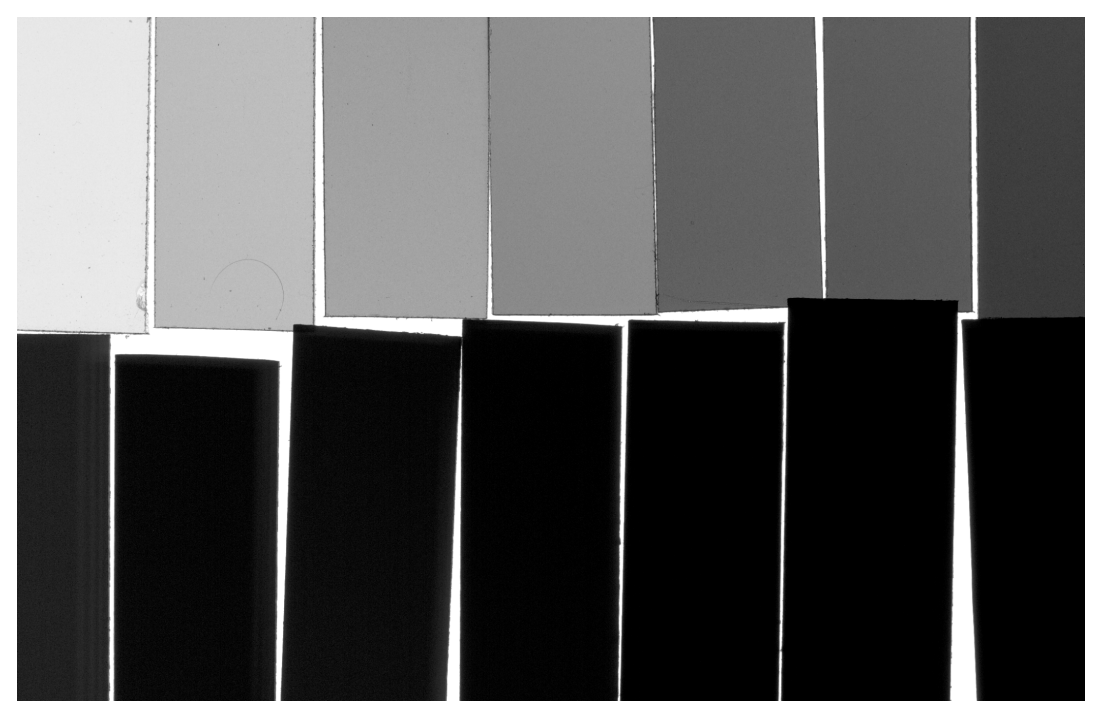

FIGURA 3.1 - Imagem digitalizada dos filmes Kodak AA, utilizados para a confecção da curva NC x E.

A FIG. 3.2 mostra o comportamento obtido para os níveis de cinza em função da exposição. De acordo com estes resultados, o intervalo de exposição para o qual o contraste ótico é máximo (indicado por setas), está compreendido entre $0<E<1,5 \times 10^{8} \mathrm{n} / \mathrm{cm}^{2}$. Nesta condição o tempo de irradiação necessário para se atingir o final do intervalo de exposição, ou seja, para se obter a radiografia com o melhor contraste possível é de no máximo 100 segundos. 


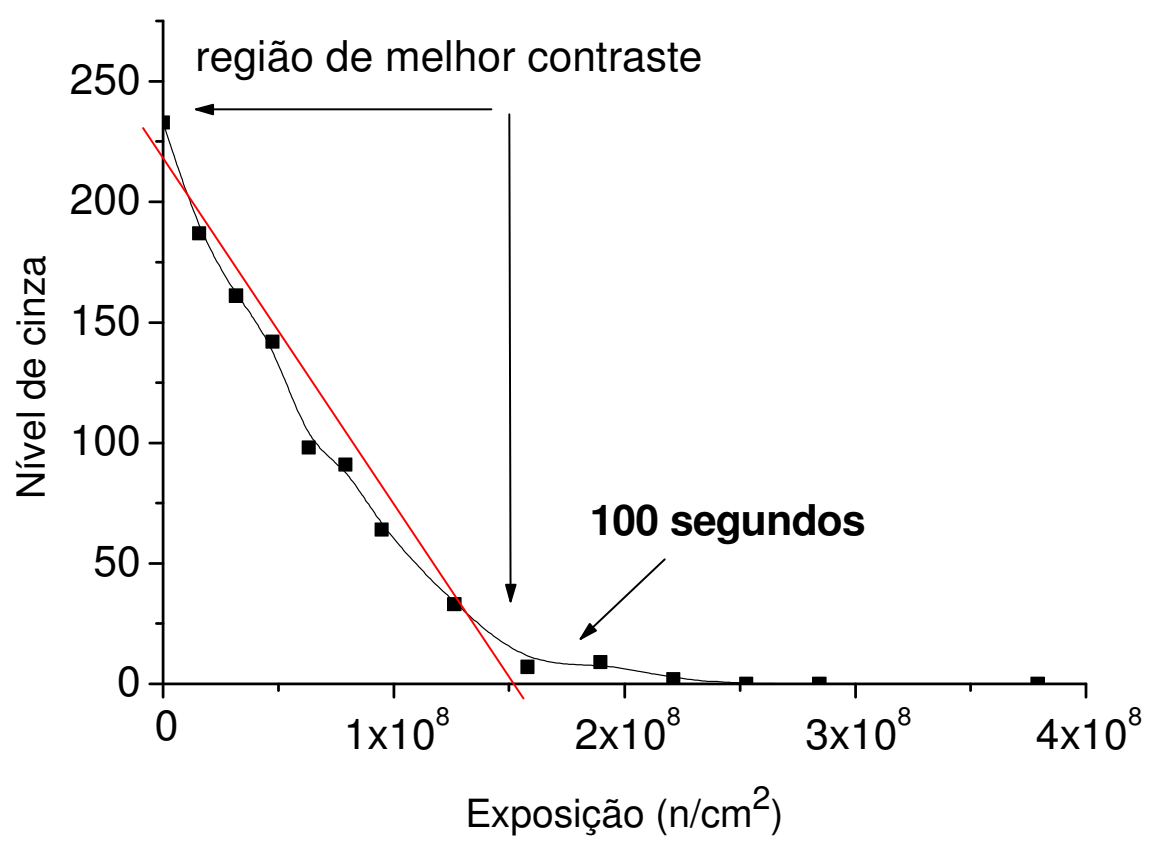

FIGURA 3.2 - Comportamento do nível de cinza em função da exposição, destacando a região de melhor contraste.

\subsubsection{Sensibilidade $[21,36,49]$}

Como já mencionado, no presente trabalho a sensibilidade foi definida como a capacidade da técnica para discernir variações de espessuras. Ela foi avaliada para quatro materiais, papel branco (celulose), alumínio, policarbonato (makrofol -KG) e, fita adesiva (durex). As amostras têm a forma de "cunhas com degraus" com espessuras variando entre 12 e $500 \mu \mathrm{m}$ e foram irradiadas durante 100 segundos. Na TAB. 3.1 estão mostrados os valores aproximados dos alcances dos elétrons de $72 \mathrm{keV}$ e de $150 \mathrm{keV}$ nestes materiais.

TABELA 3.1 - Valores do alcance dos elétrons de 72 keV e 150 keV nos materiais estudados.

\begin{tabular}{ccccc}
\hline Alcance $(\mu \mathrm{m})$ & alumínio & makrofol $-\mathrm{KG}$ & papel branco & adesivo \\
\hline $72 \mathrm{keV}$ & 40 & 60 & 150 & 80 \\
$150 \mathrm{keV}$ & 140 & 240 & 300 & 270 \\
\hline
\end{tabular}

Após serem revelados os filmes foram posicionados no scanner do sistema digital e como anteriormente, o nível de cinza correspondente a cada 
espessura de cada material foi determinado utilizando o software Image - pro, mediante a média da intensidade de aproximadamente 15.000 pixels individuais que corresponde a uma área de $1 \mathrm{~cm}^{2}$ do filme. As barras de erro correspondem aos desvios padrões das médias de cada leitura.

Pelo fato de o espectro de energia dos elétrons emitidos pela tela de gadolínio não ser conhecido, a função teórica $f(x, \mu)$ também não será e, assim o comportamento do nível de cinza em função da espessura do material é expresso por (1.20):

$N C(x)=G \times E_{0^{*}} f(x, \mu)$

Para a determinação da sensibilidade foi necessário primeiramente encontrar a função " $f(x, \mu)$ " que melhor se ajusta aos pontos experimentais. $O$ método utilizado foi o dos mínimos quadrados e dentre as funções verificadas a que melhor se ajustou foi uma exponencial do tipo:

$\mathrm{NC}(\mathrm{x})=\mathrm{A}-\mathrm{B} * \exp (-\mathrm{C} * \mathrm{x})$

onde as constantes $A, B$, e C são parâmetros livres no ajuste e " $x$ " a espessura da amostra.

Os resultados obtidos para o comportamento do nível de cinza em função da espessura das amostras bem como os ajustes de (3.1) aos pontos experimentais estão apresentados nas FIG. 3.3, 3.4, 3.5, 3.6. 


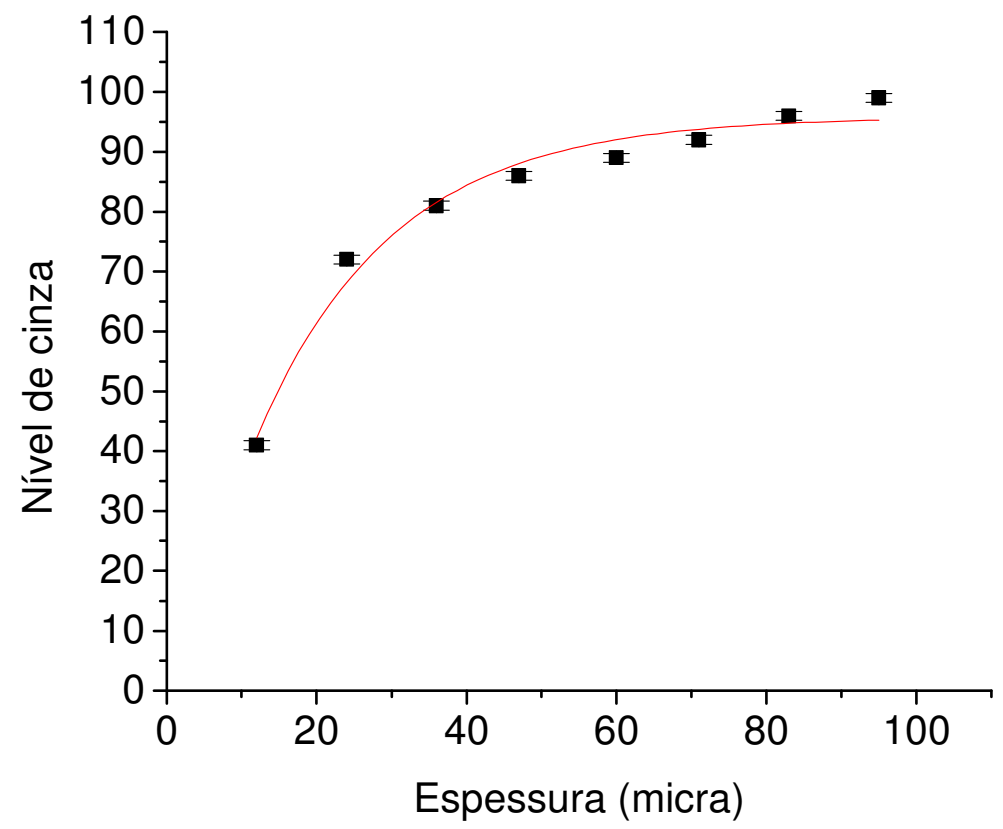

FIGURA 3.3 - Comportamento do nível de cinza em função da espessura para a amostra de alumínio.

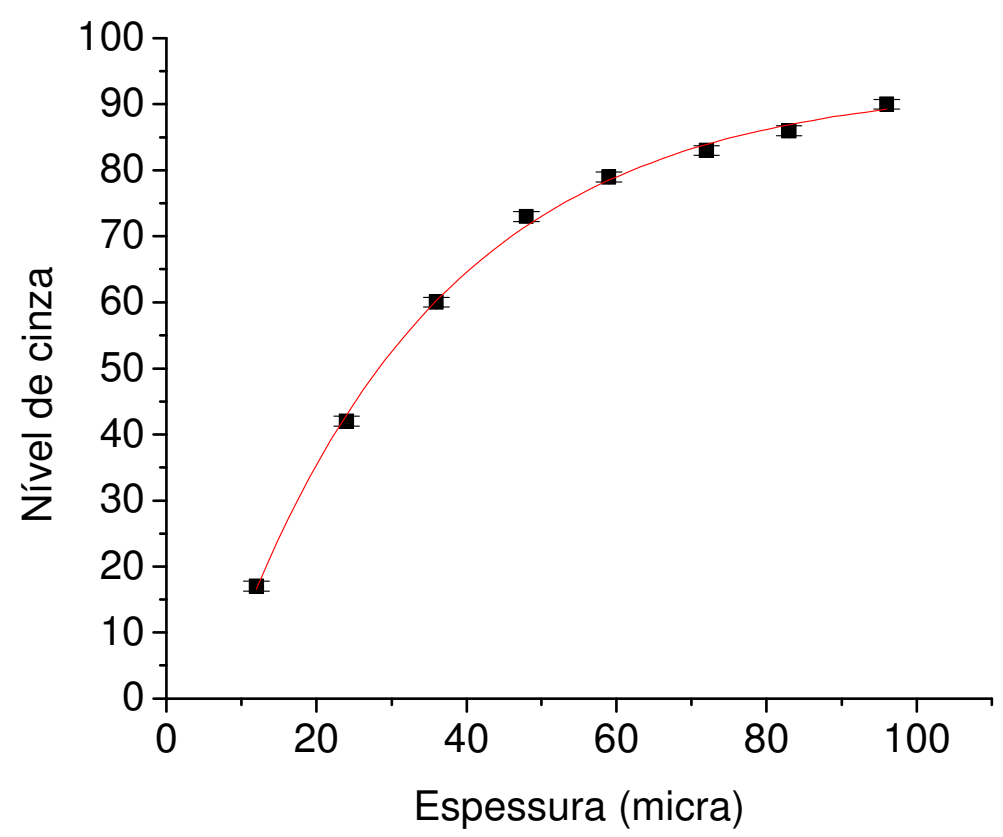

FIGURA 3.4 - Comportamento do nível de cinza em função da espessura para a amostra de makrofol - KG. 


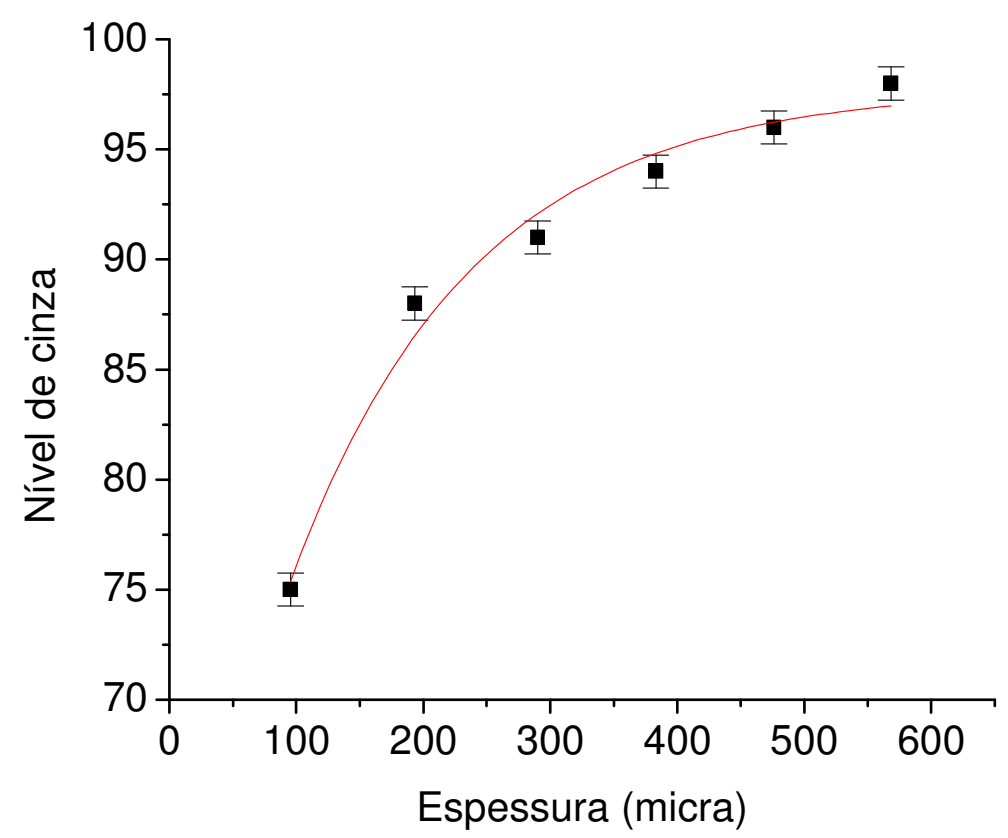

FIGURA 3.5 - Comportamento do nível de cinza em função da espessura para a amostra de papel branco.

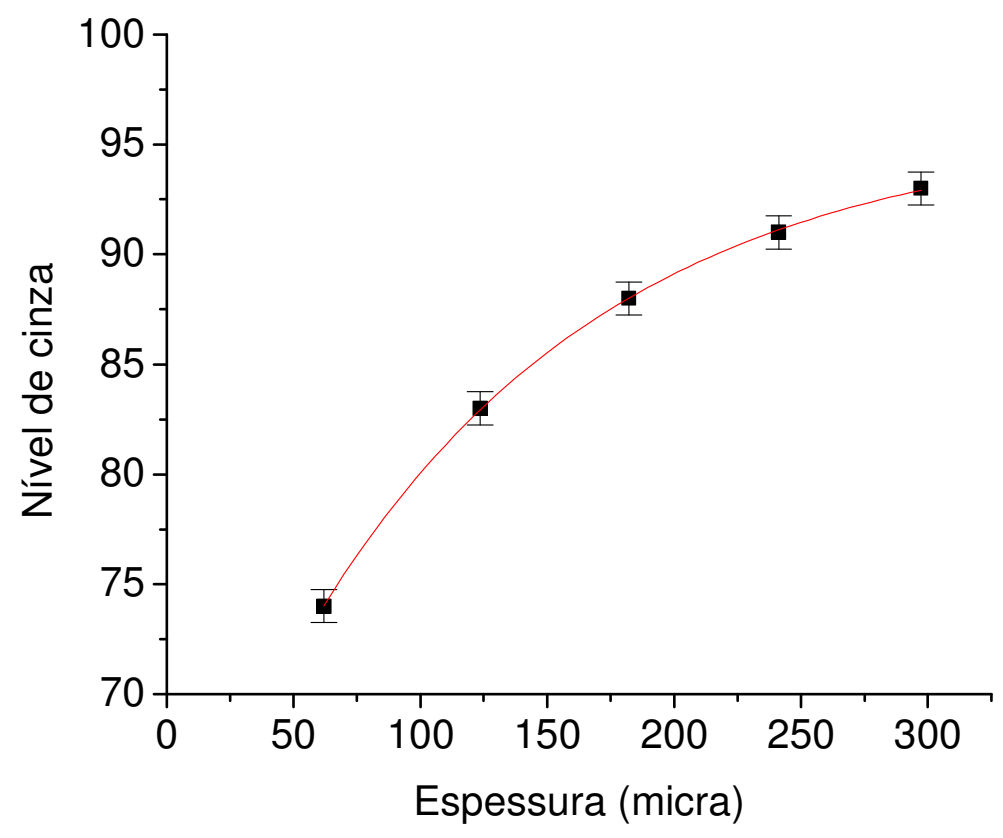

FIGURA 3.6 - Comportamento do nível de cinza em função da espessura para a amostra de adesivo. 
A sensibilidade foi calculada pela diferencial de (3.1) ou seja:

$\Delta \mathrm{x}=-\Delta(\mathrm{Nc}) /[\mathrm{B} * \mathrm{C} * \exp -(\mathrm{C} * \mathrm{x})]$

onde $\Delta(\mathrm{Nc})=1,5$ é a mínima variação de nível de cinza distinguível pelo scanner.

Nas FIG. 3.7, 3.8, 3.9, 3.10 estão apresentados os comportamentos de " $\Delta x$ " em função das espessuras nos materiais estudados.

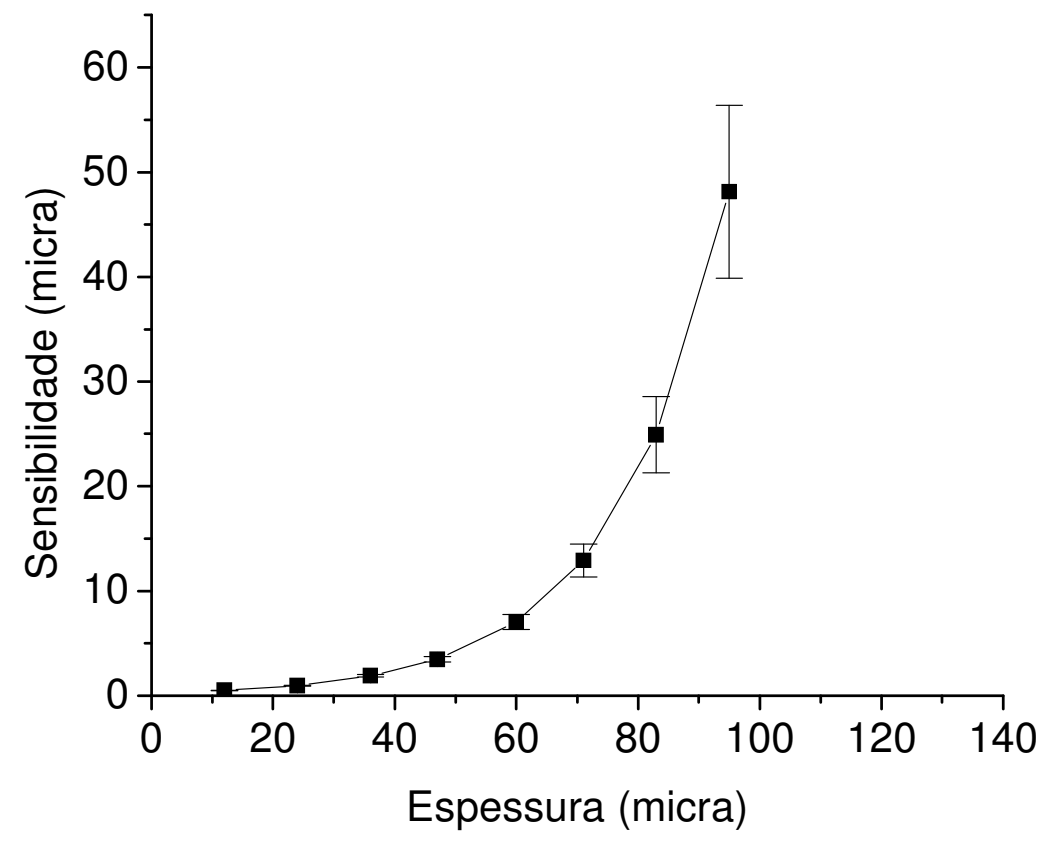

FIGURA 3.7 - Comportamento da sensibilidade " $\Delta x$ " em função da espessura para a amostra de alumínio. 


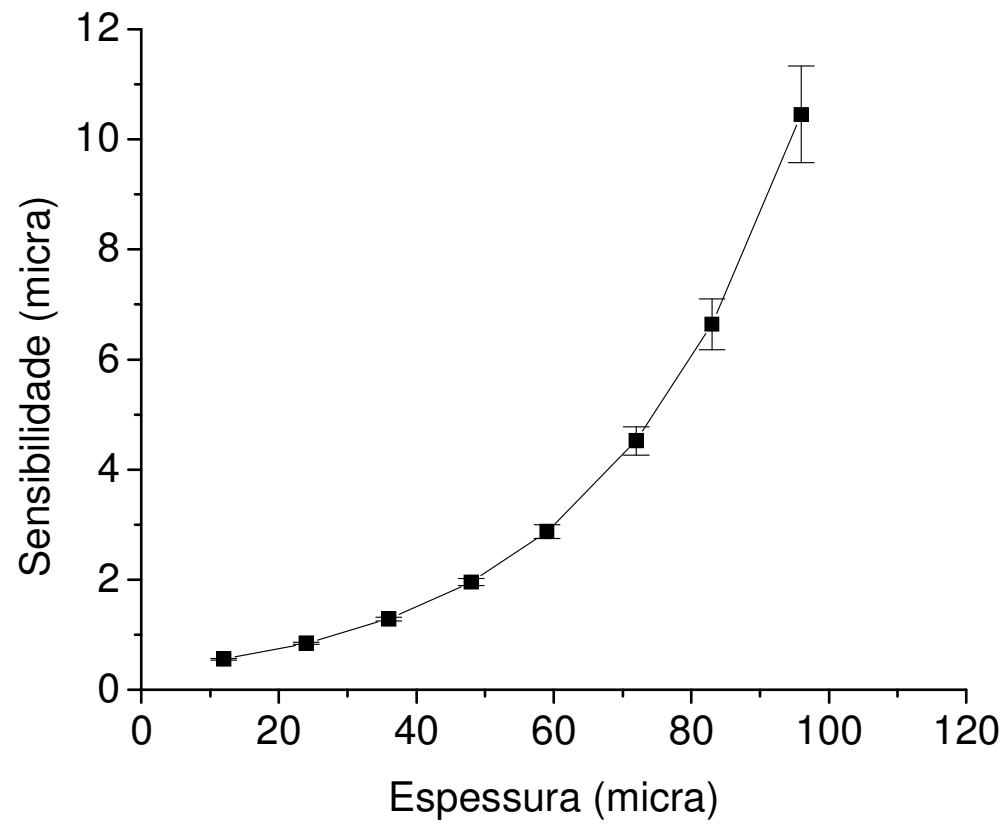

FIGURA 3.8 - Comportamento da sensibilidade " $\Delta \mathrm{x}$ " em função da espessura para a amostra de makrofol KG.

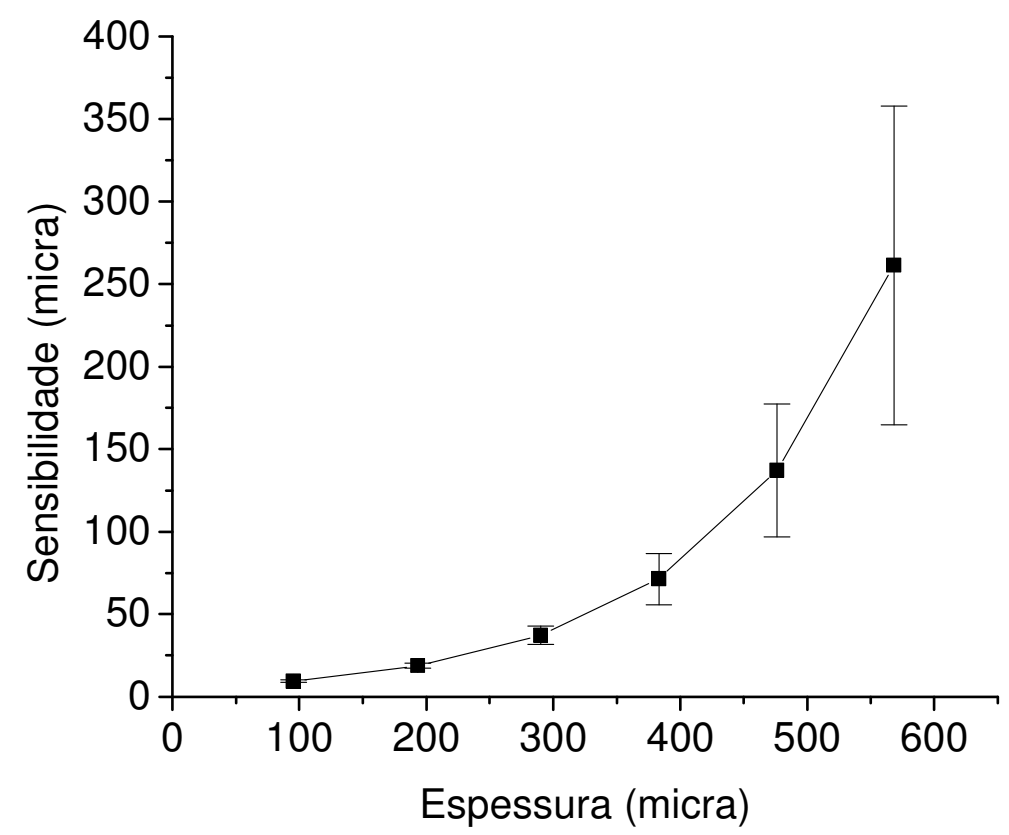

FIGURA 3.9 - Comportamento da sensibilidade " $\Delta \mathrm{x}$ " em função da espessura para a amostra de papel branco. 


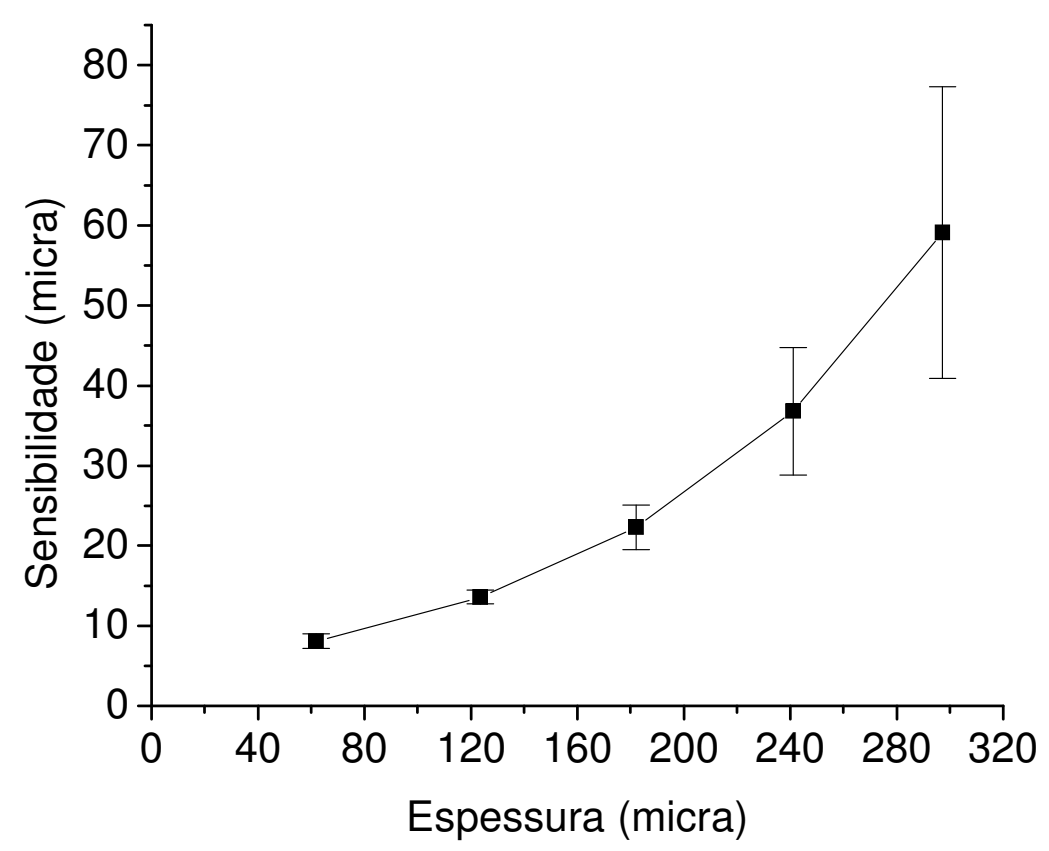

FIGURA 3.10 - Comportamento da sensibilidade " $\Delta x$ " em função da espessura para a amostra de adesivo.

Como pode ser observado nas FIG. 3.7 a 3.10 é possível discernir 1 $\mu \mathrm{m}$ em $24 \mu \mathrm{m}$ de alumínio, 0,8 $\mu \mathrm{m}$ em $24 \mu \mathrm{m}$ de makrofol - KG, $8 \mu \mathrm{m}$ em $63 \mu \mathrm{m}$ de adesivo e 9,5 $\mu \mathrm{m}$ em $95 \mu \mathrm{m}$ de papel. Foi também determinada, para cada um dos materiais a espessura mínima detectável (EMD), ou seja, a mínima quantidade de material colocada no feixe de radiação penetrante, capaz de ser percebida pela técnica. Os resultados obtidos estão apresentados na TAB. 3.2 e, foram calculados extrapolando a expressão (3.2) para $x \rightarrow 0$.

TABELA 3.2 - Resultados obtidos para a espessura mínima detectável para os materiais estudados.

\begin{tabular}{ccccc}
\hline Sistema Digital & Alumínio & makrofol - KG & papel branco & adesivo \\
\hline $\operatorname{EMD}(\mu \mathrm{m})$ & $0,26 \pm 0,01$ & $0,37 \pm 0,02$ & $4,9 \pm 0,7$ & $4,8 \pm 1,0$ \\
\hline
\end{tabular}

\subsubsection{Resolução}

Em radiografia, a resolução espacial é definida como a mínima distância que dois objetos podem estar próximos um do outro de forma que possam ser distinguidos [44]. Como os elétrons são emitidos em todas as 
direções, eles irão sensibilizar o filme em uma área maior que a da área de sua origem. Desta forma a resolução depende:

a - Da espessura da amostra;

b - Da distância entre o filme e a amostra;

c - Do tamanho do grão do filme;

d - Do alcance dos elétrons na emulsão do filme.

A resolução foi avaliada em termos de resolução total - Ut e é resultado do efeito combinado da resolução geométrica - Ug ("a" e "b") e da resolução intrínseca - Ui ("c" e "d") [36,44,45]. A amostra utilizada neste estudo foi a de alumínio, empregada no estudo da sensibilidade. Esta escolha se deve principalmente porque dentre os materiais estudados, o alumínio é o que exibiu a melhor qualidade de corte para a obtenção de uma interface bem definida. De modo a garantir que o nível de cinza correspondente a cada degrau das cunhas esteja dentro da região de maior contraste, o tempo de irradiação para a obtenção desta radiografia foi também de 100 segundos. O filme foi revelado e a imagem registrada, digitalizada pelo scanner a uma resolução de 3200 dpi. A varredura dos níveis de cinza foi feita utilizando o mesmo programa Image - pro.

Este procedimento foi realizado para os cinco primeiros degraus desta amostra e, para cada um foram obtidas varreduras em 10 posições diferentes. A cada conjunto de dados, foi ajustada pelo método dos mínimos quadrados, a função (1.24):

$N C=P_{1}-P_{2^{*}} \arctan \left[P_{3^{*}}\left(X-P_{4}\right)\right]$

O valor da resolução total para cada degrau corresponde à média destas dez medidas. Uma varredura típica obtida para o degrau de $12 \mu \mathrm{m}$ é mostrada na FIG. 3.11 e os valores obtidos para Ut estão mostrados na TAB. 3.3. 


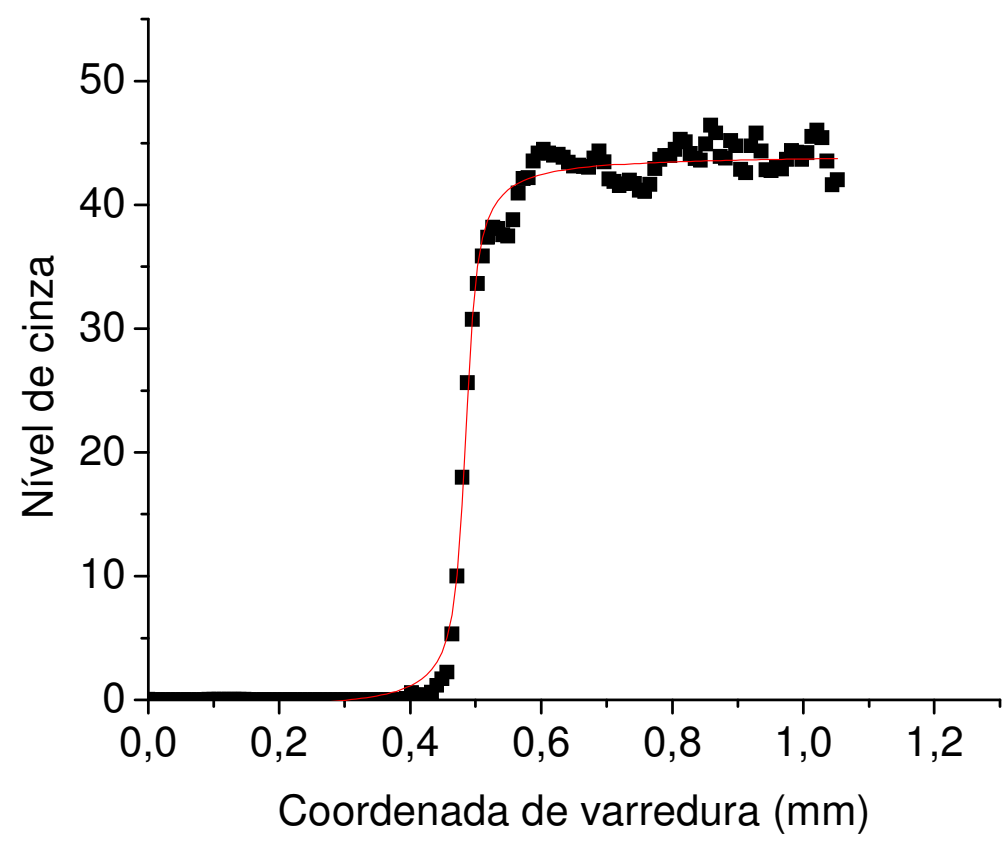

FIGURA 3.11 - Resultado típico da varredura obtido para espessura de $12 \mu \mathrm{m}$ de alumínio.

TABELA 3.3 - Valores médios de Ut em função da espessura da amostra de alumínio.

\begin{tabular}{ccccc}
\hline $\begin{array}{c}\text { Degrau 1 } \\
(12 \mu \mathrm{m})\end{array}$ & $\begin{array}{c}\text { Degrau 2 } \\
(24 \mu \mathrm{m})\end{array}$ & $\begin{array}{c}\text { Degrau 3 } \\
(36 \mu \mathrm{m})\end{array}$ & $\begin{array}{c}\text { Degrau 4 } \\
(47 \mu \mathrm{m})\end{array}$ & $\begin{array}{c}\text { Degrau 5 } \\
(60 \mu \mathrm{m})\end{array}$ \\
\hline 26 & 29 & 38 & 50 & 65 \\
29 & 32 & 39 & 44 & 51 \\
32 & 34 & 45 & 51 & 66 \\
31 & 36 & 42 & 94 & 91 \\
26 & 35 & 43 & 46 & 82 \\
42 & 40 & 37 & 51 & 66 \\
37 & 42 & 48 & 58 & 80 \\
33 & 45 & 50 & 76 & 90 \\
25 & 39 & 48 & 90 & 71 \\
37 & 24 & 48 & 73 & 45 \\
$32 \pm 2$ & $36 \pm 2$ & $44 \pm 1$ & $63 \pm 6$ & $71 \pm 5$ \\
\hline
\end{tabular}

Na FIG. 3.12 está mostrado o comportamento do valor médio de Ut em função da espessura da amostra de alumínio. 


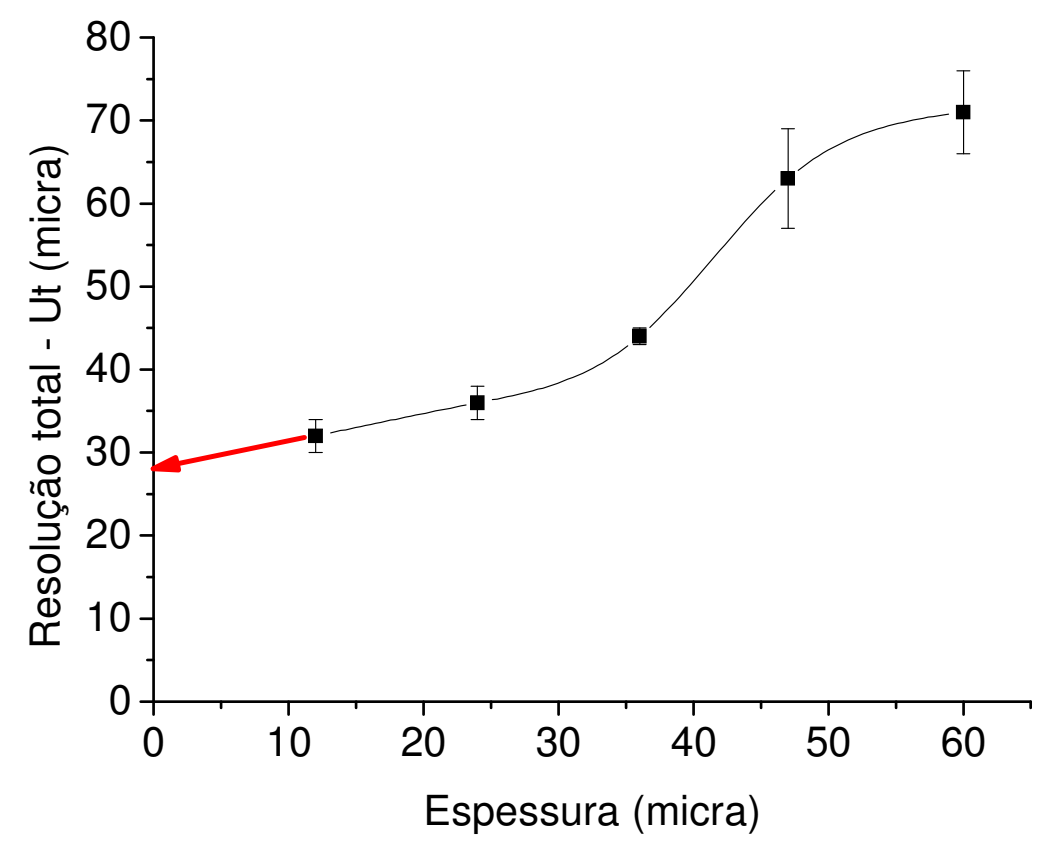

FIGURA 3.12 - Valores médios da resolução total em função da espessura do material alumínio.

Uma característica relevante desta técnica é a elevada resolução total obtida na imagem radiográfica. $\mathrm{O}$ melhor resultado obtido foi de $32 \mu \mathrm{m}$ para o degrau de $12 \mu \mathrm{m}$ de espessura (vide TAB. 3.3). Apesar de não se conhecer a expressão matemática que descreve o comportamento da resolução total para esta técnica, os dados mostrados na FIG. 3.12 permitem:

- determinar o valor da resolução total em função da distância amostra - filme;

- determinar o valor da resolução intrínseca, ou seja, a melhor resolução que pode ser obtida em uma imagem radiográfica por esta técnica. O valor obtido $\mathrm{Ui} \sim 28$ $\mu \mathrm{m}$ foi determinado extrapolando Ut para a espessura "zero", onde o efeito de penumbra é desprezível;

- concluir que o efeito da resolução geométrica na resolução total passa a ser predominante somente para amostras com espessuras superiores a aproximadamente $43 \mu \mathrm{m}$.

É importante salientar que o processo de digitalização realizado no scanner não contribui no resultado da resolução, pois como a radiografia da resolução foi digitalizada a 3200 dpi o tamanho de pixel é de $\sim 8 \mu \mathrm{m}$, o qual é 
menor do que o alcance do elétron de menor energia, $72 \mathrm{keV}$, tanto na emulsão do filme $(32 \mu \mathrm{m})$ quanto na tela conversora $(20 \mu \mathrm{m})$.

\subsubsection{Influência das outras radiações na formação da imagem}

Como já mencionado, os elétrons de $72 \mathrm{keV}$ e de $150 \mathrm{keV}$ respondem por $\sim 80 \%$ do enegrecimento do filme $[8,17,46,47,48]$. Entretanto é necessário justificar quais das outras radiações presentes no ato da radiografia, contribuem com os outros $20 \%$ restantes. Dentre estas radiações serão analisadas as oriundas do equipamento de radiografia e do decaimento do núcleo gadolínio.

No primeiro caso as radiações são nêutrons com energia média de 7 meV e radiação - $\gamma$ de $\sim 2 \mathrm{MeV}$, provenientes do núcleo do reator. Para este estudo foram utilizadas as mesmas amostras empregadas no estudo da sensibilidade. As amostras foram radiografadas utilizando a técnica da radiografia com nêutrons na mesma condição em que a radiografia com elétrons foi obtida, ou seja, foram irradiadas durante 100 segundos. Em seguida a radiografia foi avaliada no sistema digital e como mostrado nas FIG. 3.13 a 3.16, não houve qualquer variação no valor do nível de cinza ao longo dos degraus das amostras. Isto significa que o feixe de nêutrons não sofre qualquer modulação em intensidade ao atravessar as amostras e, portanto ao incidir na tela de gadolínio gerará um feixe de radiação penetrante uniforme. Em seguida as amostras foram expostas ao feixe de nêutrons sem o conversor de gadolínio e a radiação - $\gamma$ de 2 $\mathrm{MeV}$, presente neste feixe, não elevou o seu fundo ótico a níveis perceptivos.

No segundo caso as radiações são $\gamma$ de $79 \mathrm{keV}$ e raios - X de $6 \mathrm{keV}$. Para este estudo, as mesmas amostras foram cobertas com uma placa de alumínio com $150 \mu \mathrm{m}$ de espessura que é suficiente para deter os elétrons e foram radiografadas na mesma condição em que a radiografia com elétrons foi obtida. O filme foi avaliado no sistema digital e os comportamentos do nível de cinza ao longo dos degraus das amostras estão apresentados nas FIG. 3.13 a 3.16. Como pode ser observado o feixe de radiação - $\gamma$ sofreu uma pequena modulação em intensidade e contribuirá principalmente para uma elevação do fundo ótico do filme sendo a principal responsável pelos $20 \%$ do seu enegrecimento [17]. No caso dos fótons de $6 \mathrm{keV}$ a justificativa de sua não influência foi teórica. Um fóton de $6 \mathrm{keV}$ é capaz de gerar na emulsão, um elétron 
de no máximo $6 \mathrm{keV}$ e, o seu alcance nesta emulsão é de $\sim 1 \mu \mathrm{m}$. Desde que os grãos da emulsão tenham dimensões aproximadas de $1 \mu \mathrm{m}$, este elétron será capaz de sensibilizar somente 1 grão. Para os elétrons de $72 \mathrm{keV}$ o alcance é de $32 \mu \mathrm{m}$ e o número de grãos sensibilizados será 32. Ou seja, o elétron de $72 \mathrm{keV}$ enegrece o filme 32 vezes mais do que o fóton de $6 \mathrm{keV}$ e assim a sua ação na emulsão do filme é desprezível [5].

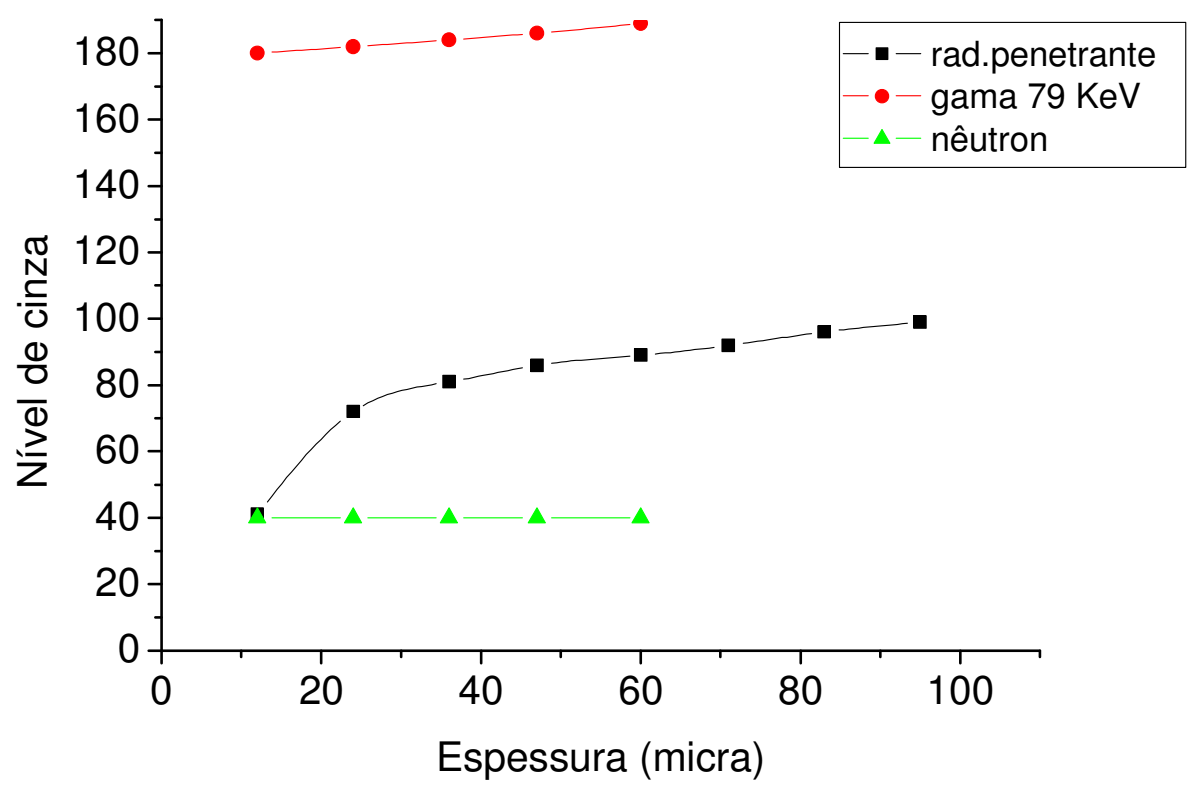

FIGURA 3.13 - Contribuições das outras radiações na formação da imagem radiográfica para a amostra de alumínio. 


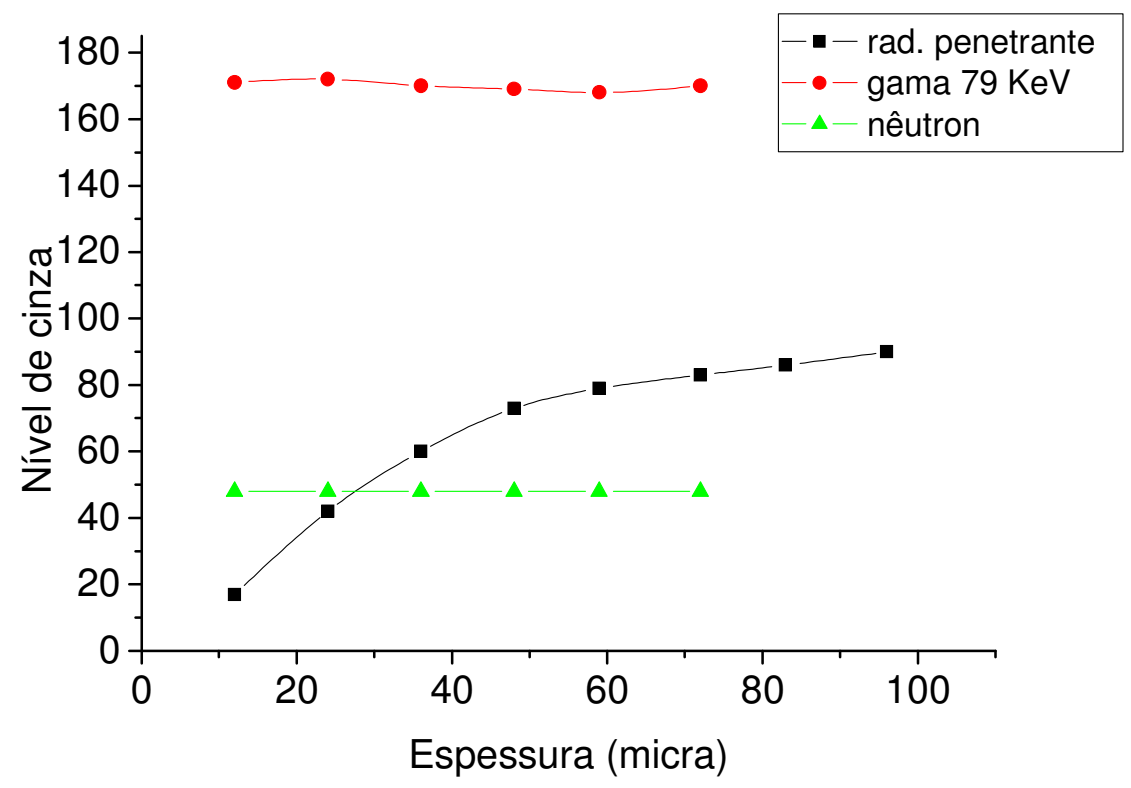

FIGURA 3.14 - Contribuições das outras radiações na formação da imagem radiográfica para a amostra de makrofol - KG.

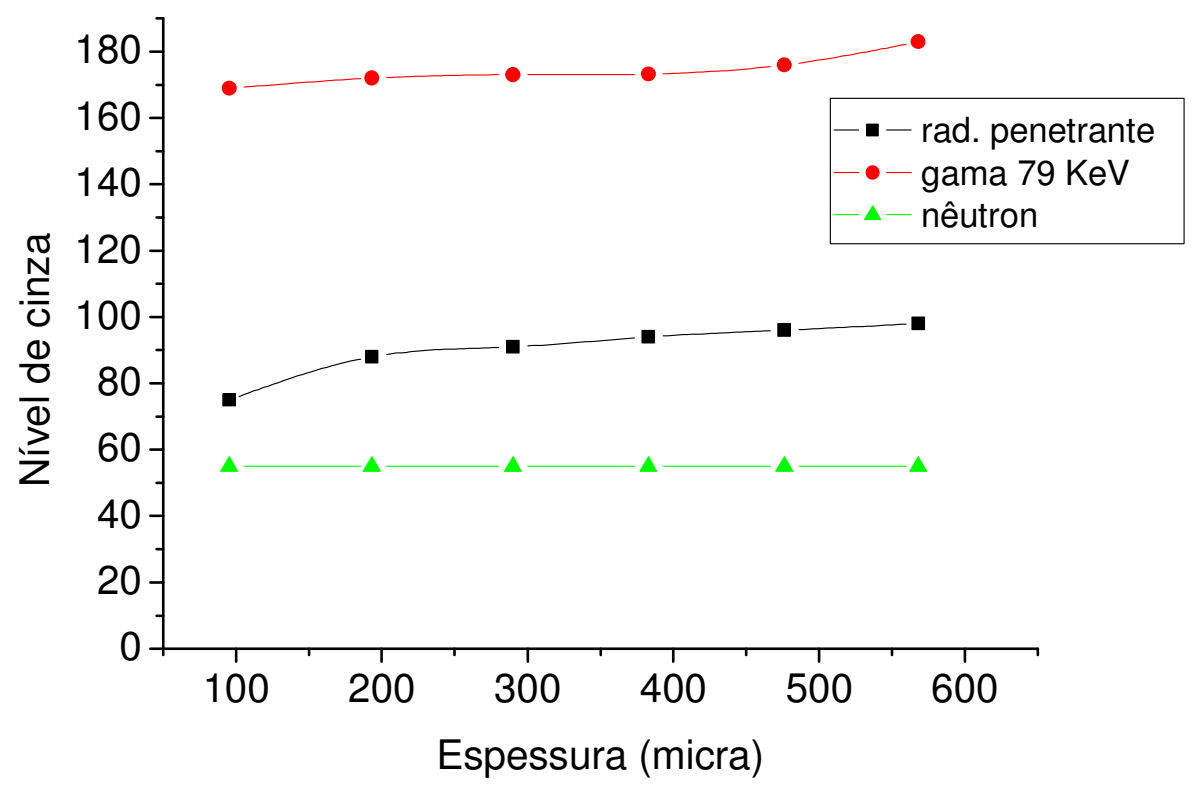

FIGURA 3.15 - Contribuições das outras radiações na formação da imagem radiográfica para a amostra de papel branco. 


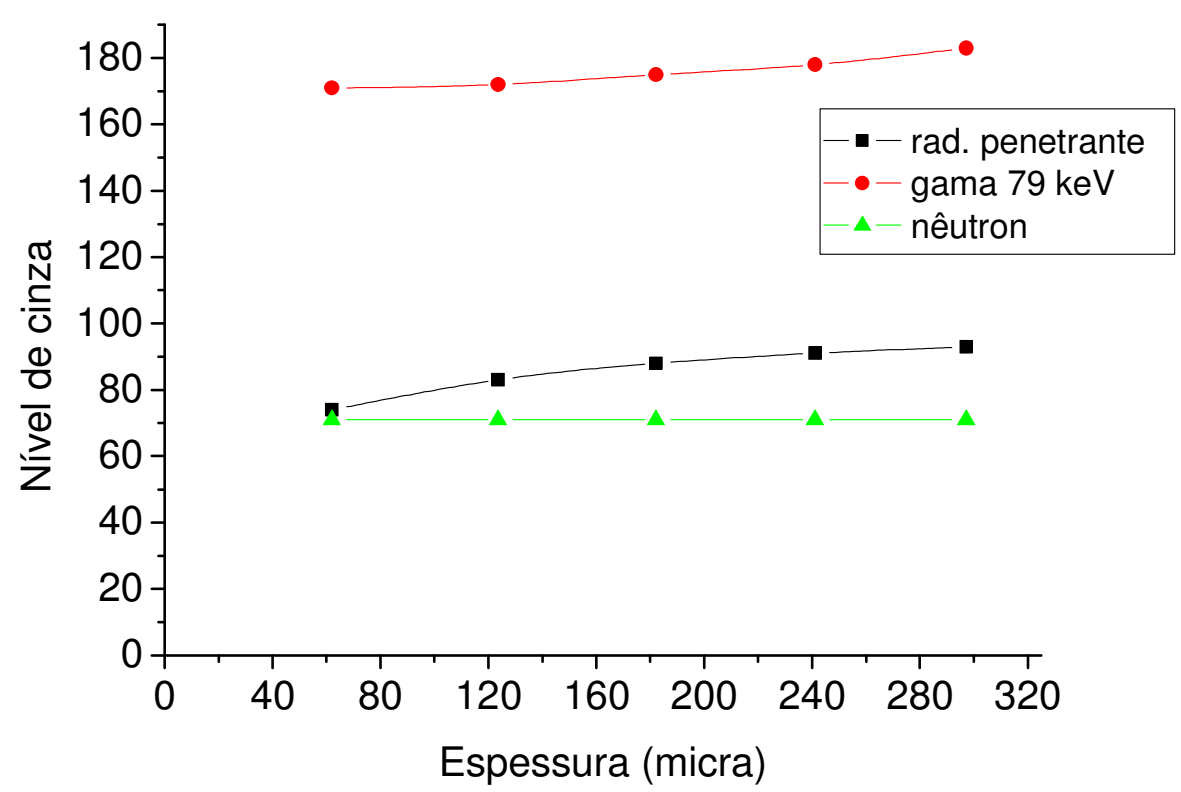

FIGURA 3.16 - Contribuições das outras radiações na formação da imagem radiográfica para a amostra de adesivo.

\subsubsection{Reprodutibilidade do sistema digital na determinação da intensidade da luz transmitida}

A caracterização da técnica radiográfica proposta, depende quase que exclusivamente da avaliação da intensidade da luz transmitida através da regiões enegrecidas do filme irradiado. Deste modo e levando em conta que se trata da primeira vez que este sistema digital é empregado para esta finalidade específica, a avaliação de sua reprodutibilidade na determinação deste parâmetro tem uma importância fundamental.

Dentre os fatores que afetam a reprodutibilidade da medida destacamse:

- Instabilidade eletrônica do sistema digital;

- Flutuações na potência do reator durante a irradiação;

- Variação nas condições de temperatura, homogeneidade e idade dos químicos da revelação;

- Variação das características do filme empregado;

- Variação na quantidade de grãos sensibilizados.

Para esta determinação foram empregados 10 pedaços de filme os quais foram irradiados e revelados individualmente. A intensidade da luz 
transmitida foi determinada segundo o mesmo procedimento mencionado em (3.1.1) e o valor do nível de cinza para cada pedaço corresponde a média de 10 medidas individuais. A reprodutibilidade da medida foi expressa como o desvio padrão das medidas dos 10 filmes e o valor obtido foi $\sigma=4$ correspondendo a uma variação de 1,7\% em relação ao valor médio.

Para verificar a influência isolada do sistema digital na reprodutibilidade, um único filme, dos 10 irradiados foi fixado no scanner do sistema digital. O procedimento de leitura do nível de cinza foi repetido por 10 vezes, sempre em uma mesma área e, a reprodutibilidade expressa como o desvio padrão destas 10 medidas forneceu o valor $\sigma_{(\text {DIGITAL })}=1$. Considerando que a influência do sistema digital na medida, aqui atribuída a sua instabilidade eletrônica, seja independente dos outros fatores que influenciam a determinação da intensidade da luz transmitida vale a seguinte relação [50]:

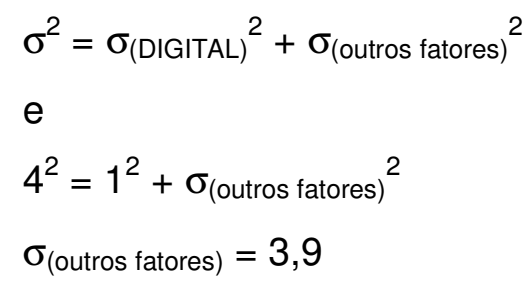

Portanto a sua influência na reprodutibilidade do método é desprezível.

\subsection{Comparação com o sistema de leitura analógico}

Os resultados obtidos para a caracterização da técnica empregando o sistema digital foram comparados com os determinados utilizando o sistema analógico para a leitura da transmissão de luz. Este sistema analógico é constituído por um negatoscópio no qual os filmes são fixados e a intensidade da luz transmitida é avaliada empregando um densitômetro ótico. O negatoscópio é composto por uma caixa metálica com dimensões $130 \mathrm{~cm}$ x $90 \mathrm{~cm}$ com $12 \mathrm{~cm}$ de espessura no interior da qual estão instaladas seis lâmpadas fluorescentes de 40 W cada uma, dispostas lado a lado. A tampa desta caixa é confeccionada em plástico translúcido através do qual a luz para inspeção dos filmes, emerge de um círculo com $30 \mathrm{~cm}$ de diâmetro, conforme mostrado na FIG. 3.17. No interior deste círculo existe uma sub - área, um quadrado de $5 \mathrm{~cm} \times 5 \mathrm{~cm}$, na qual a luz emerge 
com intensidade homogênea e onde as medidas de transmissão de luz são realizadas.

O densitômetro ótico é da marca Konica e o grau de enegrecimento dos filmes são avaliados em unidades de densidade ótica definida em (1.13). Este aparelho, apresentado na FIG. 3.18, é capaz de medir densidades óticas entre 0 e 4 com uma incerteza de $\Delta \mathrm{Dop}=0,05$, em uma área de $0,07 \mathrm{~cm}^{2}$.

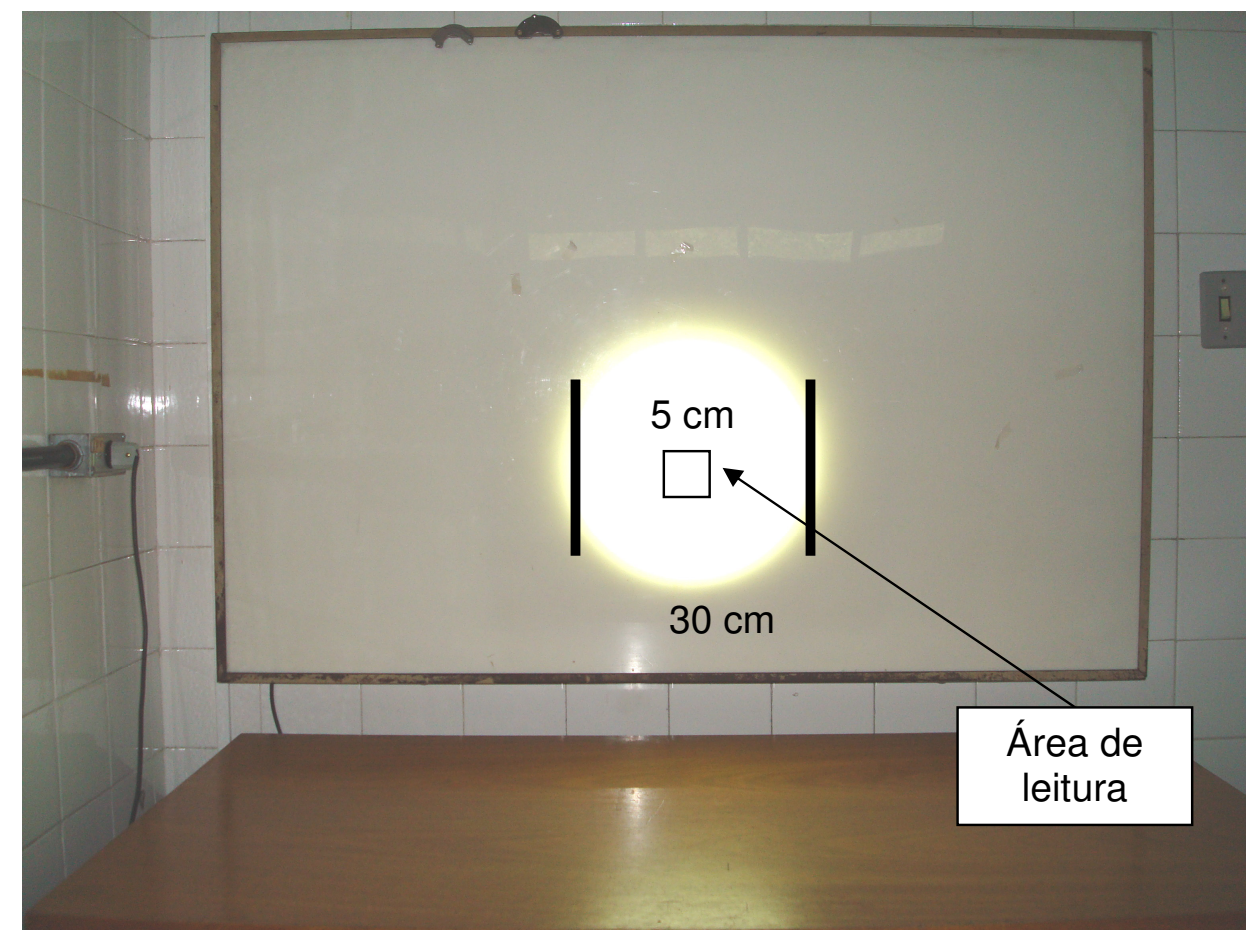

FIGURA 3.17 - Negatoscópio utilizado neste trabalho para leitura da densidade ótica dos filmes irradiados. 


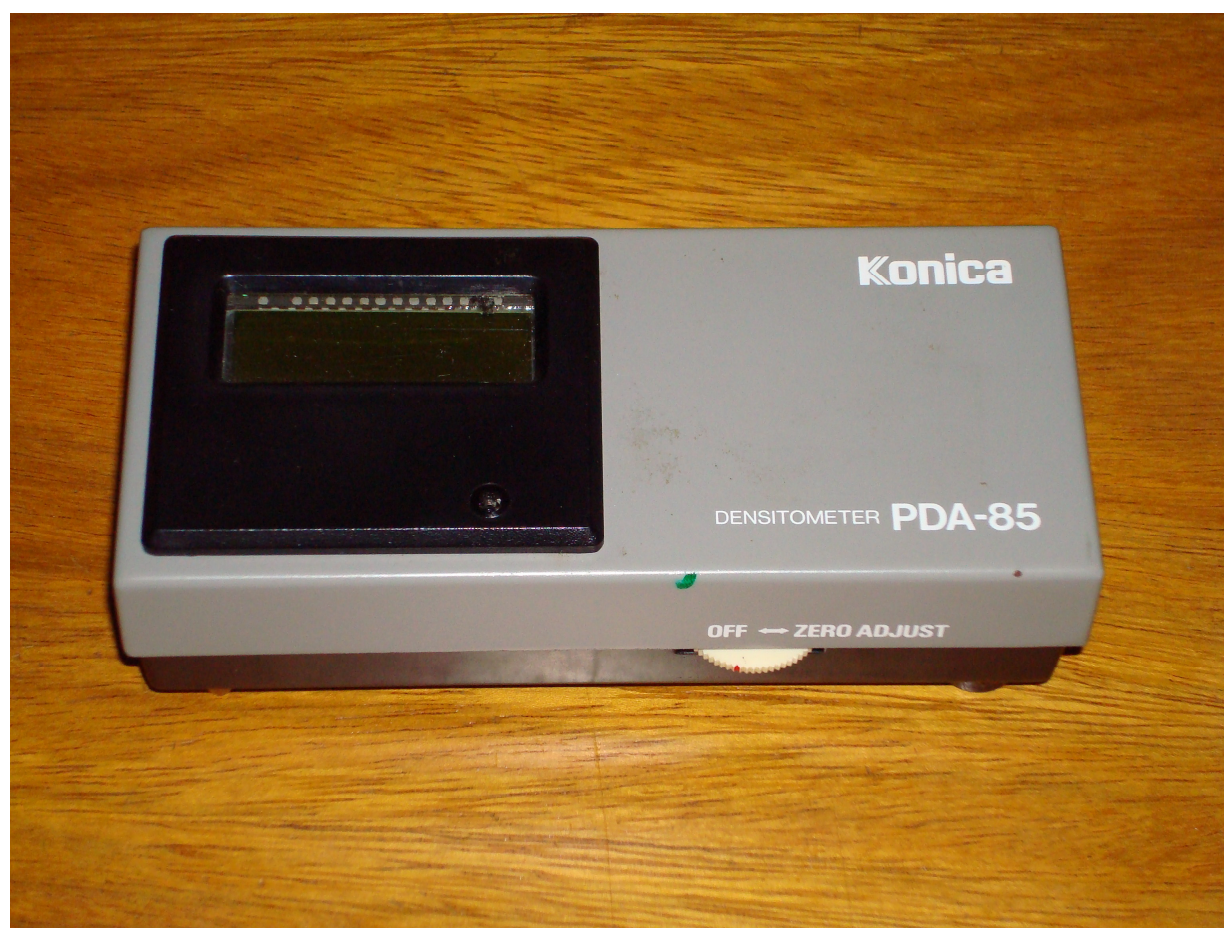

(a)

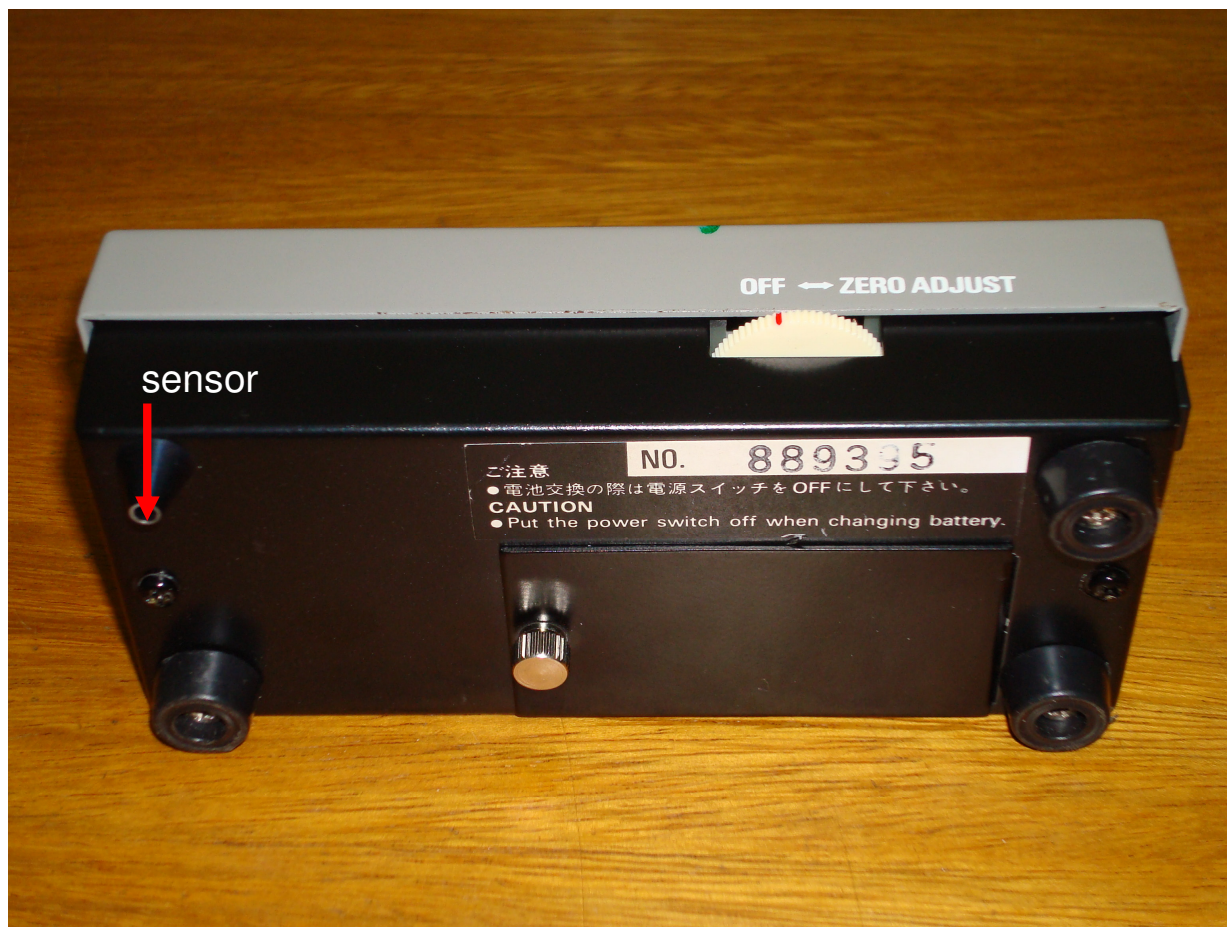

(b)

FIGURA 3.18 - Densitômetro ótico utilizado neste trabalho: a) visão superior; b) detalhe do sensor com $0,07 \mathrm{~cm}^{2}$ de área. 


\subsubsection{Intervalo de exposição}

Os filmes utilizados nesta verificação foram os mesmos empregados na caracterização com o sistema digital e o comportamento da curva que relaciona densidade ótica em função da exposição (Dop x E) está apresentada na FIG. 3.19. O intervalo de exposição para se obter o melhor contraste, ou seja, o correspondente a região mais íngreme desta curva foi $0<\mathrm{E}<1,6 \times 10^{8} \mathrm{n} / \mathrm{cm}^{2}$.

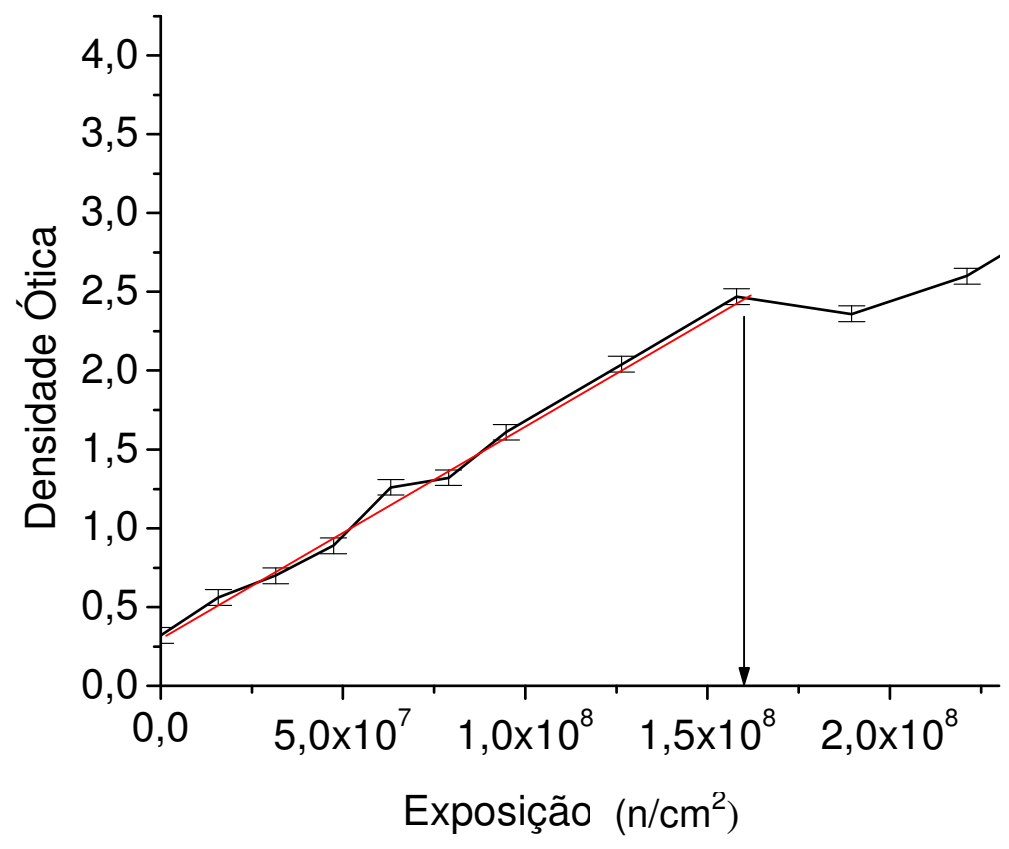

FIGURA 3.19 - Comportamento da densidade ótica em função da exposição para o sistema analógico, destacando a região de melhor contraste.

Este resultado é muito similar ao determinado para o sistema digital de modo que para ambos os sistemas o tempo de irradiação necessário para se atingir a exposição de melhor contraste é de 100 segundos.

\subsubsection{Sensibilidade}

Desde que a exposição para a obtenção do melhor contraste foi praticamente a mesma em ambos os sistemas, os filmes utilizados para a determinação da sensibilidade também foram os mesmos utilizados no item (3.1.2). A sensibilidade foi determinada para as mesmas amostras e seguindo o mesmo procedimento descrito no item 3.1.2. Nas FIG. 3.20 a 3.23 estão apresentados os resultados da sensibilidade " $\Delta \mathrm{x}$ " em função das espessuras das 
amostras, obtidos para ambos os sistemas analógico e digital e, como pode ser observado, para pequenas espessuras o sistema analógico exibe resultados próximos aos obtidos com o digital mas, conforme as espessuras aumentam os resultados para o sistema digital são melhores [21].

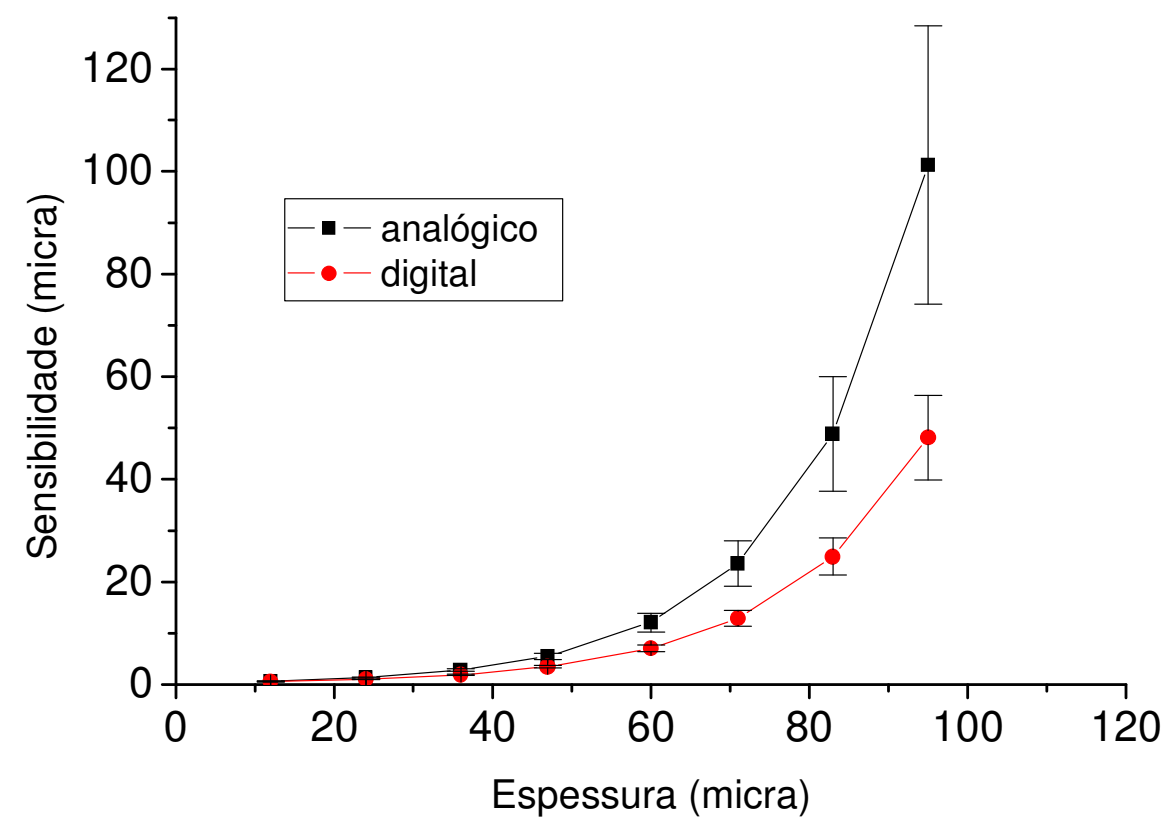

FIGURA 3.20 - Sensibilidade em função da espessura da amostra de alumínio obtida para ambos os sistemas analógico e digital. 


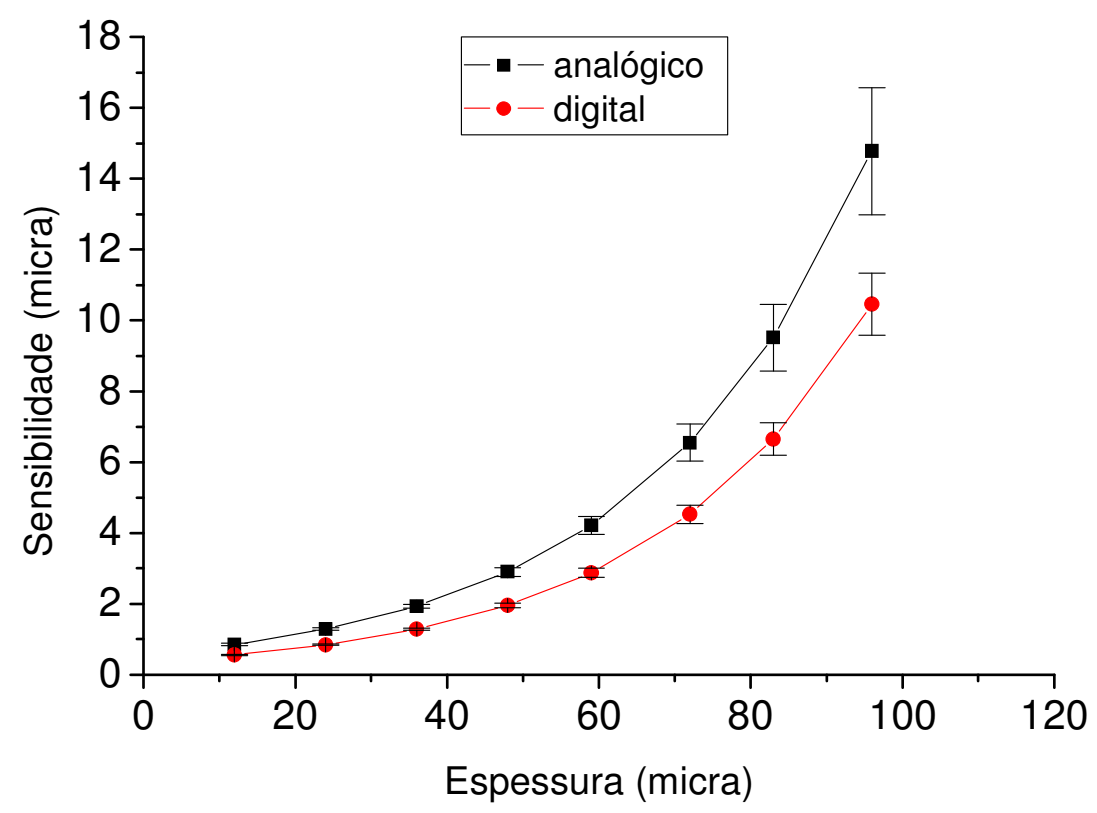

FIGURA 3.21 - Sensibilidade em função da espessura da amostra de makrofol KG obtida para ambos os sistemas analógico e digital.

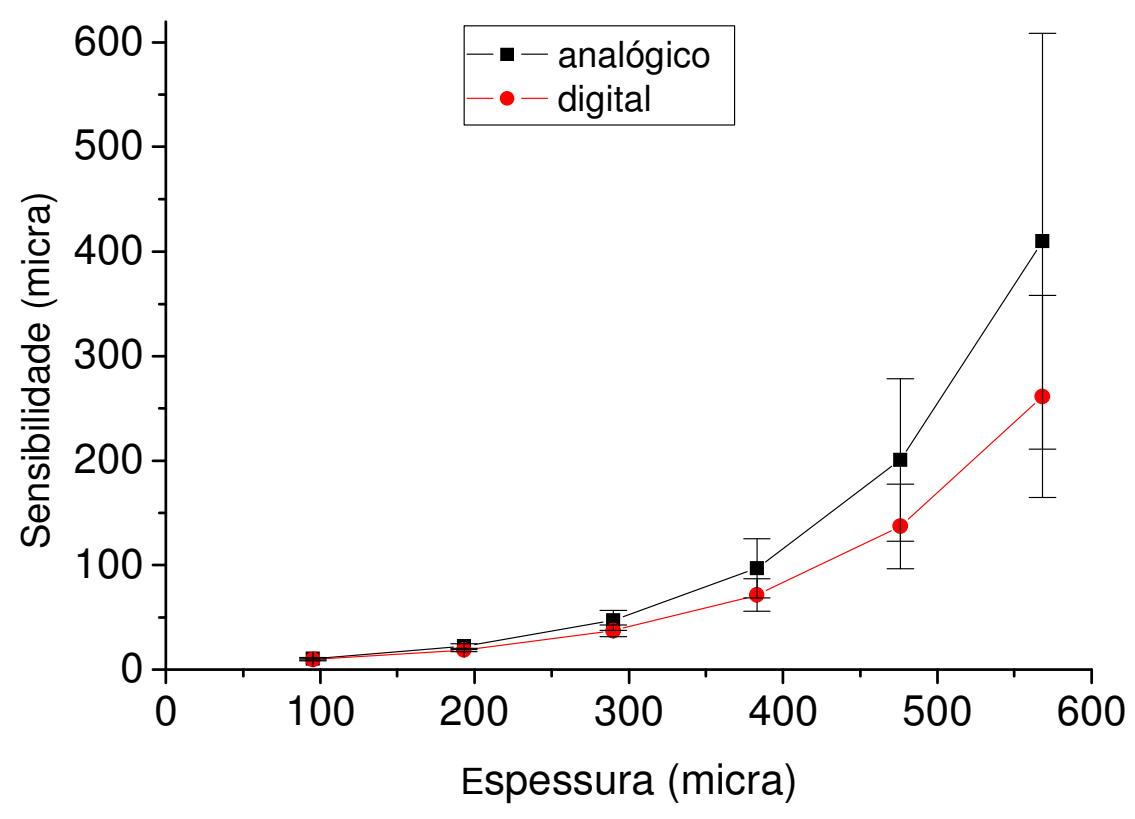

FIGURA 3.22 - Sensibilidade em função da espessura da amostra de papel branco obtida para ambos os sistemas analógico e digital. 


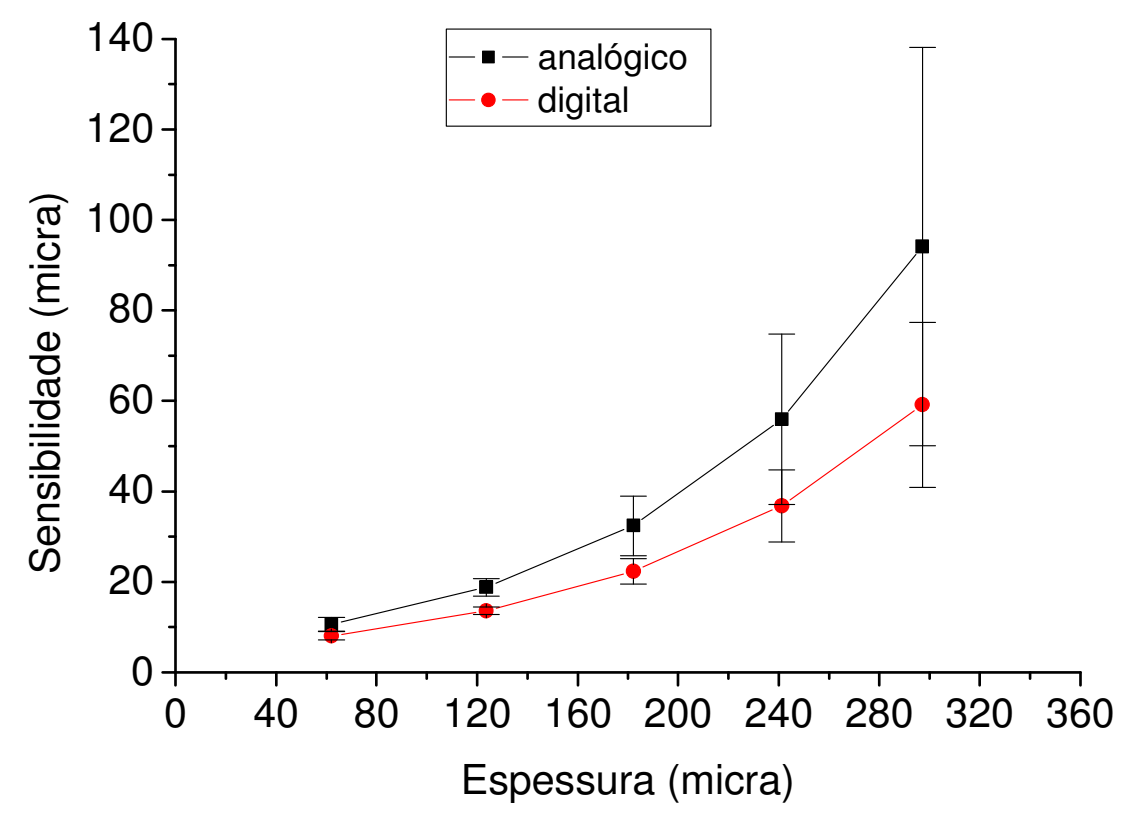

FIGURA 3.23 - Sensibilidade em função da espessura da amostra de adesivo obtida para ambos os sistemas analógico e digital.

Este comportamento pode ser explicado pelas próprias características do scanner utilizado. Este scanner foi projetado para registrar transmissões de luz que variam entre 1 e 1/16000 da intensidade incidente, ou seja, para imagens comuns nas quais as transmissões variam tipicamente entre 1 e 1/1000 e para imagens extremamente escuras com transmissões de até 1/16000. Como a fonte de luz do scanner emite sempre a uma intensidade constante é esperado que ele perca um pouco de capacidade para registrar variações de intensidade de luz em um dos limites da escala.

$\mathrm{Na}$ TAB. 3.4 estão apresentados os valores comparativos para a mínima espessura detectável (EMD) para ambos os sistemas.

TABELA 3.4 - Resultados obtidos para a espessura mínima detectável para os materiais estudados.

\begin{tabular}{ccccc}
\hline Sistema Digital & alumínio & makrofol - KG & papel branco & adesivo \\
\hline EMD $(\mu \mathrm{m})$ & $0,26 \pm 0,01$ & $0,37 \pm 0,02$ & $4,9 \pm 0,7$ & $4,8 \pm 1,0$ \\
Sistema Analógico & $\|/\||||||| \mid$ & $|/||||||| \mid$ & $\| /|||||| \mid$ & $\||||||||| \mid$ \\
EMD $(\mu \mathrm{m})$ & $0,31 \pm 0,02$ & $0,57 \pm 0,03$ & $4,9 \pm 0,8$ & $6,0 \pm 1,7$ \\
\hline
\end{tabular}


A resolução da imagem radiográfica não pôde ser estudada no caso do sistema analógico, pois o microfotômetro ótico que estava disponível para realizar as varreduras nas distribuições de densidade ótica está fora de operação permanentemente. Entretanto, é importante frisar que se trata de um equipamento de alta qualidade ótica e tomando por base as medidas realizadas anteriormente $[8,9,19]$ sabemos que este também não influencia na medida, pois o feixe de luz incidente nas amostras pode ter até $5 \mu \mathrm{m}$ de largura o que é comparável com o tamanho mínimo do pixel fornecido pelo scanner que é de $8 \mu \mathrm{m}$.

Para finalizar é importante salientar que para o sistema analógico a medida da transmissão de luz possui uma incerteza intrínseca entre 2,5 a 5\% e corresponde a uma área do filme de $0,07 \mathrm{~cm}^{2}$. Para o digital a incerteza é de $0,02 \%$ em uma área de $1 \mathrm{~cm}^{2}$. Ou seja, são necessárias realizar 14 medidas no sistema analógico para se cobrir a mesma área de leitura e, mesmo nesta condição a incerteza do valor médio seria de $0,7 \%$.

\subsection{Comparação com as outras técnicas radiográficas}

Os valores para a sensibilidade e para a resolução obtidos no presente trabalho para a técnica NIER não puderam ser comparados quantitativamente com o das outras técnicas de radiografia com elétrons devido a escassez de dados publicados em trabalhos técnicos da área. A comparação foi somente visual entre as imagens e, as obtidas com a técnica NIER apresentaram melhor qualidade em termos de sensibilidade para discernir variações de espessuras e resolução espacial.

É interessante ainda ressaltar alguns aspectos econômicos sobre a técnica proposta. Este se refere fundamentalmente ao custo da obtenção do feixe de radiação penetrante, uma vez que tanto os filmes quanto o processo de revelação empregados nesta e nas outras técnicas são praticamente os mesmos. Desde que o reator nuclear de pesquisas IEA-R1 do IPEN-CNEN/SP não opera exclusivamente para obtenção de radiografias a técnica desenvolvida no trabalho é economicamente viável perante as outras técnicas de radiografia com elétrons. 


\section{CAPÍTULO 4 - CONCLUSÕES}

A técnica radiográfica proposta neste trabalho, chamada radiografia com elétrons induzida por nêutrons - NIER mostrou-se viável para inspecionar a estrutura interna de amostras finas com espessuras da ordem de micra. O filme empregado foi o Kodak AA o qual, por causa de sua emulsão dupla e do tamanho de grão, não e o mais indicado para esta finalidade. Entretanto exibiu imagens com contraste e resolução espacial adequados quando comparadas com as imagens das outras técnicas radiográficas que utilizam elétrons como radiação penetrante [1-5]. As condições de irradiação e de revelação para se obter uma radiografia bem como as características radiográficas do sistema para estas condições são mostradas na TAB. 4.1.

TABELA 4.1 - Resumo das condições e das características radiográficas da técnica (NIER).

\begin{tabular}{|c|c|}
\hline \multicolumn{2}{|c|}{ Condições para a obtenção de uma radiografia } \\
\hline Intervalo de exposição (n.cm $\left.{ }^{-2}\right)$ & $0<\mathrm{E}<1,5 \times 10^{8}$ \\
\hline Tempo de irradiação (s) & 100 \\
\hline Revelação / parada / fixação $20^{\circ} \mathrm{C}$ (min) & $5 / 1 / 10$ \\
\hline \multicolumn{2}{|l|}{ Características radiográficas } \\
\hline Sensibilidade máxima para o alumínio $(\mu \mathrm{m})$ & 0,26 \\
\hline Resolução espacial ( $\mu \mathrm{m})$ & 28 \\
\hline
\end{tabular}

Os resultados deste trabalho tanto para a sensibilidade para discernir variações de espessuras quanto para a resolução espacial foram obtidos na condição experimental em que se utilizou uma tela de gadolínio irradiada com nêutrons térmicos como fonte da radiação penetrante, o filme convencional para raios - X, Kodak $A A$ e, um sistema digital que permite digitalizações com resolução de até 3200 dpi. Embora estes resultados sejam suficientes para 
demonstrar a capacidade desta técnica em analisar amostras de pouca espessura, estes podem ser melhorados mediante o emprego de outros conversores, filmes mais adequados para esta finalidade e um sistema que permita digitalizar uma imagem com resolução superior. Por exemplo, empregando imaging plates (item 1.2.6) para o registro da imagem [22,39,40], ou um filme que possua tamanho de grão menor que o do Kodak AA e que seja de emulsão simples e, também um sistema digital que permita digitalizar imagens com resolução superior a 3200 dpi de forma a reduzir o tamanho de pixel atualmente limitado a $8 \mu \mathrm{m}$.

Comparando as características da técnica desenvolvida neste trabalho com a das outras técnicas que empregam elétrons como radiação penetrante, pode-se concluir que:

- O tempo de irradiação para se obter uma radiografia é de 100 segundos o qual é menor do que para a grande maioria das técnicas que empregam elétrons como radiação penetrante. Nestes casos os tempos de irradiação variam tipicamente de horas a meses. Somente nos casos em que as radiografias com elétrons são obtidas empregando uma máquina de raios - X é que os tempos de irradiação são similares aos da técnica desenvolvida neste trabalho;

- A radiografia é obtida por transmissão de elétrons e o ensaio é não destrutivo, pois a amostra não permanece radioativa, mesmo após ter sido irradiada por nêutrons. É importante lembrar que dentre as técnicas que empregam elétrons como radiação penetrante, na da auto - radiografia a fonte de radiação é a própria amostra em estudo uma vez que um material radioativo líquido é inserido em seu interior.

Outras conclusões importantes que podem ser extraídas do presente trabalho são aquelas oriundas de uma comparação entre as características do sistema digital e analógico que foram utilizados para quantificar o grau de enegrecimento do filme:

- O intervalo de exposição que o filme deve ser submetido, para se obter o melhor contraste, é muito próximo para ambos os sistemas. Para a potência de $3 \mathrm{MW}$ na qual o reator estava operando na época em que as medidas foram realizadas, o tempo de irradiação como já mencionado acima foi de 100 segundos;

- A sensibilidade do sistema digital permitiu um maior poder para discernir variações de espessuras; 
- A praticidade é outra característica importante do sistema digital. Por exemplo, a determinação do grau de enegrecimento médio em um filme extenso (tipicamente $10 \mathrm{~cm} \times 10 \mathrm{~cm}$ ) pode ser realizada em uma só medida e com a mesma facilidade que se determina 0 grau de enegrecimento em uma área pequena de $1 \mathrm{~cm}^{2}$. Mediante o emprego do sistema analógico as leituras são individuais e cada uma é limitada a uma área de $0,07 \mathrm{~cm}^{2}$.

Outro exemplo típico em que sua praticidade se sobressai é na determinação da resolução da imagem radiográfica. No sistema digital a imagem do objeto opaco (item 3.1.3) é digitalizada e o software lista e disponibiliza os níveis de cinza ao longo da linha traçada na sua interface num procedimento que leva alguns segundos. No sistema analógico este procedimento é realizado no microfotômetro ótico em passos individuais de $5 \mu \mathrm{m}$ de modo que para um perfil típico ao longo de $500 \mu \mathrm{m}$ pela interface, são necessárias 100 leituras individuais do grau de enegrecimento $[8,19]$. Para este procedimento são necessárias duas pessoas, uma para ler e ditar os valores de transmissão de luz e outra para anotálas.

A fim de se demonstrar a potencialidade desta técnica, as FIG. 4.1 a 4.3 mostram algumas radiografias obtidas nas condições da TAB. 4.1. A visualização destas imagens foi realçada por processamento digital. Na FIG. 4.1 são mostradas as radiografias de diferentes tipos de plantas sendo possível visualizar detalhes de seu interior, inclusive alguns nutrientes no interior de seus caules. Nas FIG. 4.2 e 4.3 são mostradas as radiografias de duas cédulas, uma de $R \$ 2,00$ e outra de $R \$ 50,00$. Em ambas é possível se visualizar as marcas d'água e alguns outros detalhes como números e letras. E importante salientar que para as radiografias das plantas o cassete não foi evacuado de forma a evitar que estas fossem esmagadas no conversor causando danos irreversíveis a tela de gadolínio. 

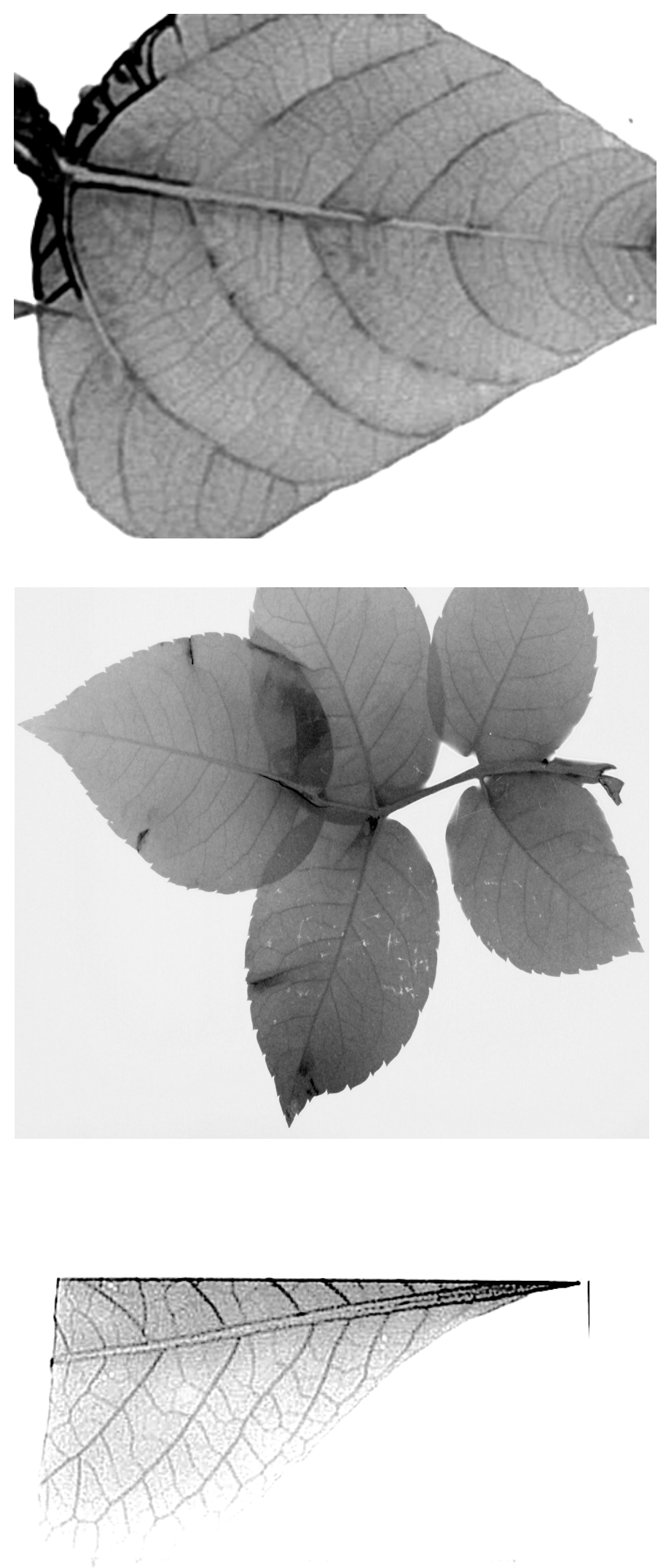

FIGURA 4.1 - Radiografias com elétrons induzidas por nêutrons de plantas. 


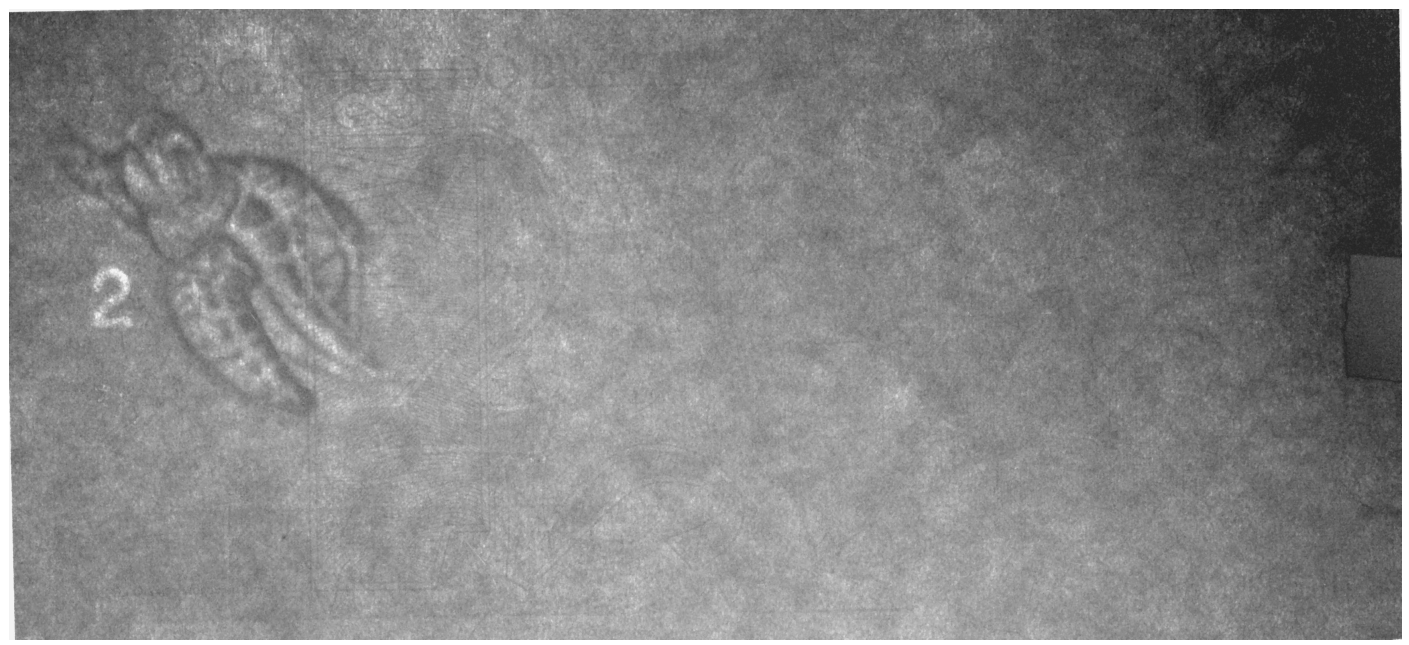

(a)

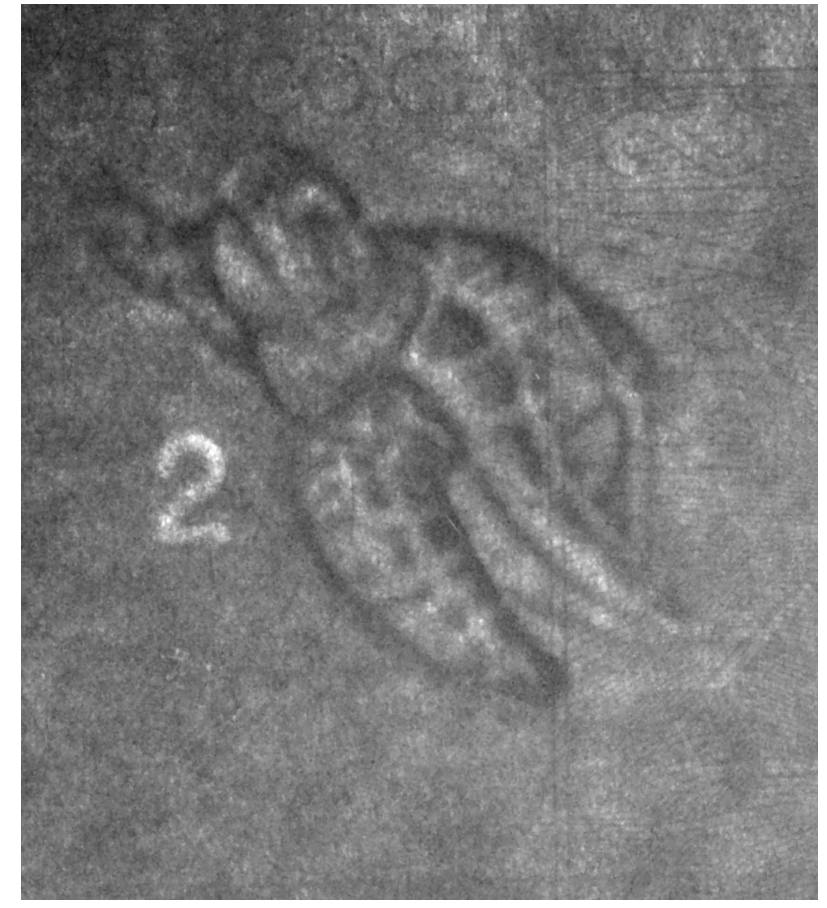

(b)

FIGURA 4.2 - Radiografias com elétrons induzidas por nêutrons. Cédula de $\mathrm{R} \$ 2,00$. a) inteira; b) detalhe com a marca d'água. 


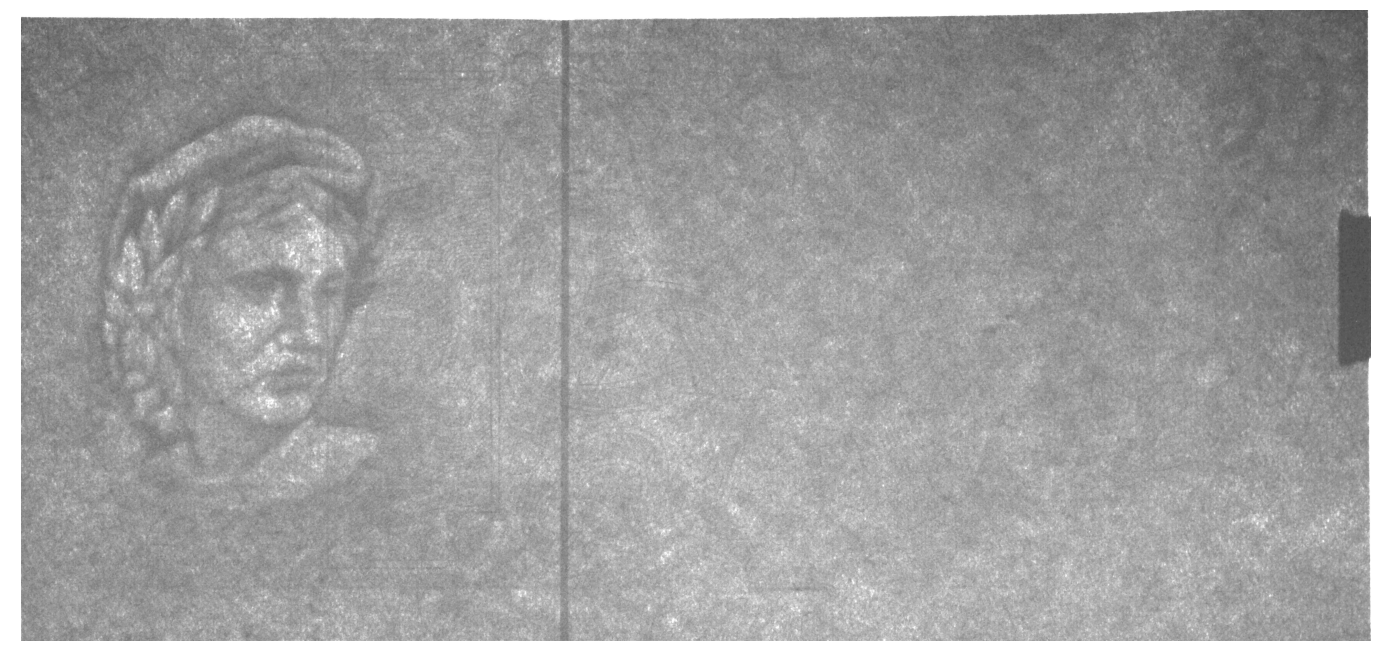

(a)

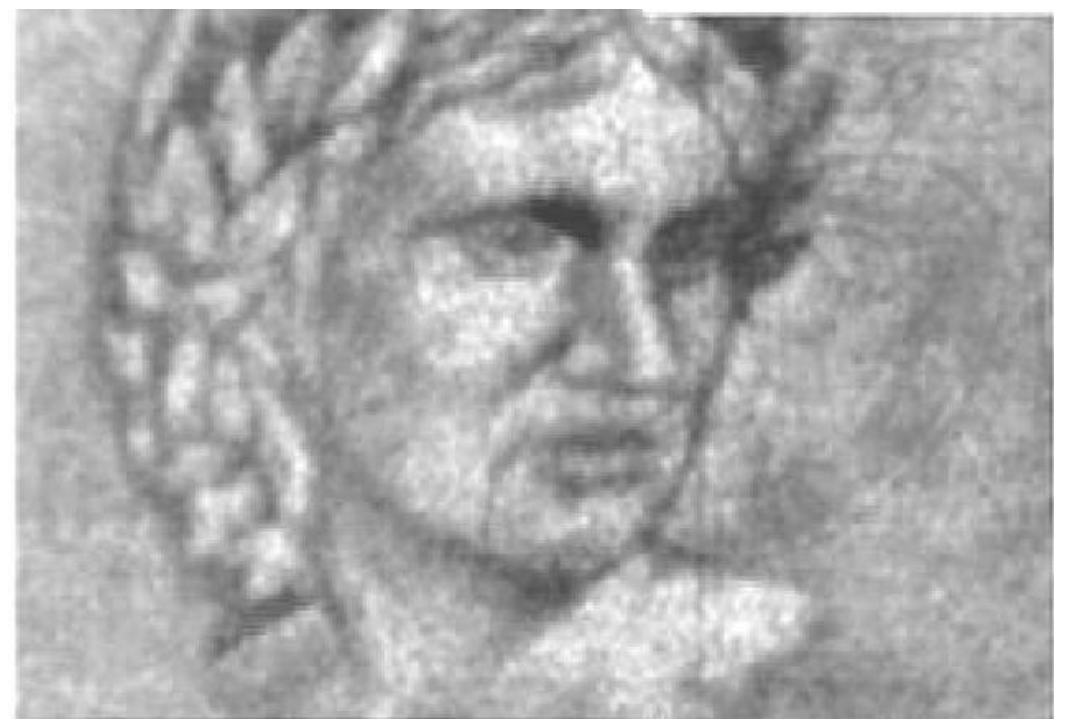

(b)

FIGURA 4.3 - Radiografias com elétrons induzidas por nêutrons. Cédula de $\mathrm{R} \$ 50,00$. a) inteira; b) detalhe com a marca d'água. 
Como mencionado anteriormente, existe a possibilidade de utilização de imaging plates - IP para o registro da imagem gerada pela técnica proposta NIER. Este fato foi comprovado em um trabalho conjunto que foi realizado pelos grupos de radiografia com nêutrons do IPEN - CNEN/SP e do Paul Scherrer Institute PSI - Villigen - Suissa [22] no qual se pode constatar que as IP exibem imagens de qualidade superior, no que se refere principalmente à sensibilidade quando comparadas com as obtidas neste trabalho empregando um conversor de gadolínio e filmes convencionais. Isto deve-se principalmente a extensa e linear faixa dinâmica das IP (intervalo de nível de cinza correspondente ao intervalo de exposição de melhor contraste) a qual inclusive não impõe qualquer restrição ao tempo de irradiação. Na FIG. 4.4 são mostradas as imagens de duas cédulas regulares de franco suíço uma de $20 \mathrm{CHF}$ e outra de $100 \mathrm{CHF}$ mostrando diversos detalhes como marcas d'água e flutuações na densidade do papel empregado em sua confecção.
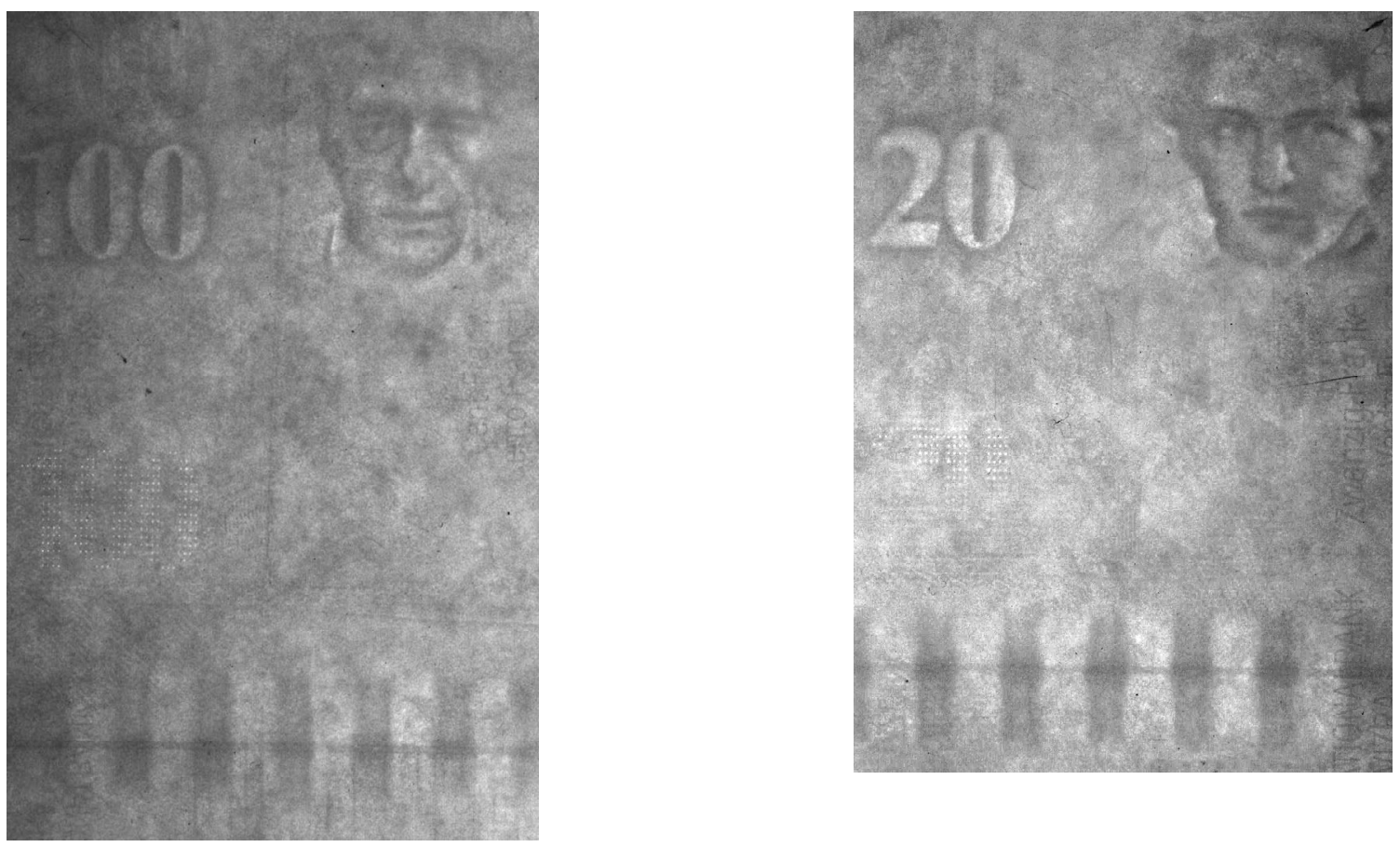

FIGURA 4.4 - Exemplos de radiografias com elétrons induzidas por nêutrons utilizando imaging plates- IP. 
Como trabalho futuro, propomos que seja estudado o espectro de energia dos elétrons emitidos pela tela de gadolínio. Esta determinação poderá ser feita tanto teoricamente pelo método de Monte Carlo quanto experimentalmente utilizando um detector do tipo GeLi ou Ge - intrínseco para obter o espectro de energia dos elétrons no ato da irradiação com nêutrons. Uma vez determinado este espectro, a seleção da função a ser ajustada aos pontos experimentais do nível de cinza em função da espessura do material, deixará de ser uma abordagem puramente matemática como foi o caso do presente trabalho.

Outro trabalho interessante seria a utilização de um radioisótopo emissor de nêutrons, como o califórnio - 252 que é comumente empregado em radiografia com nêutrons, para viabilizar sistemas transportáveis de radiografia com elétrons.

Finalmente a NIER permite várias combinações entre a energia de feixe de nêutrons e telas conversoras, dentre as quais podemos destacar a que utiliza nêutrons térmicos e tela de disprósio. Neste caso a tela emite um espectro beta que pode substituir as substâncias radioativas empregadas na auto radiografia. 


\section{REFERÊNCIAS BIBLIOGRÁFICAS}

1 AVIKAINEN, M.; ERKKILA, A.L. Comparison of traditional beta-radiography and storage phosphor screen formation measurement techniques. Paperi JA PuuPaper and Timber, v. 85, n. 5, p. 279-286, 2003.

2 KELLER, D.S.; PAWLAK, J.J. Beta-radiography imaging of paper formation using storage phosphor screens. Journal of Pulp and Paper Science, v. 27 (4), p. 117-123, 2001.

3 TOMIMASU, H.; KIM, D.; SUK, M.; LUNER, P. Comparison of 4 paper imaging techniques - beta radiography, electrography, light transmission, and soft $x$ radiography. Tappi Journal, v. 74, n. 7, p. 165-176, 1991.

4 HELLAWEL, J.M. Analysis of small-scale distribution of mass density in paper by beta-radiography. Paper Technology and Industry, v. 14, n. 1, p. 24-32, 1973.

5 HERZ, R.H. The Photographic action of ionizing radiations: in dosimetry and medical, industrial, neutron, auto and microradiography. Photographic Science and Technology and the Graphic Arts Series, John Wiley \& Sons Inc; 1969.

6 PUGLIESI, R; ANDRADE, M.L.G.; STANOJEV PEREIRA, M.A.; PUGLIESI, F. Fundamentos da Física de Nêutrons. XIV Escola de verão de física nuclear experimental "Jorge André Swieca". Fev. 13-24, 2006 - Fundamentos da técnica da radiografia com nêutrons - livro: cap. 5

7 DE MENEZES, M.O.; PUGLIESI. R; M.A.S. PEREIRA; M.L.G. ANDRADE. Real time in neutron radiography at the nuclear reactor IEA-R1m. Braz. J. Phys., v. 33, n. 2, p. 282-285, 2003.

8 ANDRADE, M.L.G. Caracterização de sistemas filme-conversor para radiografia com nêutrons. 2002. Dissertação (Mestrado) - Comissão Nacional de Energia Nuclear, IPEN-CNEN, São Paulo.

9 PEREIRA, M.A.S. Emprego dos policarbonatos makrofol-DE e CR-39 em radiografia com nêutrons. 2000. Dissertação (Mestrado). Comissão Nacional de Energia Nuclear, IPEN-CNEN, São Paulo.

10 DE MENEZES, M.O. Radiografia em tempo real. 2000. Tese (Doutorado). Comissão Nacional de Energia Nuclear, IPEN-CNEN, São Paulo. 
11 PUGLIESI, R; DE MENEZES, M.O.; ANDRADE, M.L.G.; PEREIRA, M.A.S. Radiografia com nêutrons: uma nova técnica de ensaio não destrutivo. In: XIX CONGRESSO NACIONAL DE ENSAIOS NÃO DESTRUTIVOS, 21-23 de Agosto, 2000, São Paulo.

12 PUGLIESI R.; GERALDO L.P.; DE MENEZES M.O.; ANDRADE M.L.G.; PEREIRA M.A.S.; MAIZATO M.S. Inspection of an artificial heart by the neutron radiography technique. In: 3RD INTERNATIONAL TOPICAL MEETING ON NR, March 16-19, 1998, Lucerne, Switzerland.

13 PUGLIESI, R.; ANDRADE M.L.G. Study of cracking in concrete by neutron radiography. Appl. Radiat. Isot., v. 48, n. 3, p. 339-344, 1997.

14 PUGLIESI, R.; ANDRADE, M.L.G.; DE MENEZES, M.O.; PEREIRA, M.A.S. Viabilidade para medidas de secções de choque macroscópicas utilizando a técnica da radiografia com nêutrons. In: IV ENAN - ENCONTRO NACIONAL DE APLICAÇÕES NUCLEARES, Agosto, 1997, Poços de Caldas.

15 DE OLIVEIRA, F.B.V.; PUGLIESI, R.; ANDRADE, M.L.G.; RIELLA, H.G. Auto radiografia com nêutrons de peças cilíndricas de alumina - carbeto de boro. In: VI CGEN - CONGRESSO GERAL DE ENERGIA NUCLEAR, Outubro, 1996, Rio de Janeiro.

16 DE MENEZES, M.O.; PUGLIESI, R.; ANDRADE, M.L.G.; PEREIRA, M.A.S. Effect of the scattered neutrons in radiography sensitivy. In: V WORLD CONFERENCE ON NEUTRON RADIOGRAPHY, June, 1996, Berlin, Germany.

17 PUGLIESI, R.; ANDRADE, M.L.G. Características da imagem neutrongráfica para filmes com emulsão dupla e simples. In: III ENAN - ENCONTRO NACIONAL DE APLICAÇÕES NUCLEARES, Agosto, 1995. Águas de Lindóia. Anais p. 500506.

18 ASSUNÇÃO M.P.M; PUGLIESI R; DE MENEZES M.O. Study of the neutron radiography characteristics for the solid state nuclear track detector makrofol-E. Appl. Radiat. Instrum., v. 45, n. 8, p. 851-855, 1994.

19 DE MENEZES, M.O. Desenvolvimento e aplicação da técnica da radiografia com nêutrons pelos métodos direto e indireto. 1994. Dissertação (Mestrado) - Comissão Nacional de Energia Nuclear, IPEN-CNEN, São Paulo.

20 PUGLIESI, R.; DE MENEZES, M.O.; ANDRADE, M.L.G.; ASSUNÇÃO, M.P.M.; LOPES JÚNIO, J.E.; DIAS, L.M. Aplicações da técnica da radiografia com nêutrons na inspeção de explosivos e componentes pirotécnicos. In: V CGEN Congresso Geral de Energia Nuclear, ago-set, 1994, Rio de Janeiro.

21 PUGLIESI, R.; ANDRADE, M.L.G.; PEREIRA, M.A.S.; PUGLIESI, F. Neutroninduced electron radiography. Nucl. Instrum. Methods Phys. Res., v. 542, p. 8186, 2005. Section A. 
22 PUGLIESI, R.; LEHMANN, E. Neutron-Induced electron radiography using an imaging plate. Appl. Radiat. Isot., v. 62, p. 457-460, 2005.

23 GUREVICH, I.I. \& TARASOV, L.V. Low-Energy Neutron Physics. Amsterdan, North Holland, 1968.

24 BYRNE, J. Neutrons, Nuclei and Matter - An exploration of the physics of slow neutrons. United States, Philadelphia,1995.

25 BRYANT, L.E; MCENTIRE, P. 2nd ed. Radiography and radiation testing. American Society for Nondestructive Testing (Nondestructive Testing Handbook); 1985.

26 CURTISS L.F. Introduction to neutron physics. Inc., Princenton, New Jersey: D. van Nostrand Co., 1959.

27 MURRAY R.L. Nuclear Reactor Physics. Prentice Hall, Inc. N.J., 1957.

28 FISHER C.O. The history of the first radiographs in Berlim. In: FOURTH WORLD CONFERENCE ON NEUTRON RADIOGRAPHY, May 10-16, 1992, San Francisco. Proceedings San Francisco: 1992. p. 3-10. Edit by John P. Barton. Gordon and Breach Science Publishers.

29 BERGER, H. Neutron radiography, methods, capabilities and applications. New York, N.Y.: Elsevier, 1965.

30 BERGER, H. Neutron Radiography - A state of art report. NTIAC-SR-9801. NASA (Center for Aerospace Information): Aug, 1998;

31 WINKLER, B. Applications of Neutron Radiography and Neutron Tomography Rev. Miner. Geochem.; v. 63, n. 1, p. 459-471, 2006.

32 N. KARDJILOV, N.; HILGER, A.; MANKE, I.; STROBL, M.; TREIMER, W.; BANHART, J. Industrial applications at the new cold neutron radiography and tomography facility of the HMI. Nucl. Instrum. Methods Phys. Res., v. 542, p. 1621, 2005. Section A.

33 CALZADA, E.; SCHILLINGER, B.; GRÜNAUER, F. Construction and assembly of the neutron radiography and tomography facility ANTARES at FRM II. Nucl. Instrum. Methods Phys. Res., v. 542, p. 38-44, 2005. Section A.

34 BERGER, H. Advances in neutron radiographic techniques and applications: a method for nondestructive testing. Appl. Radiat. Isot., v. 61, p. 437-442, 2004.

35 SCHILLINGER, B.; BLUMLHUBER, W.; FENT, A; WEGNER, M. 3D neutron tomography; recent developments and first steps towards reverse engineering. Nucl. Instrum. Methods Phys. Res., v. 424, p. 58-65, 1998. Section A. 
36 HARDT P. VON DER; ROETTGER H. Neutron radiography handbook: nuclear science and technology, Dordrecht, D. Reidl, 1981.

37 HAWKESWORTH, M. R. Neutron radiography: equipaments and methods. Atom. Energy Rev., v. 152, p. 169-220, 1977.

38 HUGHES D.J; HARVEY J.A. Neutron cross sections, New York, N.Y. McGRAW- Hill, 1955 (BNL-325).

39 THOMS, M.; MYLES, D. AND WILKINSON, C. Neutron detection with imaging plates part I. Image storage and readout. Nucl. Instrum. Methods Phys. Res., v. 424, p. 26-33, 1998. Section A.

40 THOMS, M. Neutron detection with imaging plates part II. Detectors characteristics. Nucl. Instrum. Methods Phys. Res., v. 424, p. 34-39, 1998. Section A.

41 KNOLL, G.F. Radiation detection and measurements. 3 ed. John Wiley \& Sons, 1999.

42 National Institute of Standards and Technology - NIST. Stopping-power and range tables for electrons. Disponível em:

http://www.physics.nist.gov/PhysRefData/Star/Text/ESTAR.html>. Acesso em: 31 out. 2007.

43 GONZALEZ, R.C; WOODS, R.E. Digital image processing. Massachusetts, M.A.: Addison-Wesley Publishing Company, 1992.

44 HARMS A.A.; ZELLINGER A. A New Formulation of Total Unsharpness in Radiography. Phys. Med. Biol., v. 22, n. 1, p. 70-80, 1977.

45 WROBEL, $M$ \& GREIM, L. Resolution functions and unsharpness in neutron radiography. Geesthacht, German, GKSS, (GKSS 88/e/12), 1988.

46 HARMS, A.A.; MCCORMACK, G. Isotopic conversion in gadolinium exposure neutron imaging. Nucl. Instrum. Methods, v. 118, p. 583-587, 1974.

47 HARMS, A.A.; NORMAM, G.R. The role of internal conversion electrons in gadolinium exposure neutron imaging. J. Appl. Phys., v. 43, n. 7, p. 3209-3212, 1972.

48 HARMS, A.A.; BLAKE, T.G.; MARTON, J.P. Neutron imaging with thin gadolinium converters. Nucl. Instrum. Methods, v. 109, p. 253-255, 1973.

49 BARTON, J.P. Contrast sensitivity in neutron radiography. Appl. Mater. Res., p. 90-96, 1965.

50 INMETRO - Instituto Nacional de Metrologia, Normatização e Qualidade Industrial. Vocabulário Internacional de Termos Fundamentais e Gerais de Metrologia - VIM, 4를. ed., Brasil, 2005. 
51 GOODHEW, P.J.; HUMPHREYS, J.; BEANLAND, R. Electron microscopy and analysis. 3.ed. New York, N.Y. 10001: Taylor \& Francis Inc., 2001.

52 REIMER, L. Transmission Electron Microscopy. 4.ed. Berlin: Springer Verlag, 1997. 